\title{
Handlungsfelder der Landnutzung
}

\author{
Sarah Baum, Peter Elsasser, Roland Goetzke, Martin Henseler, \\ Jana Hoymann und Peter Kreins
}

\section{Inhaltsverzeichnis}

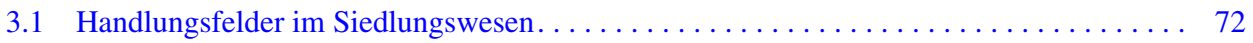

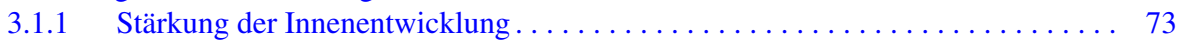

3.1.2 Reduktion der Flächeninanspruchnahme durch Verkehr . . . . . . . . . . . . 78

3.1.3 Rückzug aus der Fläche (mit dezentraler Konzentration) . . . . . . . . . . . 80

3.1.4 Erhalt und Entwicklung innerstädtischer Freiflächen . . . . . . . . . . . . 81

3.1.5 Stärkung des Öffentlichen Personennahverkehrs. . . . . . . . . . . . . . . . . . 84

3.1.6 Zusätzliche Ausweisung von Vorrang- und Vorbehaltsgebieten . . . . . . . . 85

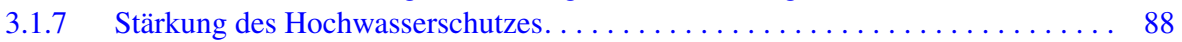

3.1.8 Restriktiverer Freiraumschutz . . . . . . . . . . . . . . . . . . . . . . 89

3.1.9 Energieerzeugung auf für Siedlungszwecke ungeeigneten nicht-agrarischen

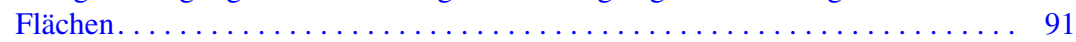

3.1.10 Nutzung von Biomasse der Landschaftspflege . . . . . . . . . . . . . . . . 92

3.2 Handlungsfelder in der landwirtschaftlichen Landnutzung . . . . . . . . . . . . . . . 93

3.2.1 Überblick über mögliche landwirtschaftliche Maßnahmen. . . . . . . . . . . . . 93

\section{P. Elsasser $(\bowtie)$}

Thünen-Institut für Internationale Waldwirtschaft und Forstökonomie, Hamburg-Bergedorf, Deutschland

E-Mail: cc-landstrad@thuenen.de

S. Baum · M. Henseler · P. Kreins

Thünen-Institut für Ländliche Räume, Braunschweig, Deutschland

R. Goetzke · J. Hoymann

Bundesinstitut für Bau-, Stadt- und Raumforschung im Bundesamt für Bauwesen und Raumordnung, Bonn, Deutschland

H. Gömann und J. Fick (Hrsg.), Wechselwirkungen zwischen Landnutzung und

Klimawandel, https://doi.org/10.1007/978-3-658-18671-5_3 


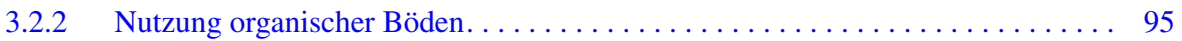

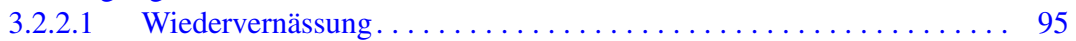

3.2.2.2 Nutzung als extensives Grünland . . . . . . . . . . . . . . 98

3.2.2.3 Nutzung mit Paludikulturen . . . . . . . . . . . . . . . . . . . . 99

3.2.3 Anpassung des Düngemanagements . . . . . . . . . . . . . . 101

3.2.3.1 Effizienzsteigerungen des Mineraldüngereinsatzes sowie der

N-Ausnutzung des Wirtschaftsdüngers............... 102

3.2.3.2 Überregionale Transporte von organischem Dünger aus

Überschuss- in Zuschussregionen. . . . . . . . . . . . . . . . 107

3.2.4 Substitution fossiler Energie durch Bioenergie . . . . . . . . . . . . . . . . 109

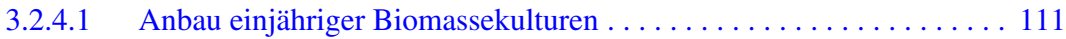



3.2.4.3 Stärkerer Fokus auf landwirtschaftlichen Nebenprodukten in

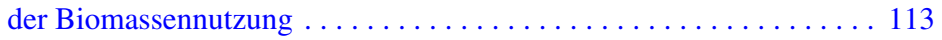

3.2.4.4 Erhalt und Schaffung von Treibhausgassenken ............. 116



3.2.5 Notwendige Anpassungen an den Klimawandel . . . . . . . . . . . . . . . . . . 118

3.3 Forstliche Handlungsoptionen für den Klimaschutz . . . . . . . . . . . . . . . . . . . . 119

3.3.1 Überblick über mögliche forstliche Maßnahmen . . . . . . . . . . . . . . . . 119

3.3.2 Erhöhung der Kohlenstoffvorräte im Wald . . . . . . . . . . . . . . . 121

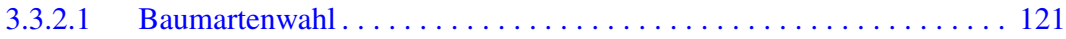

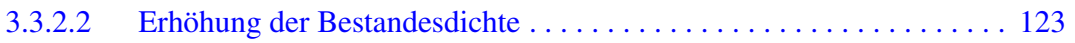

3.3.2.3 Erhöhung der Umtriebszeiten bzw. Zielstärken . . . . . . . . . . . . 124

3.3.2.4 Dauerhafter Verzicht auf die Nutzung von Einzelbäumen oder

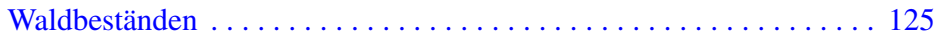

3.3.2.5 Speicheraufbau in Totholz, Streuschicht und Boden . . . . . . . . 125

3.3.2.6 Wiedervernässung von Moorwäldern ................ 126

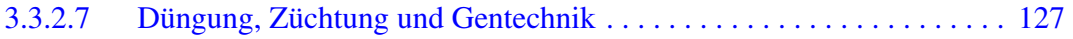

3.3.3 Vergrößerung der Waldfläche. . . . . . . . . . . . . . . . . . . . . 127

3.3.4 Ausweitung des Holzproduktespeichers und von Substitutionen . . . . . . . . . . . 128



3.3.5.1 Verluste durch forstliche Kalamitäten. . . . . . . . . . . . . . . . . 130

3.3.5.2 Verluste durch forstliche Bewirtschaftung ............. 131

3.3.5.3 Verluste durch Aktivitäten außerhalb des Forstsektors . . . . . . . . . . 132

3.3.6 Zusammenfassung zu Maßnahmenbündeln (Strategien) . . . . . . . . . . . 133

Literatur. . . . . . . . . . . . . . . . . . . . . . . . . . . . . . 134

\subsection{Handlungsfelder im Siedlungswesen}

Roland Goetzke und Jana Hoymann

\section{Zusammenfassung}

Die Gestaltung der Siedlungs- und Verkehrsflächenentwicklung kann einen Beitrag zum Klimaschutz und zur Anpassung an den Klimawandel leisten. Dafür kommen unterschiedliche Gestaltungsoptionen in Form von Maßnahmen in Betracht, die in diesem Kapitel vorgestellt werden. Diese Maßnahmen reichen von innerstädtischen Gestaltungsprozessen bis hin zur gesamträumlichen Betrachtung der Siedlungsstruktur. Sie berücksichtigen die Entwicklungsmöglichkeiten von einzelnen Nutzungsarten, aber 
auch Aspekte der Raumordnungspolitik, und decken somit ein breites Spektrum der Gestaltungsmöglichkeiten ab. Die Relevanz einer jeden Maßnahme wird hergeleitet und das Ziel erläutert. Ihr erwarteter Beitrag zum Klimaschutz und zur Anpassung an den Klimawandel wird dargestellt.

Im Sektor Siedlung und Verkehr bestehen vielfältige Möglichkeiten, durch Steuerung der Siedlungsflächenentwicklung einen Beitrag zum Klimaschutz, zur Klimaanpassung oder zum Umwelt- und Naturschutz zu leisten. Die ebenfalls betrachtete Strategie „Bioenergie“ wird im Siedlungsbereich nicht mit eigenen flächenrelevanten Maßnahmen ausgestaltet. Allerdings können einzelne Bestandteile der in diesem Kapitel vorgestellten Maßnahmen einen Beitrag zur Strategie „Bioenergie“ leisten, beispielsweise dadurch, dass sie durch die Verringerung des Siedlungsdrucks auf die Landwirtschaftsfläche die dortigen Nutzungskonflikte reduzieren.

Die einzelnen Maßnahmen wirken entweder steuernd auf die Größenordnung der Flächeninanspruchnahme (Mengensteuerung) oder auf deren räumliches Verteilungsmuster (Standortsteuerung). Die hier ausgewählten Maßnahmen wurden in einem intensiven Abstimmungsprozess mit Akteuren der Landnutzung auf regionaler (z. B. Stadtplaner) und auf nationaler Ebene (z. B. Verbände) diskutiert. Durch entsprechende Modellierung lässt sich die Wirkung der einzelnen Maßnahmen quantifizieren (Abschn. 4.4).

Die betrachteten Maßnahmen werden im Folgenden detailliert beschrieben (siehe dazu auch Abschn. 7.1). Dabei sei angemerkt, dass Maßnahmen ohne Bezug zu Landnutzungsänderungen im engeren Sinn nicht betrachtet werden, auch wenn sie einen durchaus signifikanten Beitrag im Rahmen der Strategien entfalten können. Solche Maßnahmen sind beispielsweise die Anpassung der Kanalisation an Starkregenereignisse oder die Nutzung kommunaler Dachflächen für Solarenergie. Die als landnutzungsrelevant identifizierten Maßnahmen im Sektor Siedlung und Verkehr werden in den folgenden Unterkapiteln erläutert.

\subsubsection{Stärkung der Innenentwicklung}

Durch intensivierte Innenentwicklung erzielbare höhere Siedlungsdichten haben einen positiven Effekt auf den Klimaschutz. Im Vergleich zu geringeren Dichten werden durch die in der Regel effizienteren Siedlungsstrukturen und Infrastrukturnutzung in den Bereichen Wärme- und Stromversorgung sowie Verkehr geringere THG-Emissionen verursacht (Jenssen 2009). Darüber hinaus haben höhere Siedlungsdichten aufgrund der geringeren Flächeninanspruchnahme auch positive ökologische Effekte. Allerdings besteht ein Konfliktpotenzial zwischen der verstärkten baulichen Innenentwicklung und Anpassungsanforderungen an den Klimawandel, da eine zunehmende Verdichtung den Wärmeinseleffekt erhöhen kann. Dementsprechend müssen städtebauliche Strukturen und klimatische Vorprägungen berücksichtigt werden, damit Innenentwicklung sowohl Belangen des Klimaschutzes und des Flächensparens, als auch der Klimaanpassung 
gerecht wird. In BBSR (2014b) sind einige Beispiele aufgeführt, wie sich dieser Konflikt entschärfen lässt.

Laut einer repräsentativen Umfrage unter Kommunen gibt es in Deutschland etwa 120.000 bis 165.000 ha Innenentwicklungspotenziale (IEP) in Form von Brachflächen und Baulücken (BBSR 2013). Hinzu kommen regional teils erhebliche Leerstände in Gebäuden und nicht näher zu beziffernde Möglichkeiten der Nachverdichtung im Bestand. Damit existiert ein beachtliches Flächenpotenzial im baulichen Bestand, mit dem die Neuinanspruchnahme von Flächen reduziert werden kann, die in den Jahren 2009 bis 2012 bei 74 ha/Tag lag. Daher ist der Vorrang der Innen- vor Außenentwicklung ein erklärtes Ziel der Nachhaltigkeitsstrategie der Bundesregierung (Preuß und Beißwenger 2007). Gleichwohl erfordert die Wiedernutzung von Brachflächen im Innenbereich oft erhebliche und kostspielige Altlastensanierungen. Auch die rechtlich eingeschränkte Handhabe der Kommunen beim Zugriff auf vorhandene Baulücken oder leerstehende und im Verfall befindliche Gebäude erschwert die Nutzung von Potenzialen im Innenbereich. Teilweise bestehen standörtliche Nachteile, was in der Folge dazu führt, dass vorhandene Bauflächen oder Gebäude nicht dem Bedarf angemessen sind, daher nicht genutzt und stattdessen neue Baugebiete ausgewiesen werden.

Die Maßnahme „Stärkung der Innenentwicklung“ verfolgt das Ziel, die Siedlungsflächenentwicklung auf den Bestand auszurichten, anstatt das Baulandangebot auf bisher nicht baulich genutzte Flächen im Außenbereich auszuweiten. Dabei werden die Revitalisierung von Brachflächen, die Schließung von Baulücken, die Wiedernutzung von Leerständen sowie die bauliche Nachverdichtung durch An- und Ausbauten als Möglichkeiten genutzt, die Flächeninanspruchnahme bei gleichzeitiger Befriedigung der Baulandnachfrage zu reduzieren. Hierdurch entsteht eine kompakte und effiziente Siedlungsstruktur, und Infrastrukturfolgekosten werden reduziert. Auch aus städtebaulicher Perspektive bietet Innenentwicklung zahlreiche Vorteile, da Brachen aus dem Strukturwandel revitalisiert werden, ein Beitrag zur Bewältigung von Schrumpfung geleistet wird und kommunale Infrastrukturen kosteneffizient genutzt werden. Ein wichtiges Instrument zur Stärkung der Innenentwicklung ist das Flächenmanagement bzw. die Flächenkreislaufwirtschaft (Preuß 2006, 2010).

\section{Brachflächen und Baulücken}

Den Ergebnissen o. g. Befragung zufolge (BBSR 2013) liegen die IEP (nur Brachflächen und Baulücken) in Deutschland bei 15 bis $20 \mathrm{~m}^{2}$ je Einwohner (IEP/EW). Unter Berücksichtigung weiterer Flächenkategorien gelten sogar noch höhere Potenziale. Zu diesen zählen vor allem Nachverdichtungspotenziale, leerstehende Gebäude oder künftig brachfallende Areale, die möglicherweise bald (um-)genutzt werden können. $20 \%$ der Brachflächen und Baulücken werden als kurzfristig aktivierbar und weitere $50 \%$ als langfristig aktivierbar eingeschätzt, $30 \%$ der Potenziale als nicht aktivierbar.

Bundesweit entfällt über die Hälfte der Innenentwicklungsflächen auf Baulücken (56\%), der Rest auf Brachen. Dabei dominieren in Westdeutschland die Baulücken, 
Tab. 3.1 Innenentwicklungspotenziale je Einwohner in $\mathrm{m}^{2}$ nach Bevölkerungsentwicklung. (Quelle: Berechnungen des IÖR (Institut für ökologische Raumentwicklung) im Auftrag des BBSR)

\begin{tabular}{l|l|l}
\hline $\begin{array}{l}\text { Bevölkerungsentwicklung der } \\
\text { Gemeinden }\end{array}$ & $\begin{array}{l}\text { Bevölkerungsentwicklung 01.01.2009 } \\
\text { bis 31.12.2011 }\end{array}$ & IEP/Einwohner \\
\hline Stark wachsend & Mind. $1,5 \%$ p.a & ca. $8 \mathrm{~m}^{2}$ \\
\hline Wachsend & $0,25 \%$ bis unter $1,5 \%$ p.a & ca. $12 \mathrm{~m}^{2}$ \\
\hline Stagnierend & $-0,25 \%$ bis unter $0,25 \%$ p.a & ca. $13 \mathrm{~m}^{2}$ \\
\hline Schrumpfend & $-1,5 \%$ bis unter $-0,25 \%$ p.a & ca. $17 \mathrm{~m}^{2}$ \\
\hline Stark schrumpfend & Mehr als $-1,5 \%$ p.a & ca. $38 \mathrm{~m}^{2}$ \\
\hline
\end{tabular}

Datenbasis: BBSR IEP-Befragung 2012, Berechnungen des IÖR (Institut für ökologische Raumentwicklung) im Auftrag des BBSR

in Ostdeutschland dagegen die Brachen. In Großstädten wiederum sind $90 \%$ aller Innenentwicklungspotenziale Brachflächen. Tendenziell steigen die IEP je Einwohner mit abnehmender Gemeindegröße. In größeren Städten sorgt eine überwiegend hohe Flächennachfrage meist für eine rasche Wiedernutzung brachgefallender Siedlungsflächen. Insofern verfügen große und kleine Großstädte über die geringsten IEP je Einwohner. So beträgt der Wert in großen Großstädten unter $10 \mathrm{~m}^{2}$ und in Landgemeinden über $25 \mathrm{~m}^{2}$ pro Einwohner. Ein ähnlicher Trend, jedoch etwas weniger stark ausgeprägt, ist hinsichtlich der Bevölkerungsdynamik festzustellen. Denn die wachsenden und stark wachsenden Regionen sind vor allem die Großstädte. Demgegenüber schrumpfen überwiegend die Kleinstädte und Landgemeinden ${ }^{1}$ (Tab. 3.1). Insgesamt betrachtet, liegen die IEP bei der Mehrheit der Kommunen unter $20 \mathrm{~m}^{2}$ je Einwohner. Hinsichtlich ihres möglichen Beitrags zur Entlastung der Baulandmärkte sind sie gleichwohl relevant (BBSR 2013). Bezogen auf die Gebäude- und Freifläche besteht in großen Großstädten mit 7 \% das größte Potenzial, während Kleinstädte mit IEP von $4 \%$ an der Gebäude- und Freifläche die geringsten Potenziale aufweisen.

Auch wenn die mengenmäßig größten Möglichkeiten zur Reduzierung der Flächeninanspruchnahme durch Innenentwicklung in Kernstädten und verdichteten Regionen liegen, ist die Umsetzung der Maßnahme gerade im ländlichen Raum und in Klein- und Mittelstädten wichtig. Denn Innenentwicklung wirkt der Entleerung von Ortszentren und der Verödung von Quartieren entgegen und trägt zum Erhalt lebendiger Dörfer und Städte bei. Gleichzeitig stellen die Innenentwicklung und das in diesem Zusammenhang notwendige Flächenmanagement gerade kleine und mittlere Städte mit eingeschränkten personellen und finanziellen Ressourcen vor besondere Herausforderungen.

\footnotetext{
${ }^{1}$ Bezogen auf die Kommunen, die an der IEP-Befragung beteiligt waren.
} 


\section{Leerstände}

Laut Zensus 2011 standen zum Berichtszeitpunkt mehr als 1,8 Mio. Wohnungen in Deutschland leer. Berücksichtigt man eine Fluktuationsreserve ${ }^{2}$ von $3 \%$ des Wohnungsbestands, so besteht ein Leerstand von mehr als 665.000 Wohnungen. Anhand dieser Zahlen lässt sich jedoch weder abschätzen, ob der Leerstand dauerhaft ist, noch in welchem Zustand sich die Wohnungen bzw. Gebäude befinden. Jedoch geben sie ausreichende Hinweise auf die räumliche Verteilung der Wiedernutzungspotenziale in Deutschland. Während nach Abzug der Fluktuationsreserve in stark wachsenden Städten und Kreisen keine nennenswerten Leerstände existieren (z. B. München, Hamburg), machen sie in einigen stark schrumpfenden Kreisen mehr als $10 \%$ des Wohnungsbestands aus (z. B. Dessau-Roßlau, Chemnitz). Abb. 3.1 zeigt den Leerstand in Gebäuden mit Wohnraum in Prozent.

Die Leerstände in Deutschland werden zukünftig weiter zunehmen. Zu diesem Ergebnis kommt die Studie ,Aktuelle und zukünftige Entwicklung von Wohnungsleerständen in den Teilräumen Deutschlands“ (BBSR 2014a). Die projizierten Wohnungsüberhänge belaufen sich demzufolge im Jahr 2030 auf 2,5 bis 4,6 Mio. Diese Wohnungsüberhänge sind nicht zwangsläufig mit dauerhaftem Leerstand gleichzusetzen. Unter Berücksichtigung einer Fluktuationsreserve von $3 \%$ des Wohnungsbestands, abzüglich des heute schon bestehenden (und ggf. bis 2030 wiedergenutzten) Leerstands, stehen bis 2030 mehr als 1,25 Mio. weitere Wohnungen leer, die theoretisch wiedergenutzt werden könnten. Anhand der getroffenen Annahmen zur aktuellen und projizierten Leerstandswiedernutzung bräuchte ein Neubau von mehr als 25.000 Gebäuden bis 2030 nicht erfolgen, wenn die Leerstände vollständig genutzt würden.

\section{Nachverdichtung}

Neben der Nutzung von Brachflächen und Baulücken ergeben sich weitere IEP durch die städtebauliche Nachverdichtung. Der Begriff „Nachverdichtung“ wird im fachlichen Diskurs häufig mit Innenentwicklung gleichgesetzt. Hier wird jedoch unter Nachverdichtung nur die bauliche Nutzung bisher mindergenutzter Flächen innerhalb der bestehenden Bebauung verstanden. Nachverdichtung erfolgt in diesem Sinne ,auf Grundstücken, die bereits bebaut sind, jedoch über weitere Freiflächenpotenziale verfügen“" (BBSR 2013, S. 2), woraus eine bauliche Verdichtung folgt. Hierzu zählen Zweite-Reihe-Bebauung, Hinterhofbebauungen, Gebäudeaufstockungen und Ergänzungsbauten. Empirische Erhebungen zu Potenzialen der Nachverdichtung gibt es bislang nicht. In der Studie „Umsetzung von Maßnahmen zur Reduzierung der Flächeninanspruchnahme - Innenentwicklungspotenziale“ (ders.) wird eine Methode vorgestellt, wie sich solche Potenziale GIS-gestützt erheben lassen. Jedoch lässt sich die Verfügbarkeit und Zugänglichkeit solcher Potenzialflächen nur sehr eingeschränkt ermitteln.

${ }^{2}$ Etwa 2 bis $3 \%$ des Wohnungsleerstands ergeben sich aus Umzügen und Baumaßnahmen im Bestand und sind damit Bestandteil eines funktionstüchtigen Wohnungsmarktes. 

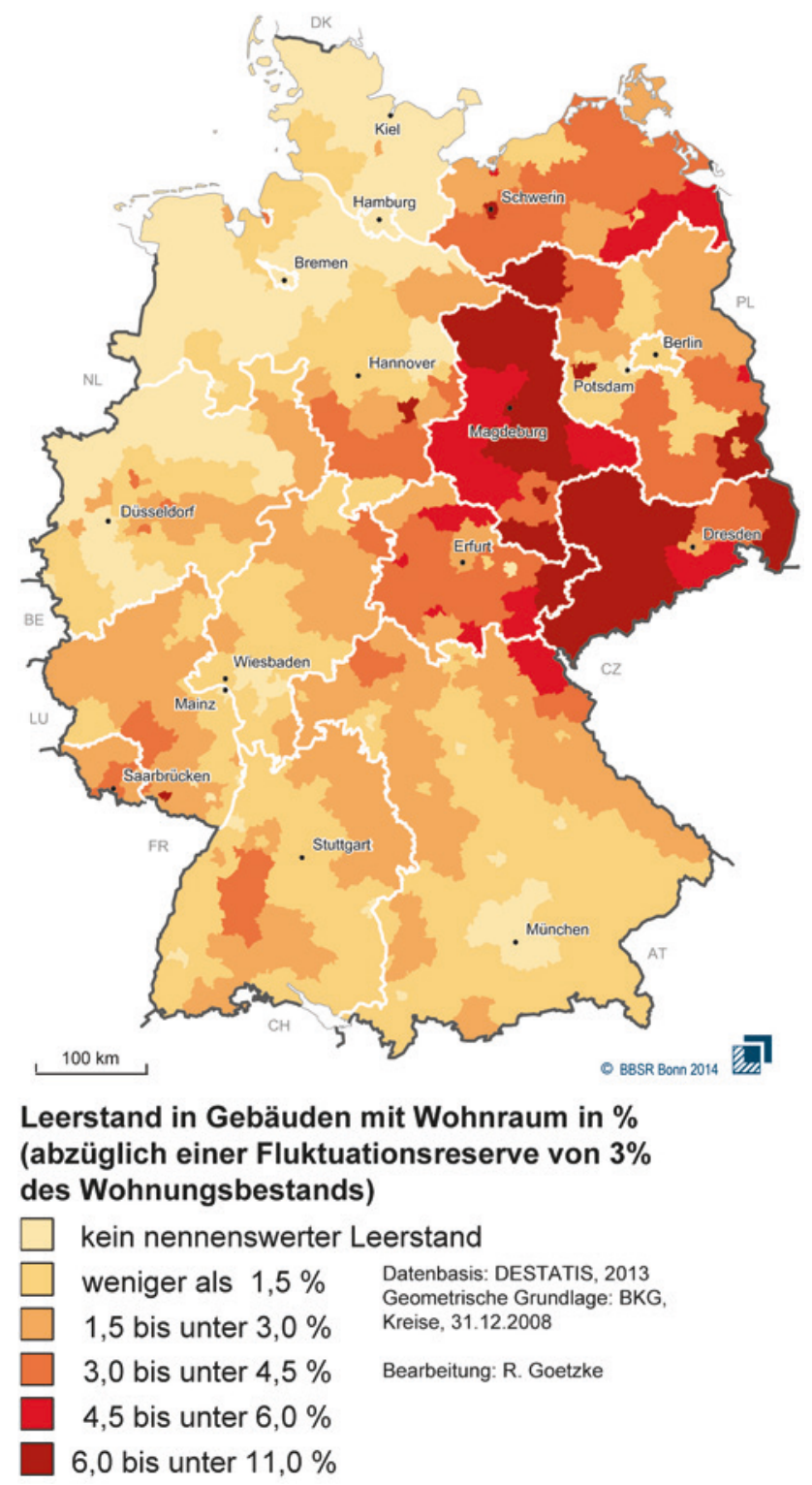

Abb. 3.1 Leerstände in Gebäuden mit Wohnraum 2011. (Abzüglich Fluktuationsreserve)

Hinsichtlich der Siedlungsdichten legt die Baunutzungsverordnung (BauNVO) Dichten für das Maß der baulichen Nutzung eines Grundstücks fest. Die baulichen Dichten der BauNVO sind als Obergrenzen definiert, die nicht überschritten werden dürfen, es sei denn aus städtebaulichen Gründen oder bei Durchführung entsprechender Ausgleichsmaßnahmen. Für Wohngebiete liegen sie bei einer Grundflächenzahl (=Anteil der überbauten Fläche eines Grundstücks) von 0,4 bis 0,6 (in Kerngebieten 
bei 1,0) und einer Geschossflächenzahl (=Verhältnis der Fläche aller Geschosse zur Grundstücksfläche) von 1,2 bis 1,6 (in Kerngebieten 3,0). Diese Obergrenzen werden jedoch vor allem in Gebieten mit geringem Flächendruck oftmals nicht ausgeschöpft. In der Folge kommt es zu geringen Siedlungsdichten, die mit einer entsprechend erhöhten Flächeninanspruchnahme einhergehen.

Grundsätzlich könnte vor allem durch eine Ausweitung des Geschosswohnungsbaus im Verhältnis zum Einfamilienhausbau erheblich flächensparender gebaut werden als bisher. Da dies, abgesehen von den Ballungszentren, städtebaulich nicht immer sinnvoll ist und häufig nicht dem nachgefragten Wohnraum entspricht, werden die in der BauNVO genannten Obergrenzen nicht überall erreicht. Bei der Umsetzung der Maßnahme „Ausschöpfung baulicher Dichte im Neubau“ sollte den regionalen Unterschieden aus städtebaulicher Perspektive Rechnung getragen werden. Zusätzlich kann die Akzeptanz der Bürger für höhere Dichten durch überzeugende Architektur gewonnen werden. In diesem Zusammenhang könnten Modellprojekte einen wichtigen Beitrag leisten.

Die aktuellen Zahlen der Baugenehmigungen in Deutschland bestätigen den Trend zu einer stärker verdichteten Bauweise. Die Baugenehmigungen von Wohnungen in Mehrfamilienhäusern sind im Jahr 2014 deutlich angestiegen (+8,8\%). Demgegenüber gab es Rückgänge bei den Genehmigungen für Ein- und Zweifamilienhäuser $(-1,4 \%$, bzw. $-5,8 \%$ ) (Waltersbacher 2015). Diese Entwicklung wird allerdings von den nachfragestärksten Städten getragen. Dort bedingt vor allem die angespannte Marktsituation die Notwendigkeit zu mehr Investitionen in den Geschosswohnungsbau.

\subsubsection{Reduktion der Flächeninanspruchnahme durch Verkehr}

Trotz einer insgesamt rückläufigen Neuinanspruchnahme von Flächen ist die Verkehrsflächenentwicklung in den vergangenen Jahren nahezu auf stabilem Niveau von 22 bis 24 ha pro Tag geblieben. Erst seit dem Betrachtungszeitraum 2009 bis 2012 ist eine erste Verlangsamung der Verkehrsflächenentwicklung zu erkennen. Dies könnte möglicherweise einen neuen Trend ankündigen: Geringeres Siedlungsflächenwachstum bedeutet weniger Erschließungsstraßen. Und auch die Investitionen in Bundesverkehrswege sollen zukünftig verstärkt auf Erhaltungsmaßnahmen konzentriert werden (Bundesregierung 2013, S. 29).

Der Straßenverkehr trägt in erheblichem Maße zur Entstehung von THG-Emissionen sowie zur Flächeninanspruchnahme bei. ${ }^{3}$ Neben der unmittelbaren Flächeninanspruchnahme ergeben sich aus der Zunahme der Verkehrsflächen erhebliche Folgewirkungen für Natur und Umwelt durch die Zerschneidungswirkung der Trassen und die Zunahme

\footnotetext{
${ }^{3}$ Seit 1990 wurde das Autobahnnetz um $2478 \mathrm{~km}$ erweitert. Zudem wurden Bundesstraßen auf einer Strecke von $3618 \mathrm{~km}$ neu- oder ausgebaut (Quelle: https://www.bmvi.de/SharedDocs/DE/ Artikel/StB/entwicklung-der-autobahnen-in-deutschland-seit-der-wiedervereinigung.html (zitiert am 08.09.2020)).
} 
von Lärm und Schadstoff-Emissionen. Zudem zieht der Infrastrukturausbau Ausgleichsund Ersatzmaßnahmen in erheblichem Umfang nach sich, wodurch Nutzungskonkurrenzen zwischen der Landwirtschaft und dem Naturschutz verstärkt werden. ${ }^{4}$

1. Reduzierung des innerstädtischen Bedarfs an Verkehrsflächen und Rückbau nicht mehr benötigter Infrastruktur

Die Maßnahme „Reduktion der Flächeninanspruchnahme durch Verkehr“ zielt im innerstädtischen Bereich auf die Verbesserung der Luftqualität ab und reduziert durch einen Rückgang der Versiegelung den Wärmeinseleffekt bei gleichzeitiger Erhöhung des Wasserrückhalts in der Fläche. Die Maßnahme kann durch unterschiedliche Instrumente gesteuert werden, wie den gezielten Rückbau von Straßen und die Einrichtung von Fußgängerzonen mit entsiegelten Bereichen. Durch die Einführung einer (City-)Maut, die Reduzierung des Parkraums oder Parkraumbewirtschaftung kann der Bedarf an Verkehrsflächen reduziert werden. ${ }^{5}$ In ländlichen Regionen können nicht genutzte Bahntrassen und stark mindergenutzte Straßen zurückgebaut werden, auch um Verbundsysteme von Freiraum und Biotopen zu stärken. Ein Rückbau in ländlichen Räumen widerspricht jedoch den Grundsätzen des Raumordnungsgesetzes (ROG), wonach in allen Teilregionen Deutschlands gleichwertige Lebensverhältnisse angestrebt werden. Durch den Rückbau von unterausgelasteter Verkehrsinfrastruktur würde sich die Erreichbarkeit verschlechtern. In Kombination mit der Maßnahme „Rückzug aus der Fläche“ kann jedoch ein gezielter und gut abgestimmter Rückbau erfolgen.

2. Konzentration auf Erhalt und Ausbau statt neuer Trassen

Aus der Grundkonzeption der aktuellen Bundesverkehrswegeplanung (BVWP) lässt sich ein Trend zu stärkerem Erhalt und Ausbau statt Neubau im Verkehrssystem ablesen. Die Mittel, die der Bund für den Erhalt und den Ausbau der Verkehrsinfrastruktur bereitstellt, steigen im Verhältnis zu den Mitteln für den Neubau. In der BVWP 2003 wurden 56 \% der Mittel für die Erhaltung vorgesehen, in der Entwurfsfassung der BVWP 2015 sind es $65 \%$ (BMVI 2014, S. 67). In der aktuellen Entwurfsfassung wird insbesondere in unzerschnittenen verkehrsarmen Räumen der Erhalt deutlich über den Neubau gestellt. In der Grundkonzeption der BVWP 2015 wird erwähnt, dass in jedem Fall der Verlust von unzerschnittenen Räumen soweit wie möglich verhindert werden soll (S. 29).

\footnotetext{
${ }^{4}$ Beispielsweise wurden in Sachsen-Anhalt seit 1990 Maßnahmen des Naturschutzes und der Landschaftspflege im Zusammenhang mit dem Straßenbau auf rund 3900 ha Fläche durchgeführt (Quelle: https://mlv.sachsen-anhalt.de/themen/verkehr-und-strassenbau/oekologische-massnahmen (zitiert am 12.03.2018)).

${ }^{5}$ Diese Maßnahmen müssen gut durchdacht sein und mit einer entsprechenden Angebotsverbesserung des ÖPNV begleitet werden, da sonst Umwegfahrten entstehen und es lediglich zu einer Verkehrsverlagerung kommt. Möglichkeiten bieten hier u. a. smarte Parkmanagement-Lösungen.
} 
3. Konzentration der Siedlungsentwicklung auf leistungsfähige Verkehrsknotenpunkte und Infrastrukturtrassen

Das Verkehrsaufkommen im motorisierten Individualverkehr (MIV) hängt erheblich von der Erreichbarkeit ab. Entstehen neue Baugebiete nahe an leistungsfähigen Verkehrsknotenpunkten oder Orten mit einer hohen Dichte an Versorgungsinfrastruktur, Arbeitsplätzen oder sozialer Infrastruktur, können Fahrtstrecken reduziert werden und der Umstieg auf andere Mobilitätsformen wird vereinfacht.

\subsubsection{Rückzug aus der Fläche (mit dezentraler Konzentration)}

In stark schrumpfenden ländlich-peripheren Regionen wird es zunehmend schwieriger, die Daseinsvorsorge aufrecht und die Infrastruktur instand zu halten. Dem lässt sich entweder durch eine Strategie der Anpassung und des geordneten Rückzugs oder durch eine aktive Strategie des Gegensteuerns begegnen (BBSR 2010, S. 3 ff.).

Ziel einer Maßnahme „Rückzug aus der Fläche“ ist die Herstellung einer effizienten Siedlungsstruktur und die Wiedergewinnung von ökologisch wertvollem Freiraum. Das bedeutet, dass diese Maßnahme mit einem Rückbau gebauter Strukturen einhergeht. Bei Rückbau kann es sich sowohl um den Abriss einzelner Gebäude handeln, wie es in den vergangenen Jahren vor allem im Rahmen des Stadtumbau Ost bei Geschosswohnungen praktiziert wurde, als auch um einen geordneten flächenhaften Rückbau von Kleinsiedlungen ohne Perspektive im ländlich-peripheren Raum. Dies würde durch die Konzentration von Funktionen der Daseinsvorsorge auf ein ggf. ausgedünntes Zentrale-OrteSystem gesteuert. Durch die Lenkung der Siedlungsentwicklung auf zentrale Orte kommt es dort zu einer Verdichtung und verbesserten Auslastung der Infrastruktur. Mittelzentrale Orte in Reichweite von Großstadtregionen werden dadurch aufgewertet und können diese funktional entlasten, wodurch eine dezentrale Konzentration gefördert wird (Brake 1998).

Die Maßnahme kommt besonders in solchen Regionen infrage, die zusätzlich noch in Gefährdungsbereichen mit hohem Schadenspotenzial liegen, wie z. B. hochwasser- oder lawinengefährdete Gebiete. Wenn dort dadurch die volkswirtschaftliche Effizienz deutlich nicht mehr gegeben ist, wird eine Absiedelung in Betracht gezogen.

Durch die Konzentration von Funktionen der Daseinsvorsorge kann es allerdings regional dazu kommen, dass längere Strecken zurückgelegt werden müssen, weil Versorgungsorte weiter entfernt sind. Zudem kann in stärker verdichteten zentralen Orten der Verkehr zunehmen. Dementsprechend muss eine solche Maßnahme mit anderen Maßnahmen, wie der „Stärkung des ÖPNV“, sinnvoll kombiniert werden.

Während gezielter Rückbau von Gebäuden und Infrastruktur zur Wiederherstellung naturnaher Landnutzung meist positiv bewertet wird, sind der Rückzug von Funktionen der Daseinsvorsorge aus der Fläche sowie die Absiedelung kleiner Ortschaften höchst umstritten und werden von vielen Akteuren, vor allem im ländlichen Raum, abgelehnt. Zudem ergäbe sich daraus ein Widerspruch zu den Grundsätzen der Raumordnung, die in allen Teilräumen Deutschlands gleichwertige Lebensverhältnisse anstrebt ( 2 Abs. 2 Satz 1 ROG). 


\subsubsection{Erhalt und Entwicklung innerstädtischer Freiflächen}

Durch das Phänomen der städtischen Wärmeinsel sind Siedlungsbereiche in besonderem Maße von klimawandelbedingten Veränderungen der Temperatur betroffen. Vor allem langanhaltende Hitzewellen können eine Belastung für die Gesundheit der Bewohner, insbesondere älterer und kranker Menschen sowie Kleinkinder bedeuten.

Erläuterung Hitzeperioden: Während an heißen Tagen der Temperaturunterschied am Tag zwischen Stadt und Umland meist nur wenige Grad beträgt, kann er in windstillen und wolkenlosen Sommernächten mehr als $10^{\circ} \mathrm{C}$ ausmachen (Oke 1997). In langanhaltenden Hitzeperioden ist die fehlende Abkühlung in der Nacht eine besondere Belastung für die Gesundheit. Weniger als die am Tage gemessene Lufttemperatur wird die sogenannte gefühlte Temperatur von Änderungen der Stadtstruktur beeinflusst, die das thermische Wohlbefinden des Menschen im Besonderen charakterisiert. Die gefühlte Temperatur beinhaltet neben der gemessenen Temperatur auch Windgeschwindigkeit, Luftfeuchte und Strahlung.

\section{Fallbeispiel}

Ein Beispiel für die Auswirkungen von extremen Starkniederschlägen im Siedlungsbereich ergab sich am 28.07.2014 in der Region Münster, wo mehr als 190 1/m² Niederschlag in zwölf Stunden fielen und zwei Todesopfer sowie eine Schadenssumme von ca. 80 Mio. € zu beklagen waren. Der Deutsche Wetterdienst (DWD) rechnet in einer Stellungnahme mit einer Verdopplung des Auftretens derartiger Wetterlagen bis zum Jahr 2100 (DWD 2014).

Auch die thermisch-mechanische Belastung von Gebäuden und Infrastrukturen nimmt unter einer steigenden Anzahl an Hitzetagen zu (BMVBS 2011). Eine zunehmende Verdichtung und Ausdehnung des Siedlungskörpers verstärkt diese Problematik. Durch die Versiegelung von Böden in Siedlungsbereichen und durch Verkehrsflächen erhöht sich zudem der Direktabfluss von Niederschlägen, da der Wasserrückhalt in Boden und Vegetation nicht gegeben ist (Arnold und Gibbons 1996) (siehe Fallbeispiel oben).

In vielen Gebieten gibt es bereits heute mehr als sieben heiße Tage (Maximaltemperatur $>30{ }^{\circ} \mathrm{C}$ ) pro Jahr. Schwerpunkte liegen am Ober- und Mittelrhein, dem Rhein-Main-Gebiet und in Brandenburg (vgl. Abb. 3.2). Bis zum Jahr 2100 wird die Anzahl heißer Tage in vielen Regionen Deutschlands deutlich zunehmen. ${ }^{6}$ Ein Großteil der deutschen Großstadtregionen liegt in den warmen Gebieten entlang von Rhein, Main

${ }^{6}$ Siehe Potsdam Institut für Klimafolgenforschung (PIK): http://www.klimafolgenonline.com/. 


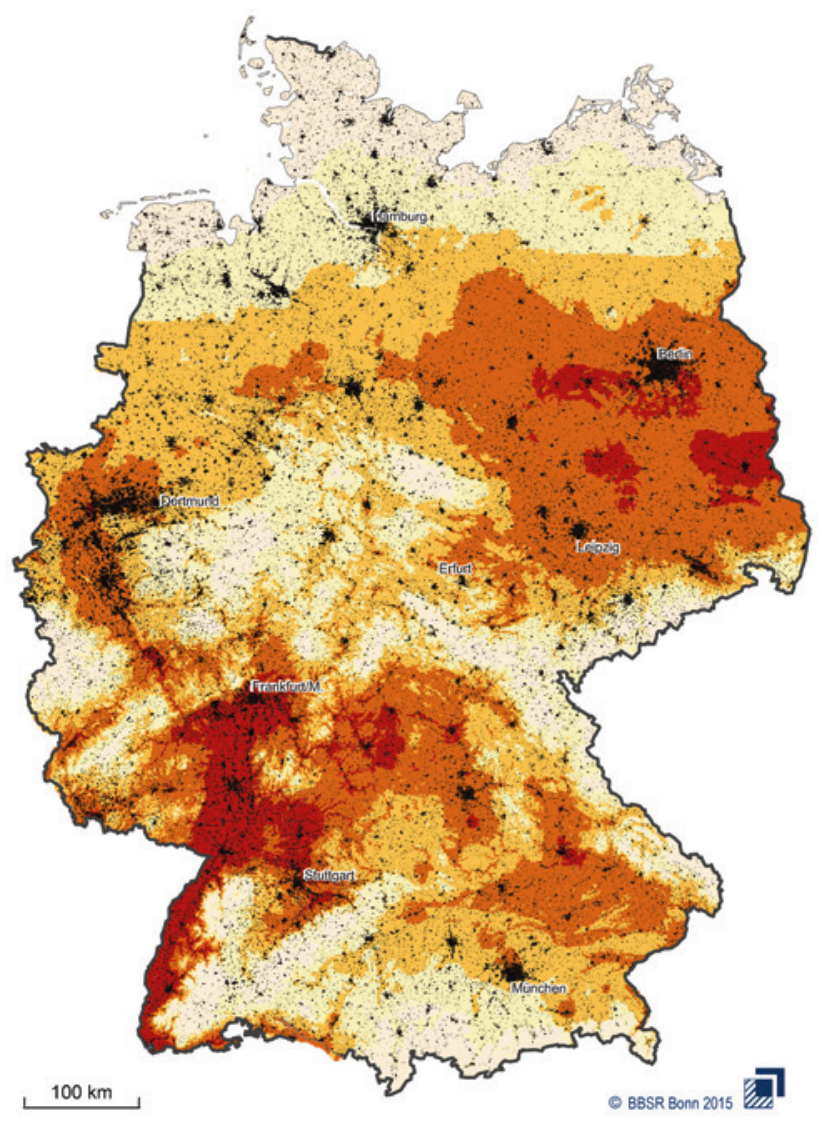

Heiße Tage

(Durchschnitt der Periode 1981-2010)

unter 3

über 3 bis 5

über 5 bis 7

über 7 bis 10

über 10

$\square$ Siedlungs- und Verkehrsfläche

Datenbasis: Corine Land Cover 2006, DFD-DLR; UA 2006, EEA; Klimadaten: DWD Geometrische Grundlage: BKG, Grenzen 31.12.2009 Gemeinden, 31.12.2012

Bearbeitung: R. Goetzke

Abb. 3.2 Anzahl heißer Tage pro Jahr in Deutschland. (Durchschnitt der Periode 1981-2010) 
und Ruhr sowie mit bspw. Berlin, Leipzig und Dresden im kontinental geprägten Ostdeutschland.

Die Maßnahme „Erhalt und Entwicklung innerstädtischer Freiflächen“ zielt auf die thermische Entlastung von Städten bei einer erwarteten Zunahme an Hitzetagen, die Stärkung der Erholungsfunktion in Metropolregionen sowie eine Erhöhung des natürlichen Wasserrückhalts und der Grundwasserneubildungsrate ab. Dies geschieht in erster Linie durch die Verbesserung der Versorgung mit und Erreichbarkeit von Grün- und Freiflächen innerhalb des Siedlungsraums und zwischen den Siedlungsräumen. ${ }^{7}$ Damit adressiert diese Maßnahme in erster Linie Klimaanpassungsaspekte. Daneben können sich positive Wirkungen für den Klimaschutz durch eine höhere Kohlenstoffspeicherung aufgrund umfangreicheren Grünvolumens im städtischen Raum ergeben. Die Maßnahme wirkt zudem positiv auf die Biodiversität, Luftreinhaltung, Lärmreduktion und Gesundheit.

1. Sicherung bestehender innerstädtischer Grün- und Erholungsflächen sowie Freiraumund Grünplanung im Neubau

Um der Entstehung weiterer thermischer Belastung vorzubeugen, muss sowohl bei der Innenentwicklung als auch in neuen Baugebieten auf eine ausreichende Freiflächenversorgung geachtet werden. Darunter ist weniger eine aufgelockerte Bebauung zu verstehen, die bei hohem Flächenbedarf ökonomisch und ökologisch wenig sinnvoll wäre, sondern die gezielte Berücksichtigung von grünen und blauen Strukturen, d. h. innerstädtischen Grün- und Wasserflächen und Luftaustauschkorridoren.

2. Erhalt regionaler Freiraumfunktionen und grüner/blauer Strukturen

In der Maßnahme findet eine Stärkung der Regional- und Landschaftsplanung bei der Sicherstellung von Kaltluftentstehungsgebieten und -leitbahnen, multifunktionaler regionaler Grünzüge und Freiraumfunktionen statt. Auch wenn der Erhalt und die Entwicklung innerstädtischer Freiflächen in erster Linie eine Aufgabe der Kommunen sind, so ist gerade die stadtregionale Freiraumstruktur ein Handlungsfeld der Regionalplanung (vgl. Knieling et al. 2013, S. 18). So könnten weitere Vorrang- und Vorbehaltsgebiete zum Siedlungsklimaschutz festgelegt oder weitere Siedlungsfreiflächen als regionale Grünzüge o. Ä. ausgewiesen werden, denen insgesamt eine hohe Bedeutung zukommt.

Die Landschaftsplanung hätte in diesem Zusammenhang große Gestaltungsoptionen, ist in weiten Teilen allerdings eher reaktiv angelegt und vor allem auf Natur- und Umweltschutzaspekte fokussiert. Durch die gezielte Verknüpfung von Naturschutz-, Klimaschutz und Freizeitnutzungsaspekten könnte die Landschaftsplanung eine höhere Steuerungswirkung entfalten.

\footnotetext{
${ }^{7}$ Auf Handlungsfelder aus dem Themenspektrum des urbanen Grüns wird in MBWSV NRW (2014) ausführlich eingegangen. Die hier modellierte Maßnahme berücksichtigt nur flächenrelevante Aspekte (z. B. keine Gebäudebegrünung), umfasst aber alle Siedlungstypen und nicht nur Städte.
} 


\section{Schaffung neuer innerstädtischer Grünflächen}

Neben dem Erhalt beinhaltet die Maßnahme die Schaffung neuer Freiflächen, z. B. durch die Nutzung von Brachflächen und Baulücken für neue Grün- und Erholungsflächen und durch die Senkung der Umwandlungskosten von Brachflächen in Grünflächen. Insgesamt steigt in städtisch geprägten Gebieten, die derzeit eine Minderausstattung mit Grün- und Erholungsflächen aufweisen, der Bedarf an Erholungsfläche je Einwohner. Feste bundesweite Richtwerte für die Grünflächenversorgung gibt es nicht. Nach einer Empfehlung des Bundesamtes für Naturschutz $(\mathrm{BfN})$, die sich an Satzungen und Erlassen von Kommunen orientiert, die hierzu Aussagen getroffen haben, sollten im Schnitt jedem Einwohner etwa 55,75 $\mathrm{m}^{2}$ Erholungsfläche zur Verfügung stehen (Rittel et al. 2014, S. 63). ${ }^{8}$

Neben der Grünflächenversorgung spielt die Erreichbarkeit von Grünflächen im Kontext von Klimaanpassung eine wichtige Rolle. Laut Empfehlungen des BfN sollten sich wohnungsnahe Grünräume in einer Entfernung von nicht mehr als $500 \mathrm{~m}$ (5 bis 10 Gehminuten) zur Wohnung befinden (Rittel et al. 2014, S. 62).

4. Rückbau, Entsiegelung und Konzentration gebauter Strukturen

In Schrumpfungsregionen und Städten mit hohem Leerstand kann ein Teil des Gebäudebestands zurückgebaut werden, um weitere Potenziale für urbane Grünflächen zu schaffen. Zwischen 2001 und 2010 wurden allein in den neuen Bundesländern ca. 284.700 Wohnungen abgerissen (BMVBS 2012, S. 23). Gerade vor dem Hintergrund der Bevölkerungsentwicklung nach 2020 bleibt ,Rückbau auch zukünftig eine Kernaufgabe des Stadtumbaus“ (ders., S. 82), jedoch tendiert der Fokus im Stadtumbau deutlich in Richtung Aufwertung (ders., S. 25). Solche freiwerdenden Flächen können als qualitativ hochwertige Grün- und Erholungsflächen genutzt werden.

Berücksichtigt man die derzeitigen und bis 2030 projizierten Leerstände (vgl. Abschn. 3.1.1), könnten nach groben Schätzungen mindestens 280.000 Gebäude zurückgebaut werden. Bei einem solchen Rückbau ist jedoch darauf zu achten, dass der städtebauliche Charakter von Quartieren nicht verloren geht. Vielfach ist den Kommunen der Zugriff auf leerstehende und im Verfall befindliche Objekte nicht ohne weiteres möglich und der Abriss sowie vor allem die Anlage und Pflege von Grünflächen mit erheblichen Kosten verbunden. Ohne die Bereitstellung finanzieller Mittel ist diese Maßnahme kaum umzusetzen.

\subsubsection{Stärkung des Öffentlichen Personennahverkehrs}

Der Pkw ist nach wie vor das wichtigste Verkehrsmittel der Deutschen. Das Wachstum des motorisierten Individualverkehrs (MIV) hat sich zuletzt jedoch abgeschwächt,

\footnotetext{
${ }^{8}$ Der Versorgungswert setzt sich aus Annahmen zur Versorgung mit allgemeinen öffentlichen Grünräumen, Sportplätzen, Bolzflächen, Spielflächen, Kleingärten und Friedhofsflächen zusammen. Diese Nutzungsformen sind in der Landnutzungskategorie urbane Grün- und Erholungsflächen subsummiert.
} 
während öffentlicher Verkehr und nicht-motorisierter Individualverkehr zugenommen haben (infas und DLR 2010, S. 1). Die $\mathrm{CO}_{2}$-Emissionen des Verkehrssektors beliefen sich im Jahr 2006 auf 160 Mio. t, wovon $93 \%$ auf den Straßenverkehr entfallen (ders., S. 5). Damit ist der Straßenverkehr für knapp $16 \%$ der $\mathrm{CO}_{2}$-Gesamt-Emissionen in Deutschland verantwortlich (UBA 2013, S. 196).

Die Art und Weise, wie Menschen sich im Raum bewegen, welche Verkehrsmittel sie nutzen und welche Strecken sie zurücklegen, ist von den Möglichkeiten geprägt, die ihnen zur Ausübung ihrer Aktivitäten geboten werden (infas und DLR 2010, S. 33). Die Siedlungsstruktur beeinflusst dies in besonderer Weise: „Orte mit hoher Bevölkerungsdichte verfügen über hohes Kontaktpotenzial [...]. Infolgedessen ist es zumindest potenziell möglich, Wege des alltäglichen Lebens in geringer räumlicher Entfernung durchzuführen. In dünn besiedelten Räumen müssen demgegenüber oft weite Strecken zurückgelegt werden, um Orte höherer Zentralität mit einem entsprechenden Angebot zu erreichen. [...] Während dicht bebaute Gebiete günstige Bedingungen für den Einsatz von öffentlichen Verkehrsmitteln bieten, können dispers verteilte Einfamilienhaussiedlungen und am Stadtrand liegende Einzelhandels- und Betriebsstandorte oft nur mit dem MIV effizient erschlossen werden. Umgekehrt hat das Verkehrssystem hohen Einfluss auf die Ausprägung der Raum- und Siedlungsstruktur“" (ders., S. 33).

Eine kompakte, effiziente und am ÖPNV ausgerichtete Siedlungsstruktur kann zur Reduktion von $\mathrm{CO}_{2}$-Emissionen beitragen, da weniger Fahrtstrecken aufgewendet werden und die Verkehrsteilnehmer energiesparendere Fahrzeuge (Bahn, Bus, Fahrrad, Fußweg etc.) als den Pkw für ihre Wegstrecken nutzen können. Zudem verringert eine kompakte Siedlungsstruktur die Zerschneidungswirkung von Siedlungen und hat damit einen positiven Effekt auf Natur und Landschaft. Aus diesem Grund zielt die Maßnahme auf eine aktive Veränderung der Verkehrsmittelwahl ab, hin zu mehr ÖPNV. Hierfür gibt es verschiedene Möglichkeiten, wie bspw. die Ausweisung gesonderter Bus- und Bahnspuren, Erreichbarkeitsnachweise des ÖPNV bei der Baulandausweisung, Vorrangschaltung für den ÖPNV an Ampeln oder die Zulassung einer höheren baulichen Dichte in der Nähe von ÖPNV-Knotenpunkten. Ziel ist es, das Verhältnis von ÖPNV zu MIV von derzeit 1:5 auf 2:1 zu entwickeln (Fuhrich et al. 2004; infas und DLR 2010).

\subsubsection{Zusätzliche Ausweisung von Vorrang- und Vorbehaltsgebieten}

Vorrang- und Vorbehaltsgebiete sind die wichtigsten Instrumente, die der Landes- und Regionalplanung zur räumlichen Steuerung der Siedlungs- bzw. Landnutzungsentwicklung zur Verfügung stehen. Bei dieser Maßnahme handelt es sich weniger um einen neuen Ansatz, der von Akteuren im Siedlungsbereich angewendet werden kann, sondern eher um die konsequentere Anwendung des vorhandenen Instrumentariums. Gerade vor dem Hintergrund des Klimawandels ergeben sich hierdurch jedoch neue Handlungsspielräume, weshalb die „Zusätzliche Ausweisung von Vorrang- und Vorbehaltsgebieten“ hier als eigene Maßnahme geführt wird. 


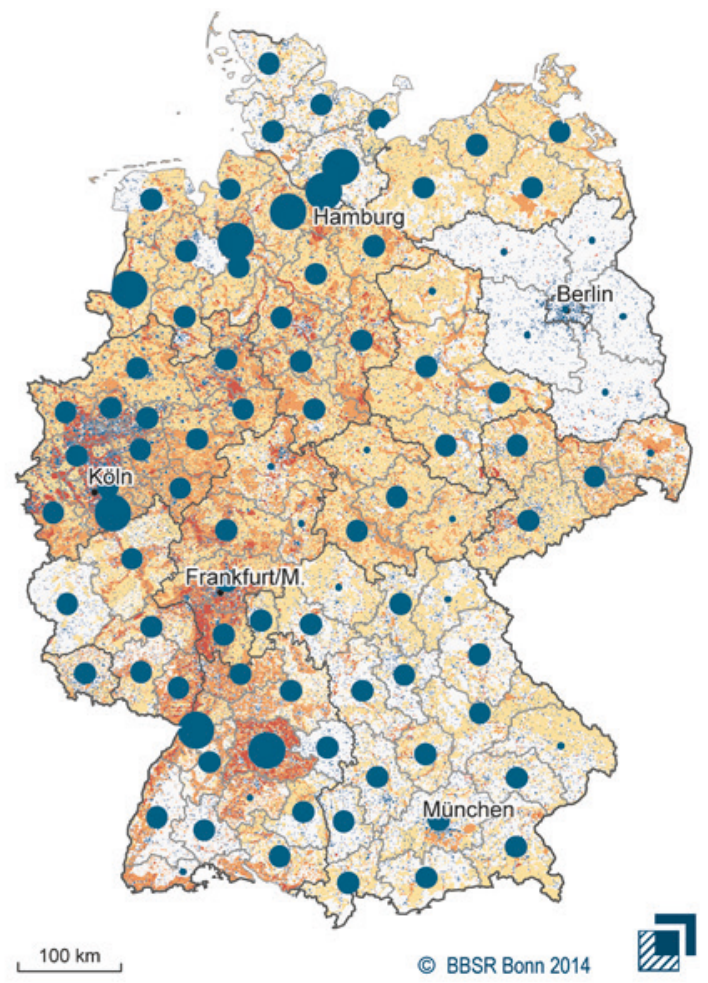

\section{Steuernde Wirkung der Regionalplanung Siedlungsdruck bis 2030 auf bestehende auf die Siedlungsentwicklung Vorrang- und Vorbehaltsgebiete}

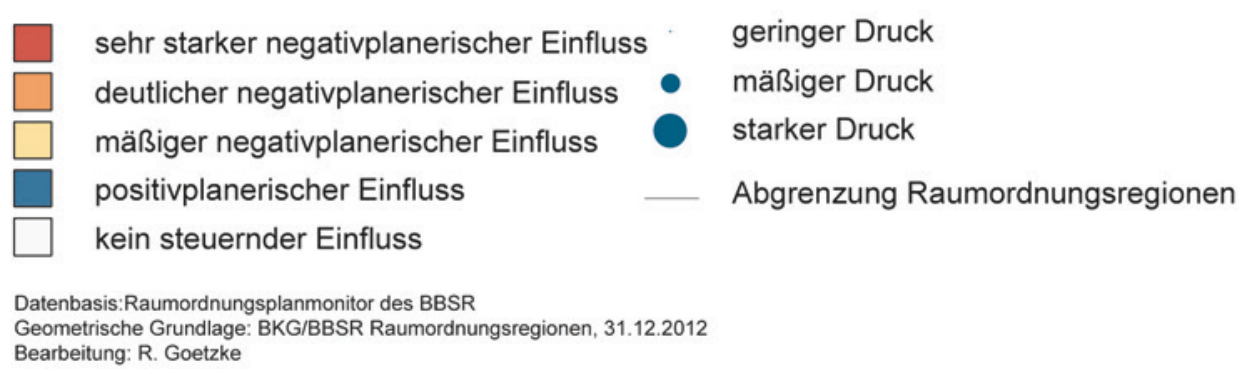

Abb. 3.3 Einfluss der Regionalplanung auf die Siedlungsentwicklung

Als Folge des Klimawandels ist eine steigende Anzahl an Extremwetterereignissen $\mathrm{zu}$ erwarten, die ein hohes Schadenspotenzial besitzen. Um dieses möglichst gering zu halten, können Flächen von bestimmten Nutzungen freigehalten werden oder die Nutzungsintensität auf diesen Flächen geregelt werden. Dafür stehen Instrumente der Raumplanung zur Verfügung (BMVBS 2010). Da Klimafolgen auf sehr unterschiedliche Regionen treffen (urban/ländlich, prosperierend/stagnierend), müssen die Auswirkungen 
des Klimawandels raumspezifisch differenziert betrachtet werden (Birkmann et al. 2013, S. 8). Durch die Steuerungswirkung der Raumplanung ist es möglich, die Raumstruktur regionsspezifisch an den Klimawandel anzupassen und die Siedlungsentwicklung entsprechend zu steuern. Dadurch kommt der Raumplanung eine Schlüsselrolle zu. In vielen Bereichen des Klimaschutzes und der Klimaanpassung ist die Raumplanung jedoch nicht der zentrale Akteur. Gerade in den Bereichen Hochwasser- und Küstenschutz spielen die Fachplanungen eine wichtige Rolle (Greiving und Fleischhauer 2008). Auch wenn im ROG die Abstimmung zwischen den unterschiedlichen Planungsstufen klar gefordert wird, ist die Koordination bei den Problemkomplexen Klimaschutz und Klimaanpassung häufig eingeschränkt (ders., S. 63). Auch der Umstand, dass im konkreten Planungsprozess raumordnerische Grundsätze (Vorbehaltsgebiete) im Rahmen des Abwägungsprozesses „weggewogen“ werden können, schwächt die steuernde Wirkung der Raumordnung.

In den einzelnen Planungsregionen werden die raumordnerischen Instrumente der Vorrang- und Vorbehaltsgebiete sehr unterschiedlich ,intensiv“ genutzt. In manchen Planungsregionen ist ein und dieselbe Fläche mit mehreren restriktiven Planzeichen belegt, in anderen Regionen werden nur sehr lokal restriktive raumordnerische Festlegungen vorgenommen. Zusätzlich finden in einigen Planungsregionen positivplanerische Festlegungen ${ }^{9}$ statt, während diese in anderen Regionen überhaupt nicht vorkommen. In Abb. 3.3 ist der Einfluss, der sich aus den regionalplanerischen Festlegungen für die Siedlungsentwicklung ergibt, zusammenfassend dargestellt. Die Abbildung zeigt einerseits, wo sich mehrere negativplanerische Festlegungen überlagern (rot), wo es positivplanerische Festlegungen gibt (blau) und wo kein steuernder Einfluss der Regionalplanung herrscht (grau). Die blauen Kreise zeigen den Umfang der Siedlungsentwicklung innerhalb negativplanerischer Vorrang- und Vorbehaltsgebiete in der Referenzprojektion bis 2030. Je größer die Kreise, desto mehr Siedlungsflächen werden trotz restriktiver Planung innerhalb dieser Flächen in Anspruch genommen, weil bei hohem Siedlungsdruck nur wenige Ausweichmöglichkeiten vorhanden sind. Beispiele hierfür sind die Regionen Stuttgart, Bonn und der Mittlere Oberrhein. In anderen Regionen, in denen ebenfalls eine hohe Siedlungsdynamik zu verzeichnen ist, wie in der Rhein-Main-Region oder im Münsterland, findet im Modell hingegen nur ein mäßiger Zuwachs innerhalb restriktiver Vorrang- und Vorbehaltsgebiete statt. Dies kann damit zusammenhängen, dass es dort ausreichende positivplanerische Festlegungen oder Gebiete ohne regionalplanerisch steuernden Einfluss gibt, die die Siedlungsentwicklung ermöglichen.

Der Schwerpunkt der Maßnahme liegt in der Stärkung raumordnerischer Festlegungen zur konsequenteren Steuerung der Siedlungsentwicklung in den Strategien „Klimaschutz“, „Klimaanpassung“ sowie „Natur- und Umweltschutz“. Ziel ist es vor allem, eine klimawandelangepasste Raumstruktur zu erhalten und dem Klimaschutz

${ }^{9}$ Positivplanerische Festlegungen erlauben eine bestimmte Nutzungsform eines Gebiets explizit, während negativplanerische Festlegungen bestimmte Nutzungsformen ausschließen. 
Raum zu geben. Wichtige Handlungsfelder der Raumordnung wurden auch von der Ministerkonferenz für Raumordnung genannt (MKRO 2013):

Für die Strategie ,Klimaanpassung“6

- Vorbeugender Hochwasserschutz in Flussgebieten

- Küstenschutz

- Schutz der Berggebiete (insbesondere Alpenraum)

- Schutz vor Hitzefolgen im Siedlungsbereich (bioklimatische Belastungsgebiete)

- Regionale Wasserknappheiten

- Veränderungen im Tourismusverhalten

- Verschiebung der Lebensräume von Tieren und Pflanzen

Für die Strategie ,Klimaschutz"6

- Energiesparende und verkehrsvermeidende, integrierte Siedlungs- und Verkehrsflächenentwicklung

- Räumliche Vorsorge für eine klimaverträgliche Energieversorgung

- Raumordnerische Sicherung von $\mathrm{CO}_{2}$-Senken

Bei konsequenter Umsetzung der Nutzungsrestriktionen ergeben sich standortsteuernde Effekte, die eine Ausweitung von Siedlungs- und Verkehrsflächen in ungeeigneten Gebieten verhindern, zum Naturschutz beitragen oder z. B. den Wasserrückhalt in der Fläche ermöglichen. Von Relevanz sind hierbei vor allem Vorrang- und Vorbehaltsgebiete aus den Bereichen Hochwasserschutz, Regionale Grünzüge, Natur- und Landschaft, Landwirtschaft, Forstwirtschaft, Freiraumschutz und Siedlungsklimaschutz sowie Vorrang- und Vorbehaltsgebiete, die zum Schutz der natürlichen Bodenfunktion beitragen (Grundwasserschutz, Bodenschutz). Zudem können neue Gebiete ausgewiesen werden, um beispielsweise das natürliche Ertragspotenzial und die $\mathrm{CO}_{2}$-Senkenfunktion von Böden zu erhalten. Im Bereich Klimaschutz können weitere Vorrang- und Vorbehaltsgebiete für erneuerbare Energien ausgewiesen oder deren Steuerungswirkung erhöht werden.

\subsubsection{Stärkung des Hochwasserschutzes}

Die Häufigkeit und Intensität von extremen Hochwasserereignissen hat in den letzten Jahrzehnten zugenommen. Die entstandenen Schäden sind enorm. ${ }^{10}$ Bereits als Reaktion auf das Hochwasser an Elbe, Donau und ihren Zuflüssen im Jahr 2002 hat die Bundes-

\footnotetext{
${ }^{10}$ Allein für das Juni-Hochwasser 2013 gehen vorläufige Schätzungen von einer Schadenssumme von 6,7 Mrd. € aus sowie weiteren $2 \mathrm{Mrd}$. $€$ für versicherte Schäden. Für die Beseitigung von Schäden an Bundesverkehrswegen und Liegenschaften des Bundes sind weitere 1,32 Mrd. € eingeplant.
} 
regierung ein 5-Punkte-Programm aufgelegt, dessen zentrales Element es war, den Flüssen „,mehr Raum“ zu geben. Dabei spielen die Sicherung und Rückgewinnung natürlicher Retentionsräume und Überschwemmungsflächen eine große Rolle. Ende 2014 wurde von der Umweltministerkonferenz das Nationale Hochwasserschutzprogramm verabschiedet, das zahlreiche Projekte zu Deichrückverlegungen und gesteuerter Hochwasserrückhaltung enthält. Die Gesamtkosten liegen bei etwa 5,4 Mrd. € (Bund/Länder-Arbeitsgemeinschaft Wasser (LAWA) 2014). Im Jahr 2007 wurde zudem die europäische Hochwasserrisikomanagement-Richtlinie (HWRM-RL) erlassen, um die Auswirkungen von Hochwasser zu verringern und zu bewältigen. Die bundesdeutsche Umsetzung der Richtlinie erfolgte durch eine Ergänzung des Wasserhaushaltsgesetztes (WHG). Darin wird die Erstellung von Gefahren- und Risikokarten für Hochwasserereignisse unterschiedlicher Intensität festgelegt, das Aufstellen von Risikomanagementplänen geregelt und die Festlegung von Überschwemmungs- und Rückhalteflächen normiert. So sollen die jeweiligen Landesregierungen innerhalb von Risikogebieten mindestens die Flächen als Überschwemmungsgebiete festsetzen, bei denen statistisch einmal in 100 Jahren ein Hochwasserereignis $\left(\mathrm{HQ}_{100}\right)$ erwartet werden kann. Diese Flächen gehen vielfach über die bislang raumplanerisch festgelegten Vorranggebiete zum Hochwasserschutz hinaus. Es kann zudem festgestellt werden, dass regionalplanerische Festlegungen zur Hochwasservorsorge bislang nicht den gewünschten Einfluss auf die Siedlungsentwicklung haben (BMVBS 2013).

Die Ziele der Maßnahme liegen in der Stärkung des raumordnerischen Instrumentariums zum Hochwasserschutz. Damit sollen vorsorgend Flächen von der Siedlungsentwicklung ausgeschlossen werden, bei denen ein erhöhtes Hochwasserrisiko besteht. Umgesetzt wird dies durch die Stärkung der vorhandenen Vorrang- und Vorbehaltsgebiete (z. B. Vorbehaltsgebiete werden als Vorranggebiete gewertet) und durch die Berücksichtigung der $\mathrm{HQ}_{100}$-Gebiete aus der HWRM-RL. Bisher werden in der Planungspraxis raumordnerische Vorrang- und Vorbehaltsgebiete nur für $\mathrm{HQ}_{100}$ ausgewiesen. Die hier modellierte Maßnahme geht darüber hinaus und legt auch $\mathrm{HQ}_{\text {extrem }}$ als Vorranggebiete fest. Während $\mathrm{HQ}_{100}$ regelmäßig neu berechnet werden muss, was auch eine Aktualisierung der Raumordnungspläne nach sich zieht, bleiben die Annahmen zu $\mathrm{HQ}_{\text {extrem }}$ über einen längeren Zeitraum konstant. Auf diese Weise ließe sich für diese Gebiete eine hochwasserangepasste Bebauung vorschreiben (BMVBS 2013). Hieraus ergeben sich höhere Kosten sowie eine verbesserte Information über die möglichen Risiken einer neuen Bebauung, sodass davon ausgegangen werden kann, dass in diesen Gebieten die Siedlungsdynamik zurückgeht. Die Festlegungen wirken sich nicht auf den Bestand aus, der nicht ohne weiteres zurückgenommen werden kann. Dies ist in Kombination mit der Maßnahme „Rückzug aus der Fläche“ jedoch möglich.

\subsubsection{Restriktiverer Freiraumschutz}

Die Flächeninanspruchnahme durch Siedlung und Verkehr hat vielfältige negative ökologische Folgewirkungen, wie den Verlust von Lebensräumen für Tier- und Pflanzen- 
arten, die Zersiedelung und Zerschneidung von Landschaften und Habitaten mit entsprechenden Folgen für die biologische Vielfalt, steigende Lärm- und Schadstoffbelastung etc. Naturschutzpolitische Instrumente leisten einen Beitrag zur Steuerung der Flächeninanspruchnahme, insbesondere in Hinblick auf die Standortsteuerung. Vor allem Schutzgebietsausweisungen können standortsteuernd auf die Flächeninanspruchnahme einwirken. Jedoch weisen sie in der Mehrzahl „keinen unmittelbaren Bezug zum Schutzgut Boden und Fläche auf - aufgrund eines fehlenden rechtlichen Auftrags“ (Heiland et al. 2006, S. 89). Das Ziel der Steuerung der Flächeninanspruchnahme ist in keiner Schutzgebietskategorie definiert. In der Folge wird in der planungspraktischen Anwendung das Potenzial der Schutzgebietsausweisungen in Bezug auf das Schutzgut Boden nicht ausgeschöpft. In einigen Schutzgebietstypen, wie Landschaftsschutzgebieten, können bei Bauvorhaben Ausnahmegenehmigungen erteilt oder Bereiche aus dem Schutzgebiet ausgegliedert werden (ders., S. 89). Hier sind demnach Anwendungsdefizite vorhanden. Andere Schutzgebietskategorien, v. a. Naturschutzgebiete, haben, auch wenn sie nicht zum Zweck des Bodenschutzes eingerichtet werden, eine hohe standortsteuernde Wirkung, da sie Bebauung ausschließen. Deren Flächenanteil ist jedoch mit 3,8\% der Bundesfläche (BfN o. J.) vergleichsweise gering und deren Steuerungsfunktion damit lokal sehr begrenzt.

Die Maßnahme zielt darauf ab, die Schutzgebietskulisse zu erweitern und die Steuerungsfunktion naturschutzpolitischer Instrumente in Bezug auf das Schutzgut Boden und Fläche zu erhöhen. In der Maßnahme werden raumplanerische Instrumente zum Schutz von Freiraum, Natur und Landschaft mit berücksichtigt. Damit ist die Maßnahme ein elementarer Bestandteil der Natur- und Umweltschutzstrategie. Durch den stärkeren Schutz natürlicher und naturnaher Vegetation kann sie jedoch auch einen Beitrag zur Klimaschutzstrategie leisten, da durch die Verlagerung der Siedlungsentwicklung auf landwirtschaftlich intensiver genutzte Flächen mit geringerem Kohlenstoffgehalt im Boden THG-Senken erhalten bleiben.

\section{Erhöhung des Schutzstatus}

Die standortsteuernde Wirkung von Schutzgebietsausweisungen (insbesondere Landschaftsschutzgebieten), Natura 2000-Gebieten und Großschutzgebieten (insbesondere Biosphärenreservaten) wird erhöht. Dies erfolgt durch stärkere Berücksichtigung des Schutzgutes Boden bei der Anwendung des fachplanerischen Instrumentariums. Daraus ergeben sich beispielsweise weniger Ausnahmegenehmigungen in Landschaftsschutzgebieten oder ein erheblich erhöhter Begründungsaufwand bei Ausnahmen in Natura 2000-Gebieten.

\section{Stärkung der Regionalplanung zum Schutz von Natur und Landschaft}

Die steuernde Wirkung der Regionalplanung im Bereich Natur und Landschaft wird gestärkt, beispielsweise durch die Stärkung der Funktionen regionaler Grünzüge. Dies geschieht u. a. durch eine Aufwertung von Vorbehaltsgebieten zu Vorranggebieten. 
3. Vergrößerung der Schutzgebietsflächen

Die bestehende Schutzgebietskulisse wird vergrößert, indem um Schutzgebiete mit hohem Schutzstatus, wie Naturschutzgebiete und Nationalparke, ein Abstandspuffer von $100 \mathrm{~m}$ gelegt wird, dessen Steuerungsfunktion über die von Landschaftsschutzgebieten hinaus geht.

\subsubsection{Energieerzeugung auf für Siedlungszwecke ungeeigneten nicht-agrarischen Flächen}

Neben der Flächeninanspruchnahme durch Siedlung und Verkehr stellt, bedingt durch die Energiewende, die Energiewirtschaft zunehmend Ansprüche an die begrenzte Ressource „Fläche“. Durch den Ausbau erneuerbarer Energien - insbesondere Windkraft, Photovoltaik und Biomasse - sowie dem damit verbundenen Ausbau der Übertragungsnetze, nehmen die Flächenkonkurrenzen mit anderen Landnutzern, v. a. der Landwirtschaft, zu. Während es in Deutschland 1990 nur 200 Windkraftanlagen gab, waren es im Jahr 2013 fast 24.000 (BfN und BBSR 2014). Biomasseanlagen haben zwischen 1990 und 2011 von 50 auf mehr als 14.000 zugenommen.

Die Anzahl der Netzanschlüsse von Photovoltaikanlagen stieg zwischen 1990 und 2011 von 100 auf über 1,2 Mio. (BfN und BBSR 2014). Die installierte Leistung der Photovoltaikanlagen lag 2011 bei über 24.000 MW. Schätzungsweise ein Fünftel davon lieferten Freiflächen-Photovoltaikanlagen, die eine entsprechende Flächeninanspruchnahme nach sich ziehen. Die Flächeninanspruchnahme durch Freiflächen-Photovoltaikanlagen beläuft sich eigenen Schätzungen zufolge auf mindestens 15.600 ha (2012). ${ }^{11}$ Laut des Erneuerbare-Energien-Gesetzes (EEG) 2014 waren im Außenbereich Freiflächenanlagen nur auf solchen Flächen förderfähig, die entweder in einem Abstand von $110 \mathrm{~m}$ längs von Autobahnen oder Schienenwegen liegen, bereits versiegelt sind oder auf Konversionsflächen aus wirtschaftlicher, verkehrlicher, wohnungsbaulicher oder militärischer Nutzung liegen ( $\$ 51$ Absatz 1 Nummer 3 c) aa) EEG 2014). Insgesamt wurde durch die EEG-Novelle der Ausbau von Freiflächen-Photovoltaikanlagen deutlich begrenzt. Seit 2016 dürfen zusätzlich jährlich maximal zehn Freiflächen-Photovoltaikanlagen mit einer Leistung von höchstens $10 \mathrm{MW}$ auf Ackerflächen in benachteiligten Gebieten errichtet werden. Daneben sollen Flächen der Bundesanstalt für Immobilienaufgaben (BImA) einbezogen werden. ${ }^{12}$ Der Ausbaupfad laut EEG zur Steigerung der installierten Leistung durch Anlagen zur Erzeugung von Strom aus solarer Strahlungs-

\footnotetext{
${ }^{11}$ Die Flächen wurden aus dem ATKIS Basis-DLM ermittelt und anhand der Anlagenstammdaten der Übertragungsnetzbetreiber $50 \mathrm{~Hz}$, Amprion, TenneT und TransnetBW unter Einbeziehung von Luftbildauswertungen ergänzt.


flaechenausschreibungsverordnung.pdf
} 
energie liegt bei 2500 MW (brutto) pro Jahr ( 3 Nummer 3 EEG 2014). Werden insgesamt 52.000 MW installierte Leistung in Deutschland erreicht, so wird die Förderung und damit der Ausbau gedeckelt (§ 31 Absatz 6 EEG 2014).

Das Ziel der Maßnahme ist es, den Nutzungsdruck auf die landwirtschaftlichen Flächen zu verringern, indem für den Ausbau erneuerbarer Energien vorrangig Flächen vorgesehen werden, die für die Landwirtschaft nicht rentabel nutzbar sind. Gleichzeitig soll es sich dabei um Flächen handeln, die für die Siedlungsnutzung nicht geeignet sind, um weitere Flächeninanspruchnahme durch Siedlungsnutzung zu vermeiden. Dabei handelt es sich in erster Linie um die in $\$ 51$ Absatz 1 Nummer 3 c) cc) EEG 2014 genannten wirtschaftlichen und militärischen Konversionsflächen. Durch die Nutzung von Deponien, Altlastenstandorten und ehemaligen militärischen Übungsgeländen lässt sich der Nachfragedruck insbesondere für Freiflächen-Photovoltaikanlagen auf landwirtschaftlichen Flächen reduzieren. Da die Flächeninanspruchnahme durch Windkraftanlagen gering ist und diese eine andere (landwirtschaftliche) Nutzung nicht flächenhaft ausschließen, werden in dieser Maßnahme (bzw. den nachfolgenden Analysen vgl. Kap. 4) nur Freiflächen-Photovoltaikanlagen berücksichtigt.

\subsubsection{Nutzung von Biomasse der Landschaftspflege}

Bei der Pflege von Grünflächen im Bereich der Siedlungs- und Verkehrsflächen fällt beträchtliche Biomasse an, die einer energetischen Nutzung zugeführt werden könnte. Solcher Grünschnitt fällt beispielsweise bei der Biotoppflege und der Pflege von Straßenund Schienenbegleitgrün an. In einer Studie aus dem Jahr 2004 wurden für Rheinland-Pfalz Biomassepotenziale u. a. aus der kommunalen Landschaftspflege ermittelt (Landtag Rheinland-Pfalz 2004). Demnach belaufen sich in Rheinland-Pfalz die Potenziale durch thermisch verwertbare Biomasse (Holzhackschnitzel) aus kommunalem Grünschnitt auf 166.000 bis $220.000 \mathrm{MWh}$, aus Straßenbegleitholz auf 22.000 bis 25.000 MWh und aus der Schienenpflege auf 3000 bis 3500 MWh. Die Potenziale für vergärbare Biomasse (Biogas) belaufen sich auf 6000 bis $7500 \mathrm{MWh}$ aus kommunalem Grünschnitt, auf 36.000 bis $40.000 \mathrm{MWh}$ aus der Straßenpflege und auf 4000 bis $4500 \mathrm{MWh}$ aus der Schienenpflege. Diese Zahlen zeigen exemplarisch das Potenzial, das zur Reduzierung der Nutzung fossiler Energieträger aus der Landnutzung im Siedlungsund Verkehrsbereich bereitgestellt werden kann. Bundesweite Auswertungen liegen nicht vor. Es gibt allerdings regionale Modellprojekte, die die Umsetzung solcher Maßnahmen erproben, u. a. in der Altmark im Rahmen des Bundeswettbewerbs Bioenergie-Regionen.

Neben der Nutzung vorhandener Biomassepotenziale bestehen auch Möglichkeiten zur Gewinnung neuer Biomassepotenziale im Siedlungsraum, beispielsweise durch die Anlage von Kurzumtriebsplantagen auf Friedhofserweiterungsflächen etc. Da diese Maßnahmen allerdings keine flächenhaften Auswirkungen auf die Landnutzung haben, werden sie hier nicht weiter betrachtet. 


\subsection{Handlungsfelder in der landwirtschaftlichen Landnutzung}

Sarah Baum, Martin Henseler und Peter Kreins

\section{Zusammenfassung}

Anhand intensiver Literaturrecherchen und Diskussionen mit Akteuren wurden landwirtschaftliche Maßnahmen zusammengetragen, die in erster Linie der Einsparung von THG-Emissionen dienen, zum Teil aber auch zur Erzeugung von Energie aus Biomasse sowie zum Natur- und Umweltschutz beitragen können.

Ein besonders hohes THG-Einsparpotenzial bei positiven Effekten für den Natur- und Umweltschutz haben Maßnahmen zur angepassten Nutzung organischer Böden, die mit einem langfristigen hohen Wasserstand vereinbar sind. Allerdings sind viele Moore nicht wiedervernässbar und die regionale Betroffenheit wäre groß. Maßnahmen zur Steigerung der Düngeeffizienz bspw. über präzisere Ausbringungsverfahren und verzögerte Nährstofffreisetzung reduzieren Emissionen aus der Düngung, ohne zu Ertragseinbußen zu führen. Die Substitution fossiler Energien durch Bioenergie dient zwar der THG-Reduzierung, ist aber oft mit negativen Auswirkungen auf andere Umweltaspekte und indirekte Landnutzungsänderungen verbunden. Da unter Grünland wesentlich mehr Kohlenstoff als unter Ackerland gespeichert wird, tragen Grünlanderhalt und Umwandlung von Acker in Grünland zur THG-Reduzierung bei.

\subsection{1 Überblick über mögliche landwirtschaftliche Maßnahmen}

Sich ändernde gesellschaftliche Ansprüche und technische Möglichkeiten bedingen einen ständigen Wandel der landwirtschaftlichen Landnutzung (Abschn. 2.2.3). Zu den wesentlichen aktuellen gesellschaftlichen Anforderungen gehören neben dem Klimaschutz im Sinne einer Einsparung von THG-Emissionen der Natur- und Umweltschutz sowie der Ausbau erneuerbarer Energien. Verschiedene Maßnahmen der landwirtschaftlichen Landnutzung tragen diesen Ansprüchen in unterschiedlichem Maße Rechnung und sind je nach Maßnahmen mit einem mehr oder minder starken „Trade off“ verbunden, d. h., die Umsetzungen einer Maßnahme erfüllt Ansprüche in einem Bereich zu Lasten anderer Ansprüche.

Vor diesem Hintergrund sind Strategien entwickelt worden, die diesen gesellschaftlichen Ansprüchen in der Landwirtschaft Rechnung tragen. Mittels einer intensiven Literaturrecherche sowie Interviews mit Akteuren der Landwirtschaft wurde eine Liste mit Maßnahmen erstellt, die zur THG-Einsparung beitragen können. Diese Liste wurde auf einem Akteurs-Workshop im November 2012 diskutiert. Nach dieser umfangreichen Vorauswahl wurden insgesamt 19 Maßnahmen ausgewählt, wobei sich die Auswahl auf Maßnahmen und Handlungsoptionen mit unmittelbarem Bezug zur Landnutzung konzentriert (Abschn. 5.3). 
Liste der modellierten Maßnahmen im Sektor Landwirtschaft, die in der Modellierung (explizit oder implizit) berücksichtigt wurden

- Nutzung organischer Böden

- Wiedervernässung

- Extensive Grünlandnutzung

- Nutzung mit Paludikulturen

- Änderung der Anbautechnologie

- Effizienzsteigerung des Mineraldüngereinsatzes sowie der N-Ausnutzung des Wirtschaftsdüngers

- Überregionale Transporte von organischem Dünger aus Über- in Zuschussregionen

- Änderung der Anbaustruktur

- Anbau von Biomasse zur energetischen Verwendung (unter Einbeziehung alternativer Energiepflanzen): annuelle Kulturen

- Anbau von Biomasse zur energetischen Verwendung (unter Einbeziehung alternativer Energiepflanzen): mehrjährige Kulturen

- Verminderung des Maisanbaus

- Ackerflächenumwandlung in Grünland

- Stärkerer Fokus auf landwirtschaftliche Nebenprodukte in der Biomassenutzung

- Anbau von Leguminosen

- Erhöhung der Anbaudiversität i. S. einer Erweiterung der Fruchtfolge

- Erhalt von Grünland

- Ökologische Anbauverfahren

- Änderung der Bewirtschaftungsintensität

- Steigerung der Bewirtschaftungsintensität

- Verringerung der Bewirtschaftungsintensität

- Produktion auf Stilllegungsflächen

- Erhöhung der Anzahl der Grünlandschnitte

- Grünlandextensivierung

Die Maßnahmen können in unterschiedlichem Maße zur Erreichung der Strategieziele beitragen, wobei die Umsetzungsweise sowie regionale Gegebenheiten eine entscheidende Rolle spielen. Im Folgenden werden die Maßnahmen und Handlungsoptionen näher beschrieben, die besonders zur Verringerung von THG-Emissionen aus der landwirtschaftlichen Landnutzung beitragen können. Ihre Auswirkungen auf die Ausdehnung der Bioenergieproduktion und den Natur- und Umweltschutz sowie mögliche Synergien zwischen den Strategien werden dargestellt. Steckbriefe zu allen Maßnahmen befinden sich im Anhang (Kap. 7). 


\subsubsection{Nutzung organischer Böden}

In organischen Böden haben sich über Jahrtausende sehr große Mengen an organisch gebundenem Kohlenstoff und Stickstoff auf vergleichsweise kleinen Flächen angelagert (vgl. Abschn. 2.3). Angesichts des hohen Kohlenstoffspeichers einerseits und des bedeutenden Emissionspotenzials bei ihrer Nutzung andererseits stellen organische Böden einen zentralen Ansatzpunkt für mögliche THG-Einsparungen im Bereich der landwirtschaftlichen Landnutzung dar. Aus diesem Grund werden die Auswirkungen unterschiedlicher Optionen der Nutzung organischer Böden quantitativ analysiert (vgl. Abschn. 4.5.2.1).

Da eine Nutzung organischer Böden zumeist mit einer Wasserstandsabsenkung einhergeht, sind über $90 \%$ der organischen Böden dräniert (Gensior et al. 2012). Um den durch die Wasserstandsabsenkung erfolgenden aeroben Abbau von organisch gebundenem Kohlenstoff zu unterbinden, sind mittlere Jahreswasserstände von $10 \mathrm{~cm}$ unter Flur anzustreben (Freibauer et al. 2009).

Die Intensität der Moornutzung, der Beitrag zur Qualität des Landschaftswasserhaushaltes und der Zustand des Bodens können regional und flächenspezifisch sehr unterschiedlich ausfallen, weshalb das Wiedervernässungspotenzial sowie der Beitrag zum Klima- sowie Natur- und Umweltschutz im Einzelfall abgeschätzt werden muss. So ist nicht in allen Fällen auf Grund von hydrologischen und klimatischen Faktoren eine Wiedervernässung überhaupt technisch möglich. Ferner kann der Schutz von bestehenden Gebäuden und Infrastruktureinrichtigungen vor einem steigenden Wassertand technisch nicht möglich sein oder unverhältnismäßig hohe Kosten verursachen (Bonn et al. 2015).

Die Zielsetzung der in diesem Abschnitt aufgeführten Maßnahmen ist die Verringerung der THG-Emissionen aus landwirtschaftlich genutzten organischen Böden durch eine adäquate Einstellung des Bodenwasserhaushaltes sowie eine damit verbundene Extensivierung der Nutzung. Vor diesem Hintergrund ist es selbstverständlich, dass der Schutz bestehender Moore allerhöchste Priorität haben sollte.

\subsubsection{Wiedervernässung}

Für eine Wiedervernässung ist der Rückbau der Entwässerungssysteme (Gräben, Schöpfwerke, Deiche, Dränagen) sowie eine Anhebung des Grundwasserstandes notwendig (Köbbing et al. 2012). Dränierte organische Böden sind starke $\mathrm{CO}_{2}$ - und $\mathrm{N}_{2} \mathrm{O}$ Emittenten; dagegen besteht bei Überstau die Gefahr hoher $\mathrm{CH}_{4}$-Emissionen (vgl. Abschn. 2.3). Ein Klimaschutzeffekt kann nur durch naturnahe Wasserstände erzielt werden (Drösler et al. 2011).

Durch die Renaturierung landwirtschaftlicher Flächen im Sinne einer Wiedervernässung wird die Mineralisierungsrate des Torfs und somit die Emission von THG verringert. Eine Wiedervernässung führt nicht sofort $\mathrm{zu}$ niedrigeren Emissionen, da sie in drei Phasen verläuft (Augustin und Joosten 2007): Zunächst kommt es infolge der Wiederflutung $\mathrm{zu}$ extrem hohen $\mathrm{CH}_{4}$-Emissionen in Verbindung mit geringer 
$\mathrm{CO}_{2}$-Aufnahme, was einen negativen Effekt für das Klima hat. In der zweiten Phase sind die $\mathrm{CH}_{4}$-Emissionen stark reduziert und die $\mathrm{CO}_{2}$-Aufnahme erreicht ihr Maximum, sodass sich ein leicht positiver Klimaeffekt einstellt. Schließlich, in Phase drei, wird sowohl die $\mathrm{CH}_{4}$-Freisetzung als auch die $\mathrm{CO}_{2}$-Aufnahme gering erwartet und von einem neutralen Klimaeffekt ausgegangen. Verlässliche Angaben zur Dauer der einzelnen Phasen in Verbindung mit den dafür ausschlaggebenden Variablen existieren bisher nicht (Augustin und Joosten 2007). Jedoch berechneten Augustin und Joosten (2007) die THG-Emissionen für drei Szenarien, die sich hinsichtlich der Dauer der Phasen unterschieden und zeigten, dass sogar unter der pessimistischen Annahme die Wiedervernässung des degradierten Moorbodens das Global Warming Potential (GWP) über 100 Jahre betrachtet um $80 \%$ gegenüber einem Szenario ohne Wiedervernässung verringerte. Huth et al. (2013) haben ähnlich hohe $\mathrm{CH}_{4}$-Emissionen in einem vor 15 Jahren wiedervernässten und einem ursprünglichen Niedermoor in Mecklenburg-Vorpommern festgestellt.

Das THG-Reduktionspotenzial wiedervernässter organischer Böden hängt davon $\mathrm{ab}$, wie intensiv zuvor dräniert wurde und ist bis in 60 bis $80 \mathrm{~cm}$ Tiefe umso höher, desto niedriger der abgesenkte Grundwasserstand ist (Drösler et al. 2011). Untersuchungen von Drösler et al. (2011) ergaben, dass das Klimaschutzpotenzial pro Hektar in landwirtschaftlich genutzten Hoch- und Niedermooren ähnlich ist und sich bei mäßiger und intensiver Dränage unter $-20 \mathrm{~cm}$ nicht unterscheidet; während Hochmoore bei nasseren Verhältnissen klimaneutral und bei Überstau geringe THG-Quellen sind, bleiben Niedermoore auch in wiedervernässtem Zustand geringe Quellen. Die wesentlichste Einflussgröße auf die Höhe der THG-Emissionen ist der mittlere Jahreswasserstand, aber auch Nutzung und Nutzungsintensität spielen eine wichtige Rolle, wobei die Nutzungsintensität die mit dem Erntegut entzogene Menge an Kohlenstoff darstellt. Ackernutzung und Intensivgrünland führten zu den höchsten Emissionen und haben ein THG-Einsparpotenzial von ca. 30 bis $35 \mathrm{t} \mathrm{CO}_{2} \mathrm{ha}^{-1} \mathrm{a}^{-1}$ (Drösler et al. 2011).

Durch eine vollständige Wiedervernässung landwirtschaftlich genutzter Hoch- und Niedermoore (1,3 Mio. ha) ließen sich in Deutschland theoretisch bis zu 35 Mio. $\mathrm{t}$ $\mathrm{CO}_{2}$ - ̈̈qu. $\mathrm{a}^{-1}$ bzw. $76 \%$ der aktuellen THG-Emissionen aus Mooren einsparen, wobei durch Niedermoorrenaturierung im Mittel $30 \mathrm{t} \mathrm{CO}_{2}$ - ̈̈qu. $\mathrm{ha}^{-1} \mathrm{a}^{-1}$ und bei Hochmoorrenaturierung $15 \mathrm{t} \mathrm{CO}_{2}$ - ̈̈qu. ha ${ }^{-1} \mathrm{a}^{-1}$ eingespart werden können (Freibauer et al. 2009). Unter der Annahme, dass $75 \%$ der landwirtschaftlich genutzten Moore bzw. 0,9 Mio. ha auf naturnahen Wasserstand renaturiert werden, gehen auch Osterburg et al. (2013) bei dauerhafter Wiedervernässung von 30 bis 35 Mio. t $\mathrm{CO}_{2}$ - ̈̈qu.a ${ }^{-1}$ Minderungspotenzial aus. Das Wiedervernässungspotenzial kann durch die fortgeschrittene Degradierung im Sinne einer Sackung und bereits stark fortgeschrittenen Torfzehrung (Mineralisation) oder durch veränderte Wasserhaushaltsbedingungen, die das Wasserangebot reduzieren, eingeschränkt sein, sodass längst nicht alle Flächen wiedervernässt werden können. Eine Einschätzung des Wiedervernässungspotenzials kann nur fallspezifisch erfolgen. Auch schränken vorhandene Siedlungs- und Verkehrsflächen oder anderweitige 
Landnutzungen das flächenhafte Potenzial für Wiedervernässungen ein (Röder und Grützmacher 2012).

Drösler et al. (2011) geben für Nutzungsaufgabe und Wiedervernässung THG-Minderungskosten zwischen 10 bis $135 € \mathrm{t}^{-1} \mathrm{CO}_{2}$ bei einer Maßnahmendauer von 20 Jahren an, wobei die Höhe der Kosten von der Nutzungsintensität der Fläche abhängt: bei extensiver oder keiner Nutzung entstehen vergleichsweise geringe Kosten, aber auch geringere THG-Einsparungen. Intensiv landwirtschaftlich genutzte Flächen hingegen haben ein sehr hohes THG-Einsparpotenzial, dem allerdings hohe Opportunitätskosten sowie höhere Renaturierungskosten entgegenstehen. Die THG-Minderungskosten zeigen auch aufgrund landwirtschaftlicher Flächenprämien regionsspezifische Unterschiede. Ohne Kosten für die Wiedervernässung gehen Osterburg et al. (2013) im Allgemeinen von unter $70 € \mathrm{t}^{-1} \mathrm{CO}_{2}$-Äqu. bei dauerhafter Wiedervernässung aus. Dennoch ist Klimaschutz durch Moorschutz volkswirtschaftlich sinnvoll, ,da die THG-Minderungskosten vergleichbar sind mit den Schadenskosten des Klimawandels und weitere Nutzen, z. B. für Biodiversität, Wasserschutz und Tourismus, entstehen“ (Drösler et al. 2011, S. i) (siehe auch Abschn. 4.5.4). Röder und Grützmacher (2012) nennen Vermeidungskosten von 20 bis $70 € \mathrm{t}^{-1} \mathrm{CO}_{2}$ - ̈̈qu. bzw. ca. $1600 €$ ha $^{-1}$, was 835 Mio. $€$ entspricht, wenn alle bisher bewirtschafteten Moorflächen Deutschlands aus der Nutzung genommen würden. Hierbei sind nur die Opportunitätskosten der landwirtschaftlichen Betriebe berücksichtig worden, während Kosten für die Wiedervernässung unberücksichtigt blieben. Bei der Betrachtung von Vermeidungskosten muss bedacht werden, dass Moore zahlreiche Ökosystemleistungen erbringen, die monetär schwer zu messen sind, die Bilanz aber entscheidend verändern würden (Köbbing et al. 2012) (siehe Abschn. 5.1).

Die Wiedervernässung organischer Böden ist eine langfristige Maßnahme. Betroffene Flächen werden im Prinzip aus der Nutzung genommen, was eine Kompensation der betroffenen Landeigentümer bzw. begleitende Maßnahmen für besonders betroffene Betriebe erfordert. Da sich eine Anhebung des Wasserstandes bei Niedermooren in der Regel auf angrenzende Bereiche auswirkt, kann Wiedervernässung nur großräumig erfolgen und muss an die lokalen Gegebenheiten angepasst sein, was eine langwierige Planung erfordert. Als weitere Hemmnisse der Wiedervernässung sind Einbußen beim landwirtschaftlichen Einkommen und die Verringerung des Produktionspotenzials $\mathrm{zu}$ nennen, sodass Anreize zur Umsetzung der Maßnahme unumgänglich sind. Eine Wiedervernässung ist oft nicht über Agrarumwelt- und Klimamaßnahmen (AUKM) realisierbar, da der Nutzer der Fläche der Eigentümer sein muss und angrenzende Bereiche auch betroffen wären. Eine mögliche Lösung wäre ein großflächiger Flächenankauf. Flächenhafte Renaturierungen können sich negativ auf die regionale Wertschöpfung auswirken. Alternative Nutzungen mit hohen Grundwasserständen sind grundsätzlich möglich (Arznei- und Kosmetikpflanzen, nachwachsende Rohstoffe für Fasern, Baumaterial und Torfersatz, Beeren etc.; vgl. Osterburg et al. 2013) und verschiedene Pilotprojekte sind hierzu in Erprobung, so z. B. Paludikulturen zur Gewinnung von Bioenergiepflanzen (Abschn. 4.5.2). Bei der Bewertung der Maßnahme muss auch die Produktionsverlagerung z. B. ins Ausland beachtet werden. 
Aufgrund des hohen THG-Einsparpotenzials je Flächeneinheit ist Wiedervernässung als sehr gut geeignete Maßnahme für den Klimaschutz $\mathrm{zu}$ bewerten. Organische Böden können innerhalb kurzer Zeit große Wassermengen aufnehmen, sodass Wiedervernässung auch dem Hochwasserschutz dient. Für die Strategie „Bioenergie“ ist Wiedervernässung als nachteilig zu bewerten, da im Falle einer Entwässerung mit intensivem Anbau mehr Biomasse zur Energiegewinnung produziert werden könnte. Neben der THG-Einsparung können Wiedervernässung und Extensivierung zur Reduktion diffuser Nährstoffeinträge in Gewässer führen, was die Gewässerqualität steigert und für die Trinkwassergewinnung vorteilhaft ist. Da Moore Lebens- und Durchzugsraum vieler seltener Arten sind, hat eine Renaturierung oftmals positive Effekte für die Biodiversität des Standorts, gerade im Hinblick auf hochspezialisierte Arten, die an nasse, nährstoffarme Standorte und einen niedrigen $\mathrm{pH}$-Wert angepasst sind. Wiedervernässung kann allerdings auch häufig Zielen des Artenschutzes entgegenstehen: Für FFH-Gebiete sind beispielsweise klare Artenschutz-Ziele definiert, die durch Wiedervernässung gefährdet werden können. So kann die Wiedervernässung extensiv genutzten Moorgrünlands u. a. eine Verdrängung bestimmter Orchideen- und Insektenarten bewirken (Bonn et al. 2015) (siehe dazu auch Abschn. 4.5.4).

\subsubsection{Nutzung als extensives Grünland}

Der mittlere Jahreswasserstand ist entscheidend für die Klimawirkung organischer Böden (s. o.). Eine Wasserstandsanhebung schließt eine intensive Nutzung aus, da Befahrbarkeit sowie Beweidung eingeschränkt werden. Eine Umwandlung von Acker zu Grünland oder eine Grünlandextensivierung kann erforderlich sein, sofern eine weitere Nutzung angestrebt wird.

Neben einer extensiven Schnittnutzung ist eine extensive Beweidung wiedervernässter Feuchtwiesen möglich. So können Rinder in Mutterkuhhaltung mit einem jährlichen mittleren Besatz unter 1,4 Rinder-GV ha ${ }^{-1}$, auf einigen Standorten mit bis zu 2 Rinder$\mathrm{GV} \mathrm{ha}^{-1}$, gehalten werden (Schuler et al. 2014). Verschiedene Rinderarten wie Heckrind und Galloway sowie Wasserbüffel sind bei geringen Viehbesatzdichten ebenfalls zur Beweidung geeignet.

$14 \%$ der Grünlandfläche Deutschlands befinden sich auf Moorböden (Drösler et al. 2011). Ergebnisse von Drösler et al. (2011) zeigen, dass eine Wasserstandsanhebung auf mindestens $-20 \mathrm{~cm}$ in Verbindung mit einer extensiven Grünlandnutzung die THGEmissionen auf etwa 50 bis $75 \%$ gegenüber intensiver Grünlandnutzung senkt. Im Vergleich zu Acker und Intensivgrünland können durch Extensivgrünland in Verbindung mit Wasserstandsanhebung 20 bis $26 \mathrm{t} \mathrm{CO}_{2}$ - ̈̈qu. ha/a eingespart werden. Ohne Veränderung des Wasserstandes führt die Umwandlung von Acker zu extensiv genutztem Grünland zu einer THG-Einsparung von ca. 5 t $\mathrm{CO}_{2}$ - ̈̈qu. ha/a (Flessa et al. 2012). Im Sinne des Klimaschutzes ist also eine Anhebung des mittleren Wasserstandes auf mindestens $-20 \mathrm{~cm}$ anzustreben (Osterburg et al. 2013).

Je nach Intensität der Wasserstandsanhebung variieren die Kosten in Abhängigkeit lokaler Gegebenheiten stark. Bei einer Extensivierung, die zu einer Einsparung von $5 \mathrm{t}$ 
$\mathrm{CO}_{2}$ - Äqu. ha ${ }^{-1}$ führt, belaufen sie sich auf über $100 € \mathrm{t}^{-1} \mathrm{CO}_{2}$ - ̈̈qu. ha ${ }^{-1}$ (Osterburg et al. 2013). Eine höhere Einsparung, die durch höhere Wasserstände erreicht werden kann, reduziert diesen Betrag.

Als Hemmnisse sind neben den zur Wiedervernässung genannten Punkten (Abschn. 3.2.2.2) insbesondere Opportunitätskosten zu nennen, die sich aus der verringerten Produktivität ergeben. Neben Ertrags- kommt es zu Qualitätseinbußen beim Futter (Schuler et al. 2014).

Die für den Klimaschutz gut geeignete Maßnahme der Grünlandextensivierung auf organischen Böden ist für die Strategie „Bioenergie“ aufgrund ertragreicherer Alternativen ungeeignet. Für den Natur- und Umweltschutz ergeben sich aus der extensiven Nutzung bei hohen Wasserständen positive Wirkungen auf das Bodengefüge, eine Verringerung von Einträgen in Böden und Gewässer sowie Vorteile für den Artenschutz (Schuler et al. 2014).

\subsubsection{Nutzung mit Paludikulturen}

Paludikultur benennt die standortgerechte Bewirtschaftung von nassen oder wiedervernässten Moorstandorten (lateinisch palus: Morast, Sumpf), durch die Moor-, Klima- und Gewässerschutz sowie landwirtschaftliche Wertschöpfung miteinander vereinbart werden (Wichmann und Wichtmann 2009; Wichtmann et al. 2010). Hierunter fallen neben der traditionellen Rörichtgewinnung für Dachreet-Verfahren wie die Erlenwertholz-Gewinnung und die Nutzung von Biomasse zur stofflichen Verwertung oder Energiegewinnung auf Nieder- und Anmoorstandorten sowie die Kultivierung von Torfmoosen als torffreie Alternative für den Gartenbau auf Hochmoorstandorten (Joosten et al. 2010). Ziel dieser Bewirtschaftungsformen ist der Erhalt oder die Neubildung von Torf, was durch natur- bzw. flurnahe Wasserstände erreicht werden kann. Seit über 20 Jahren wurde und wird in einer Reihe von Forschungsvorhaben zu Möglichkeiten der nachhaltigen, klimaneutralen Moornutzung geforscht (Wichtmann und Wichmann 2011a).

Die häufigsten Anbauarten auf wiedervernässten Niedermoorstandorten sind Rohrglanzgras (Phalaris arundinacea), Gewöhnliches Schilf (Phragmites australis), Rohrkolben (Typha spec.) und Großseggen (Carex spec.) (Wichtmann und Wichmann 2011a). Aufgrund der nassen Bodenbedingungen sind ein gefrorener Boden und/oder eine angepasste Landtechnik für die Ernte notwendig. Während für kleinere Flächen und Erntemengen bereits Verfahren für Mahd und Abtransport entwickelt wurden, sind für großflächige Beerntung mit hohem Biomasse-Volumen bei geringem Gewicht schlagkräftigere, schwerere Fahrzeuge notwendig. Hier kommen modifizierte Pistenraupen oder Fahrzeuge mit Ballonreifen zum Einsatz, die durch Mähwerk- oder Häckslervorsätze ergänzt wurden. Die Fahrzeuge üben nur einen geringen Druck auf den Boden aus und verhindern so Schäden an der Pflanzendecke und mechanische Bodenstörungen. Konventionelle Grünlandtechnik ist zwar am günstigsten, kann jedoch nur im Sommer bei ausreichend trockenem Boden eingesetzt werden (Wichmann und Wichtmann 2009). 
Im Gegensatz zur Wintermahd hat die Sommermahd den entscheidenden Nachteil, dass mit der grünen Biomasse Nährstoffe entzogen werden, was ohne Düngung keine langfristig stabilen Erträge sicherstellt (Wichtmann und Wichmann 2011a). Des Weiteren kann Schilf bei später Sommermahd (August bis September) zurückgedrängt werden, was neben einem Ertragsrückgang langfristig, frühestens nach etwa 10 bis 20 Jahren, zum Verschwinden der Bestände führen kann, sodass sich die Wintermahd im Zeitraum Dezember bis März empfiehlt (Wichmann und Wichtmann 2009). Während die SchilfBiomasse aus der Winterernte für die Verbrennung in Heizkraftwerken geeignet ist, kann das Erntegut aus der Sommermahd zur Vergärung in Biogasanlagen verwendet werden, wenn die Anlagentechnik entsprechend ausgerichtet ist (Köbbing et al. 2012). Neben der energetischen ist auch eine Nutzung als Tierfutter oder eine stoffliche Verwertung möglich (Wichtmann und Wichmann 2011a).

Die ansteigende Nachfrage nach Bioenergie erhöht den Druck auf Moorstandorte. Durch die bei Paludikulturen möglichen naturnahen Wasserstände ist eine klimaneutrale Bewirtschaftung möglich. Bei Nutzung der Biomasse zur Substitution fossiler Energien treten zusätzliche THG-Emissionsminderungen auf, ohne in Konkurrenz zur Nahrungsmittelproduktion zu stehen. Das THG-Einsparpotenzial sei an folgendem Beispiel verdeutlicht: Unter der konservativen Annahme eines Ertrags von 12 t TM ha/a und einem Heizwert von 17,5 $\mathrm{MJ} \mathrm{kg}^{-1} \mathrm{TM}$, kann die Schilfernte eines Hektars fossile Rohstoffe einer Kraft-Wärme-Kopplungsanlage ersetzen, die andernfalls 15 t $\mathrm{CO}_{2}$-Äqu. emittiert hätten. Bezieht man Emissionen, die bei den Verfahren der Schilfproduktion anfallen und $2 \mathrm{t} \mathrm{CO}_{2}$ - ̈̈qu. ausmachen sowie die THG-Einsparungen aus der Wiedervernässung von ca. $15 \mathrm{t} \mathrm{CO}_{2}$ - ̈̈qu. mit ein, so werden durch die energetische Nutzung des Schilfs aus Paludikulturen fast $30 \mathrm{t} \mathrm{CO}_{2}$ - ̈̈qu. ha ${ }^{-1}$ vermieden (Wichtmann und Wichmann 2011b). Couwenberg et al. (2007) zeigen, dass alle auf dränierten Moorstandorten gewonnenen Bioenergieträger höhere Emissionen aufweisen als fossile Energieträger. So beträgt die Emissionshöhe für Energiemais zur Biogasproduktion auf entwässerten, gepflügten Moorstandorten $880 \mathrm{t} \mathrm{CO}_{2} \mathrm{TJ}^{-1}$, wohingegen der direkte Verbrauch von Heizöl lediglich $73 \mathrm{t} \mathrm{CO}_{2} \mathrm{TJ}^{-1}$ emittiert; inklusive indirekter Emissionen (Transport, Umwandlung) sind es $81 \mathrm{t} \mathrm{CO}_{2} \mathrm{TJ}^{-1}$.

Bisherige Modellkalkulationen zeigten, dass die Nutzung der Biomasse zur Verfeuerung trotz Spezialtechnik mit anderen halmgutartigen Energieträgern (Stroh, Miscanthus) konkurrenzfähig ist, wenn keine Anpflanzung notwendig ist (Wichtmann et al. 2010; Wichmann und Wichtmann 2009).

Neben den zur Wiedervernässung genannten Hemmnissen (Abschn. 3.2.2.1) sehen Landwirte ein wirtschaftliches Risiko hinsichtlich Anlagekosten, Erntetechnik und Absatzmarkt sowie fehlende Erfahrungswerte (Wichmann und Wichtmann 2009). Die Wirtschaftlichkeit wird von zahlreichen Faktoren wie beispielsweise der Infrastruktur in Form von geeigneten Heizkraftwerken und Erntemaschinen, Transportkosten, Bodenbefahrbarkeit sowie Opportunitätskosten beeinflusst. Neben den Produktionskosten und erzielbaren Erlösen sind politische und rechtliche Rahmenbedingungen ausschlaggebend 
für die Wirtschaftlichkeit der Biomasseproduktion in Paludikulturen (Wichmann und Wichtmann 2009). Bisher wird Paludikultur überwiegend in Pilotprojekten betrieben.

Die für den Klimaschutz sehr gut geeignete Maßnahme ist für die Strategie „Bioenergie" aufgrund ertragreicherer Alternativen ungeeignet. Für den Natur- und Umweltschutz ergeben sich aus der extensiven Bewirtschaftung positive Wirkungen auf das Bodengefüge. Der Ausschluss des Dünge- und Pflanzenschutzmitteleinsatzes führt zur Verringerung von Einträgen in Böden und Gewässer. Als wiedervernässte Nieder- oder Anmoorstandorte bieten Paludikulturen Lebensräume für zahlreiche spezialisierte Arten, wobei durch geeignete Bewirtschaftungsmaßnahmen (z. B. Mahdtermin) bestimmte seltene Arten des Schilfgürtels gefördert werden können, wie beispielsweise Rohrdommel (Botaurus stellaris) und Seggenrohrsänger (Acrocephalus paludicola, Wichtmann und Wichmann 2011b). Allerdings sind auch negative Effekte mit Paludikulturen verbunden, da Etablierung und Ernte Störungen darstellen, die mit Bodenverdichtung, Nährstoffentzug (bei Sommermahd, s. o.), verändertem Licht-, Temperatur- und Wasserhaushalt zusammenhängen (Wichmann und Wichtmann 2009). Schilf- und nasse Rohrglanzgrasbestände sind durch eine geringe Pflanzendiversität, aber eine hohe Vielfalt an Tierarten charakterisiert (Wichmann und Wichtmann 2009). Ersetzen Paludikulturen eine abweichende vorherige Nutzung wie z. B. Grünland, sind die hierauf spezialisierten Arten negativ betroffen, sodass der Effekt auf die Biodiversität regional differenziert und abwägend betrachtet werden muss.

\subsubsection{Anpassung des Düngemanagements}

Um Ertrag und Qualität der landwirtschaftlichen Anbauprodukte zu gewährleisten, ist im Allgemeinen eine Nährstoffzufuhr in Form von mineralischen oder organischen Düngemitteln notwendig. Bei der Ausbringung von Stickstoffdüngern entsteht ein großer Teil der THG-Emissionen aus der Landwirtschaft, wobei es sich in erster Linie um Lachgas handelt (Abschn. 3.2.3.1). Dabei wird zwischen direkten und indirekten THG-Emissionen unterschieden. Direkte THG-Emissionen entstehen durch die Ausbringung von Düngern, während indirekte Emissionen über die atmosphärische Deposition reaktiven Stickstoffs sowie durch Auswaschungen erfolgen, wenn reaktive Stickstoffverbindungen wie Nitrat und Ammoniak über das Sickerwasser und Oberflächenabflüsse in die umliegende Landschaft gelangen und über Nitrifikations- und Denitrifikationsprozesse Lachgas entsteht (Abschn. 2.3). THG-Emissionen treten nicht nur bei und direkt nach der Düngung auf, sondern können im gesamten Jahresverlauf erfolgen. Zudem ist die Herstellung von Mineraldünger durch den Verbrauch fossiler Energien mit hohen THG-Emissionen verbunden.

Die Höhe dieser Emissionen ist neben der Menge der Düngerausbringung von den natürlichen Boden- und Klima-Gegebenheiten (Humus-, Stickstoffgehalt, pH-Wert, Bodenbelüftung bzw. Niederschlag, Temperatur und Frostperioden) und dem Verhältnis von N-Input zu N-Output (Flessa et al. 2012; Osterburg et al. 2013) sowie von der 
eingesetzten Ausbringungstechnik abhängig. Weiterhin kommt dem Ausbringungszeitpunkt eine große Bedeutung zu (Flessa et al. 2014). Für die Klimawirksamkeit muss der Düngewert in die Gesamtbetrachtung einbezogen werden, da dieser mit zunehmenden $\mathrm{NH}_{3}$-Emissionen aufgrund hoher $\mathrm{N}$-Verluste sinkt (Flessa et al. 2014). $\mathrm{NH}_{3}$-Emissionen begrenzen sich auf die Tage nach der Ausbringung, während $\mathrm{N}_{2} \mathrm{O}$-Emissionen zusätzlich im Jahresverlauf auftreten. Für die Bewertung von Ausbringungstechniken ist daher der gesamte Jahresverlauf der Emissionen zu betrachten, da THG-Einsparungen bei der Ausbringung ggf. im Jahresverlauf ausgeglichen werden könnten (Flessa et al. 2014).

Die Wirtschaftsdüngerlagerung und -ausbringung sind die wichtigsten Ursachen für Ammoniak- $\left(\mathrm{NH}_{3}\right)$-Emissionen in Deutschland, wobei das Einsparpotenzial bei der Ausbringung absolut gesehen größer ist als bei der Lagerung (Flessa et al. 2012). Pro Kilogramm eingespartem Rein-Stickstoff bei der Mineraldüngung kann von einer Emissionsminderung von $17,5 \mathrm{~kg} \mathrm{CO}_{2}-\ddot{A} q u . \mathrm{kg}^{-1} \mathrm{~N}$ ausgegangen werden. Diese Menge setzt sich aus 6,1 kg CO 2 - ̈̈qu. $\mathrm{kg}^{-1} \mathrm{~N}$ durch direkte $\mathrm{N}_{2} \mathrm{O}$-Emissionen, 3,9 kg CO 2 $\mathrm{kg}^{-1} \mathrm{~N}$ durch indirekte Emissionen sowie $7,5 \mathrm{~kg} \mathrm{CO}$ - $\mathrm{Äqu} . \mathrm{kg}^{-1} \mathrm{~N}$ durch die Bereitstellung des chemisch-synthetischen N-Düngers zusammen (Flessa et al. 2012). Für ein durch Feldversuche zur teilflächenspezifischen Düngung ermitteltes mittleres Einsparpotenzial von ca. $18 \mathrm{~kg} \mathrm{~N}$ ha $^{-1}$ ergeben sich somit $315 \mathrm{~kg} \mathrm{CO}_{2}$-Äqu. ha ${ }^{-1}$, die bei der Mineraldüngung vermeidbar sind (Flessa et al. 2012, Abschn. 3.2.3.1). Smith et al. (2008) gehen davon aus, dass über ein geeignetes Nährstoffmanagement auf Ackerflächen der kühl-feuchten Klimazonen Einsparungen von 0,62 $(0,02-1,42)$ t $\mathrm{CO}_{2}$ - $\mathrm{Äqu}$. ha/a möglich sind.

Die Zielsetzung der in diesem Abschnitt aufgeführten Maßnahmen ist die Verringerung der THG-Emissionen, die direkt oder indirekt mit der Düngung in Verbindung stehen. Die Höhe des Flächenertrags soll hierbei nicht reduziert werden, um Verlagerungseffekte zu vermeiden.

\subsubsection{Effizienzsteigerungen des Mineraldüngereinsatzes sowie der $\mathrm{N}$-Ausnutzung des Wirtschaftsdüngers}

In Deutschland werden jährlich etwa $100 \mathrm{~kg} \mathrm{~N}$ aus Mineral- sowie $75 \mathrm{~kg} \mathrm{~N}$ aus Wirtschaftsdünger pro Hektar ausgebracht (BMU und BMELV 2012); die Düngung setzt sich also zu $57 \%$ aus Mineral- und zu $43 \%$ aus Wirtschaftsdünger zusammen. Grundsätzlich ist eine bedarfsgerechte Düngung anzustreben, sodass Stickstoffüberschüsse vermieden werden (Osterburg et al. 2013). Durch den Abbau von Düngungssicherheits-Aufschlägen, die zum Ausgleich von nicht vorhersehbaren Ereignissen wie Auswaschungsverlusten, Ertragsschwankungen oder Verringerung der N-Verfügbarkeit bei Trockenheit ausgebracht werden, kann die N-Nutzungseffizienz (Ertrag pro Menge gedüngten Stickstoffs) erhöht werden. Im Mittel betrug der landwirtschaftliche Stickstoffüberschuss in den letzten Jahren $97 \mathrm{~kg} \mathrm{~N}$ ha/a und lag damit deutlich über dem Ziel von $80 \mathrm{~kg} \mathrm{~N} \mathrm{ha/a}$, das nach der Nachhaltigkeitsstrategie der Bundesregierung bereits 2010 erreicht werden sollte (Geupel und Frommer 2014). Ein Teil des als Dünger applizierten Stickstoffs wird nicht durch die Pflanze aufgenommen, sondern verlässt das Boden-Pflanze-System über 
Auswaschung (Nitrat) und gasförmige Emissionen $\left(\mathrm{N}_{2} \mathrm{O}, \mathrm{NO}, \mathrm{NH}_{3}, \mathrm{~N}_{2}\right)$. Um diesen Anteil möglichst gering zu halten, muss sich die N-Düngung am Ertragspotenzial orientieren, wobei (Teil-)Flächen mit vergleichsweise geringem Ertragspotenzial geringere N-Applikationsraten erfordern und vice versa.

Durch die Ausbringung von Mineraldüngern wurden im Jahr 2012 ca. 9,5 Mio.t $\mathrm{CO}_{2}$ - ̈̈qu. und durch die der Wirtschaftsdünger 4,7 Mio. t $\mathrm{CO}_{2}$ - ̈̈qu. emittiert (NIR 2014). Durch eine gesteigerte Stickstoff-Effizienz und Reduzierung von N-Überschüssen ließen sich insgesamt etwa 5,8 Mio. $\mathrm{CO}_{2}$ - ̈̈qu. $\mathrm{a}^{-1}$, also $40 \%$ der Emissionen aus der Düngerausbringung, einsparen, wobei die Kosten unter $50 € \mathrm{t}^{-} \mathrm{CO}_{2}$ - ̈̈qu. liegen (Osterburg et al. 2013). Hierfür gibt es mehrere Ansätze, von denen einige im Folgenden näher beschrieben werden.

\section{Präzisere Ausbringungsverfahren}

Präzisere Ausbringungsverfahren, bei denen der Luftkontakt möglichst gering gehalten wird, führen zu niedrigeren THG-Emissionen und höherem Nährstoffangebot im Boden, wodurch ca. 0,33 t CO 2 -Äqu. ha/a vermieden werden können (Schuler et al. 2014). Eine bodennahe, abdriftarme Ausbringung kann beispielsweise durch Schleppschlauch- und Injektionsverfahren, bei denen die Nährstoffe direkt in den Boden eingebracht werden, oder durch Exaktstreuer zur gleichmäßigen Verteilung der Nährstoffe, erfolgen. Die THG-Minderungskosten liegen je nach System zwischen ca. 50 bis $200 € \mathrm{t}^{-1} \mathrm{CO}_{2}$ - ̈̈qu. und steigen mit der Emissionseinsparungshöhe (Schuler et al. 2014).

Wenngleich hinsichtlich der absoluten Ammoniak-Minderungspotenziale unterschiedlicher Gülleausbringungsverfahren Unsicherheiten bestehen, so sind sich Experten bzgl. der Relationen der Verfahren zueinander weitestgehend einig (vgl. Flessa et al. 2014): Für unbewachsene Flächen ist die sofortige Einarbeitung, möglichst innerhalb der ersten Stunde nach der Ausbringung der Gülle- und Gärreste, das emissionsärmste Verfahren. So werden $\mathrm{NH}_{3}$-Emissionen größtenteils ( $>80 \%$ gegenüber oberflächlicher Breitverteilung ohne Einarbeitung) vermieden und bewirken einen hohen Düngewert des Wirtschaftsdüngers. Für bewachsene Flächen sind bodennahe, streifenförmige Ausbringungsverfahren wie Schleppschlauch (Acker: 22 bis $48 \%$ geringere Emissionen) oder Schleppschuh (Acker: 28 bis $78 \%$, Grünland: 40 bis $66 \%$ ) geeignet, wobei auf eine Mindestwuchshöhe des Aufwuchses zu achten ist. Injektionsverfahren in Verbindung mit dem Verschließen der Schlitze mit Boden sind bzgl. $\mathrm{NH}_{3}$-Emissionsreduktion auf bewachsenen Flächen am effektivsten (Acker: 82 bis $86 \%$, Grünland: 81 bis $89 \%$; Flessa et al. 2014).

Auch bei Injektionsverfahren werden die $\mathrm{NH}_{3}$-Emissionen erheblich reduziert. Allerdings ist eine erhöhte $\mathrm{N}_{2} \mathrm{O}$-Bildung in der Injektionszone aufgrund der engen Kopplung von Nitrifikation und Denitrifikation möglich, wenn der flüssige Wirtschaftsdünger nicht in den Boden eingemischt, sondern konzentriert in einem Kanal abgelegt wird. Die Bildung von $\mathrm{N}_{2} \mathrm{O}$ in der Injektionszone wird durch eine hohe Sauerstoffzehrung bei gleichzeitiger, eingeschränkter Sauerstoffzufuhr durch lokal entstehende anoxische Bedingungen, hohe Gehalte an mineralischem Stickstoff in den Injektions- 
zonen sowie die Verfügbarkeit leicht abbaubarer organischer Substanz in den Injektionszonen begünstigt. $\mathrm{Ob}$ ein Großteil der $\mathrm{N}_{2} \mathrm{O}$-Emissionen sowie der Emissionen aus dem erhöhten Energieaufwand bei der Gülleausbringung durch die vermiedenen $\mathrm{NH}_{3}$-Verluste und dem somit höheren Düngewert ausgeglichen werden können, kann bislang nicht mit einer gesicherten Gesamtbewertung festgestellt werden (Flessa et al. 2014). Des Weiteren muss noch erforscht werden, inwiefern Injektionstiefe, -abstände, offene und geschlossene Injektion die Höhe der $\mathrm{N}_{2} \mathrm{O}$-Emissionen beeinflussen, ebenso, ob der Einsatz von Nitrifikationshemmstoffen hierbei eine geeignete Option zur Reduktion sein könnte (Flessa et al. 2014).

Zur Effizienzsteigerung des Mineraldüngereinsatzes ist zudem Präzisionslandbau/ Precision Farming eine Option, bei dem die Arbeitsgeräte der Landmaschinen GPSund sensorbasiert gesteuert werden. Bei dieser teilflächenspezifischen Bewirtschaftung werden Unterschiede bezüglich des Bodens und der Ertragsfähigkeit innerhalb eines Feldes berücksichtigt, sodass die Nährstoffverteilung optimiert werden kann. Auf diese Weise lässt sich der Ertrag steigern und der Einsatz von Dünger sowie Pestiziden reduzieren. Präzisionslandbau ist also umso nützlicher, je heterogener ein Standort ist. Feldversuche zur teilflächenspezifischen Düngung deuten auf ein mittleres Einsparpotenzial von ca. $18 \mathrm{~kg} \mathrm{~N} \mathrm{ha}^{-1}$ (mit einhergehenden N-Produktivitätssteigerungen um $3,4 \mathrm{~kg} \mathrm{Nt}^{-1}$ Getreide) und damit $315 \mathrm{~kg} \mathrm{CO}_{2}$ - ̈̈qu. ha ${ }^{-1}$ hin (Flessa et al. 2012). Etwas niedriger ist die Annahme von Rösch et al. (2005), die davon ausgehen, dass der Mineraldüngereinsatz durch Präzisionslandbau auf heterogenen Feldern im Durchschnitt um ca. $7 \%$ bzw. $14 \mathrm{~kg} \mathrm{~N}^{-1}$ reduziert werden kann, wobei der Ertrag gleich bleibt oder um bis zu $6 \%$ ansteigt. Rösch et al. (2005) geben an, dass, gemessen am Ertrag, teilflächenspezifische Düngergaben die N-Verluste um 5 bis $10 \%$ vermindern können. Nach Osterburg et al. (2013) beträgt das Minderungspotenzial der v. a. für den Marktfruchtbau geeigneten teilflächenspezifischen Düngung $300 \mathrm{~kg} \mathrm{CO}_{2}$ - $\mathrm{Äqu}$. ha ${ }^{-1}$ mit Kosten von mindestens $50 € \mathrm{t}^{-1} \mathrm{CO}_{2}$ - ̈̈qu.

\section{Verzögerte Nährstofffreisetzung}

Nitrifikationsinhibitoren bewirken eine verzögerte Bildung von Nitrat in der Injektionszone, indem die mikrobielle Oxidation von $\mathrm{NH}_{3}$ bzw. $\mathrm{NH}_{4} \mathrm{zu}$ Nitrit gehemmt und so die Nitratbildung um mehrere Wochen verzögert wird. Hohe Nitratgehalte nach der Düngung werden vermieden und so die Gefahr der Nitratauswaschung und Denitrifikation verringert. Nitrifikationsinhibitoren werden hauptsächlich in flüssigen oder granulierten Mineraldüngern eingesetzt, können aber auch in Flüssigmistdüngern oder Biogasgülle eingesetzt werden. Auswertungen verschiedener, in Flessa et al. (2014) zitierter Studien zur $\mathrm{N}_{2} \mathrm{O}$-Emissionsminderung durch Einsatz von Nitrifikationsinhibitoren zeigten, dass ein Minderungspotenzial von im Mittel $40 \%$ realistisch ist, wobei dieses Potenzial sehr variabel ist und von Standortbedingungen, eingesetzter Düngerart und -form, Art des Nitrifikationshemmstoffs und gedüngter Kulturart abhängig ist. Osterburg et al. (2013) gehen beim Einsatz von Nitrifikationsinhibitoren unter der vereinfachten Annahme, dass bei $50 \%$ der Mineraldüngermenge $25 \%$ der 
$\mathrm{N}_{2} \mathrm{O}$-Emissionen eingespart werden, von einem theoretischen Reduktionspotenzial von 1,1 Mio. $\mathrm{t} \mathrm{CO}_{2}$ - ̈̈qu. für Deutschland bzw. von $0,2 \mathrm{t} \mathrm{CO}_{2}-\ddot{\mathrm{A} q u}$. ha ${ }^{-1}$ aus. Bei der Ermittlung des Reduktionspotenzials sind ganzjährige Messungen notwendig, da es zur zeitlichen Verschiebung der $\mathrm{N}_{2} \mathrm{O}$-Emissionen kommen kann. Wenn die Düngehäufigkeit durch eine längere Düngerwirkung reduziert werden kann, sinken mit der Anzahl der Überfahrten zusätzlich die Emissionen aus dem Dieselverbrauch. Weiter sind Emissionen aus der Herstellung der Hemmstoffe zu berücksichtigen. Wenngleich für Nitrifikationsinhibitoren ein hohes THG-Einsparpotenzial angenommen werden kann, besteht Forschungsbedarf hinsichtlich der Emissionseinsparung, der Wirkungen auf den Ertrag, des Einflusses der Standortparameter sowie der ökotoxikologischen Langzeitwirkungen der Hemmstoffe, wozu vor allem Langzeituntersuchungen notwendig sind (Flessa et al. 2014). In Sonderkulturen mit hohen Deckungsbeiträgen und verhältnismäßig geringen Kosten für die Düngung an den Gesamtkosten, wie z. B. dem Gemüseanbau, ist seitens der Landwirte eine höhere Motivation zum Einsatz von Nitrifikationsinhibitoren gegeben (Flessa et al. 2014). Die Kosten für THG-Einsparungen durch den Einsatz von Nitrifikationsinhibitoren liegen bei unter $50 € \mathrm{t}^{-1} \mathrm{CO}_{2}$ - ̈̈qu. (Osterburg et al. 2013).

Wie Nitrifikationsinhibitoren dienen kunststoffummantelte Langzeitdünger dazu, gedüngten Stickstoff möglichst ausreichend lange im Wurzelhorizont zu halten und damit eine lange Pflanzenverfügbarkeit zu gewährleisten. In Abhängigkeit von der Art der Umhüllung und den temperatur- und feuchteabhängigen Lösungsprozessen verzögern kunststoffummantelte Langzeitdünger auf mechanischem Weg die Freisetzung von Düngerstickstoff und minimieren auf diesem Wege die mikrobiell induzierten Transformationen des Stickstoffdüngers. Dies verringert Auswaschungs- und Ausgasungsverluste (Sommer 2005). Akiyama et al. (2010) werteten zahlreiche Studien aus und kamen zu dem Ergebnis, dass, in Abhängigkeit von Bodentyp und Landnutzung, die Reduktion der $\mathrm{N}_{2} \mathrm{O}$-Emission im Vergleich zur konventionellen Düngung im Schnitt bei $35 \%$ liegt, weisen aber auf die mangelnde Repräsentativität der zugrundeliegenden Untersuchungen hin.

Direkte und indirekte $\mathrm{N}_{2} \mathrm{O}$-Emissionen lassen sich auch durch Düngung im CULTAN-Verfahren (Controlled Uptake Long Term Ammonium Nutrition) reduzieren. CULTAN-Verfahren sind sowohl für Mineral- als auch Wirtschaftsdünger geeignet, wobei verschiedene Depot- und Ausbringetechniken je nach Kultur und Standort zum Einsatz kommen (vgl. Sommer 2005). Auch Gärreste aus Biogasanlagen können zu CULTAN-Düngern aufgearbeitet werden. Einmal pro Vegetationsperiode wird Ammonium hoch konzentriert punkt- oder linienförmig auf oder in den Boden leicht versetzt zur Saat- oder Pflanzreihe ausgebracht und über die Wurzeln der Pflanzen bedarfsangepasst aufgenommen: Ammonium ist phytotoxisch und kann deshalb nur über die Wurzelspitzen aufgenommen werden, wenn deren Kohlenhydratgehalt ausreichend hoch ist, und wird dann direkt in den Stoffwechsel der organischen N-Verbindungen aufgenommen. 
Durch Ansäuerung von Gülle und Gärresten mit Schwefel- oder Salpetersäure kann die Reduktion von $\mathrm{NH}_{3}$-Emissionen sowie indirekten $\mathrm{N}_{2} \mathrm{O}$-Emissionen signifikant erhöht werden, wodurch der Düngewert bzw. die N-Verfügbarkeit steigt. Hierfür existieren erst seit wenigen Jahren zugelassene Verfahren, die derzeit in deutschen Betrieben erprobt werden (Flessa et al. 2014).

\section{Zeitpunkt der Düngung}

Zur Vermeidung hoher $\mathrm{N}_{2} \mathrm{O}$-Emissionen im Winterhalbjahr sollten hohe Nitratgehalte im Herbst und Winter vermieden werden, wobei die Höhe der Emissionen stark vom Temperaturverlauf, der Anzahl der Frosttage sowie von Frost-Tau-Perioden abhängt. Winterzwischenfrüchte können Nitratauswaschungen und $\mathrm{N}_{2} \mathrm{O}$-Emissionen verringern und sind vor allem nach der Ernte von Kulturen, die während der Vegetationsperiode geerntet werden (z. B. Feldgemüse) und hohe Restnitratgehalte aufweisen, von Bedeutung. Wird die Zwischenfrucht im Frühjahr eingearbeitet, steht der Stickstoff der nachfolgenden Kultur zur Verfügung. Da es durch Zwischenfruchtanbau zu erhöhten $\mathrm{N}_{2} \mathrm{O}$-Emissionen kommen kann, ist die Verwendung als Biogassubstrat mit anschließender Ausbringung der Gärreste zur Düngereinsparung sowie Substitution fossiler Energieträger möglich (Flessa et al. 2014).

Die zeitliche Verteilung von N-Applikationsraten entscheidet über die N-Nutzungseffizienz. Während einmalige Düngergaben pro Kultur höhere Sicherheitsaufschläge erfordern, da die Bestandsentwicklung und die Auswaschungsgefahr nur abgeschätzt werden können, erlaubt die zeitlich bedarfsgerechte Düngung geringere Risikoaufschläge, ist aber mit häufigeren Überfahrten verbunden.

\section{Umsetzungshemmnisse und Beitrag der Maßnahmen zu den Strategiezielen}

Viele der hier aufgeführten Verfahren stehen noch in der Anfangsphase, sodass zuverlässige Angaben zu Kosten und Wirkung fehlen. Dies hat zur Folge, dass die Techniken zur N-Effizienzsteigerung bei der Beratung der Landwirte entweder keine Rolle spielen oder zu viele Informationslücken enthalten, sodass diese einer Umsetzung skeptisch gegenüber stehen. Des Weiteren ist die Umsetzung mit z. T. hohen Investitionen in Maschinen und Technik (GPS, Sensortechnik etc.) sowie in Dünger-Zusatzstoffe verbunden. Durch den Einsatz anderer als der bisher verwendeten Maschinen zur Düngerausbringung kann sich die Arbeitsbreite verringern, was den Zeitaufwand und somit die Kosten anhebt. Je nach Maßnahme und den Voraussetzungen vor Ort ergeben sich unterschiedliche Hemmnisse. Dies sei hier am Beispiel des Präzisionslandbaus dargestellt: Die hohen Kosten der Technologie und die Komplexität der Technik stellen das Haupthemmnis für die Landwirte dar (Reichardt und Jürgens 2009). Auch lässt sich der ökonomische Vorteil des Präzisionslandbaus schwer quantifizieren (ebd.) und hängt von der Betriebsgröße, den Eigenschaften der genutzten Flächen und der Fruchtart ab, sodass die Kosten auf etwa -30 bis $+20 €$ ha $^{-1}$ geschätzt werden (Rösch et al. 2005). Teilflächenspezifische N-Düngung wurde 2005 auf etwa 3,4 \% der Ackerflächen Deutschlands praktiziert (ebd.). Interviews auf landwirtschaftlichen Messen haben ergeben, dass 
die Zahl der Landwirte, die Präzisionslandbau einsetzen, zwischen 2001 und 2006 von 6,7 auf $11,0 \%$ gestiegen ist, wobei diese vor allem in Ostdeutschland wirtschaften, wo die Betriebs- und Schlaggrößen über dem Bundesdurchschnitt liegen (Reichardt und Jürgens 2009). Dennoch ist die Haltung der Landwirte meist ablehnend, was z. T. an der Unkenntnis ökonomischer und ökologischer Effekte liegt (Rösch et al. 2005).

Eine Verbesserung der N-Effizienz trägt direkt zur THG-Einsparung bei. Zudem werden Reduktionen indirekter Emissionen durch die verringerte Produktion von mineralischem Stickstoff erzielt. Die effektivere Ausbringung hat durch die Reduzierung diffuser Nährstoffeinträge (v. a. Nitrat) in Grund- und Oberflächengewässer außerdem positive Effekte für den Gewässerschutz, sodass hier zum Erreichen der Wasserschutzziele beigetragen werden kann. Des Weiteren können Stickstoffüberschüsse als eutrophierende und versauernde Luftschadstoffe in empfindliche Ökosysteme eingetragen werden und die Bodenversauerung beschleunigen (Flessa et al. 2014), sodass deren Vermeidung dem Biodiversitätsschutz dient.

\subsubsection{2 Überregionale Transporte von organischem Dünger aus Überschuss- in Zuschussregionen}

Die Spezialisierung in der Landwirtschaft führt in Regionen mit intensiver Nutztierhaltung zu einem Überangebot an Wirtschaftsdünger. Die N-Überschüsse aus der Viehhaltung stehen oft in einem Missverhältnis zu der zur Verfügung stehenden Ausbringungsfläche. Gleichzeitig muss in vieharmen Regionen Mineraldünger eingesetzt werden, bei dem zusätzlich THG-Emissionen während der Produktion entstehen. Der Transport der Nährstoffüberschüsse der Veredelungsregionen in Ackerbauregionen kann in beiden Regionen zur Emissionsreduzierung beitragen. Aus Klimaschutzsicht gilt es dabei zu beachten, dass die bei der überregionalen Verteilung des Wirtschaftsdüngers anfallenden Transport-Emissionen die durch den geringeren Mineraldüngereinsatz eingesparten THG-Emissionen nicht überschreiten.

Zum aktuellen Stand überregionaler Wirtschaftsdüngertransporte sei auf die Nährstoffberichte der Bundesländer Niedersachsen und Nordrhein-Westfalen hingewiesen. So wurden 2013/2014 in Niedersachsen 8400 abgebende Betriebe erfasst, die eine Nettomenge von ca. 17,7 Mio. t Wirtschaftsdünger meldeten, wovon 17.300 niedersächsische Betriebe 16,7 Mio. $t$ und Betriebe in anderen Bundesländern sowie im Ausland 0,97 Mio.t aufnahmen. Die überregional verbrachte Wirtschaftsdüngermenge betrug 2,76 Mio.t, wovon die Region Weser-Ems 2,28 Mio.t in andere Regionen Niedersachsens transportiert hat. Hierbei ist Hannover mit $34 \%$ die größte Aufnahmeregion des exportierten Wirtschaftsdüngers. Der Import spielt in Niedersachsen als viehstarkes Bundesland eine geringere Rolle: Aus anderen Bundesländern wurden 0,23 Mio. t Wirtschaftsdünger und Gärreste importiert; weitere 0,9 Mio. t kamen aus den Niederlanden. Für Niedersachsen wird auf Landesebene ein Stickstoffüberschuss von $67.000 \mathrm{t} \mathrm{N}$ bzw. $26 \mathrm{~kg} \mathrm{~N}^{-1}$ angegeben, was ,ein erhebliches Einsparpotenzial an Mineraldüngerstickstoff vermuten lässt“" (Landwirtschaftskammer Niedersachsen 2015). Nach Berechnungen von Kreins et al. (2007) verursacht die Einhaltung der laut Dünge- 
verordnung zulässigen regionalen $\mathrm{N}$-Bilanzüberschüsse in den viehintensiven Regionen Niedersachsens rund 100 bis 140 Mio. $€$ an Kosten, um die Wirtschaftsdüngerüberschüsse in Ackerbauregionen zu transportieren.

Nordrhein-Westfalen ist ebenfalls ein viehstarkes Land. Hier wurden für 20135800 Abgabe- und 13.300 Aufnahme-Betriebe gemeldet (2300 Betriebe waren beides). Insgesamt wurden 3,6 Mio. kg Stickstoff und 2,4 Mio. kg Phosphat aus Nordrhein-Westfalen exportiert. Aus den Niederlanden wurden 1,4 Mio. t Wirtschaftsdünger importiert (v. a. in die Regierungsbezirke Düsseldorf und Köln). Importe aus anderen Ländern und Bundesländern machten gut $10 \%$ der aus den Niederlanden stammenden Wirtschaftsdüngermenge aus und stammten zu $90 \%$ aus Niedersachsen. Auf Landesebene wird unter der Einbeziehung der Mineraldüngung ein N-Überschuss von $18 \mathrm{~kg} \mathrm{~N}^{-1}$ angegeben (Landwirtschaftskammer Nordrhein-Westfalen 2014).

Bronsema et al. (2012) modellierten unter Einhaltung der gesetzlichen Restriktionen zwei Szenarien für Wirtschaftsdüngertransporte (Flüssig- und Festdünger) innerhalb Niedersachsens und zeigten, dass aufgrund der hohen Transportkosten lediglich ein geringer Teil der Transporte im Vergleich zum Einsatz von Mineraldünger wirtschaftlich ist. Die Wirtschaftlichkeit ist hierbei vom Preisniveau des Energie- und Düngermarktes abhängig und könnte durch die Schaffung eines Mehrwertes, wie z. B. durch die Vergärung von Wirtschaftsdüngern in Biogasanlagen, verbessert werden (Bronsema et al. 2012). Durch die Erzeugung eines transportablen Guts, der nährstoffreichen Festphase, die z. B. durch Separierung gewonnen werden kann, lässt sich die Wirtschaftlichkeit überregionaler Transporte steigern. Ein Verfahren zur Gülleseparierung besteht seit den 1970er-Jahren, war aber aufgrund bisher fehlender Absatzmärkte ökonomisch nicht attraktiv (vgl. Kröger et al. 2014).

Die Reduzierung der Mineraldüngung durch überregionale Wirtschaftsdüngertransporte hat ein hohes Potenzial zur THG-Einsparung: Durch die Vermeidung von DüngeÜberschüssen lassen sich pro eingespartem Kilogramm Mineraldünger-Stickstoff inklusive der Emissionen aus der Bereitstellung 17,5 $\mathrm{kg} \mathrm{CO}_{2}$ - ̈̈qu. vermeiden (Flessa et al. 2012).

In Veredelungsregionen stellt der Düngerexport eine Alternative zur Flächenzupacht dar, wobei je nach Transportkosten- und Pachtpreishöhe die Wirtschaftlichkeit der einen oder anderen Option überwiegt. Hohe Transportkosten lassen den Einsatz von transportierten Wirtschaftsdüngern anstelle von Mineraldünger unattraktiv werden (vgl. Bronsema et al. 2012). Ein Vorteil von Mineral- gegenüber Wirtschaftsdüngern ist, dass bei ersteren die Nährstoffmenge gleichbleibend ist, sodass eine gezielte Düngung einfacher ist als mit Wirtschaftsdüngern. Außerdem ist Mineraldünger zeitlich flexibler einsetzbar.

Durch den überregionalen Handel mit organischem Dünger kann die N-Effizienz durch die Vermeidung von Überdüngung in Überschussregionen gesteigert und zugleich der Einsatz von Mineraldünger in Ackerbauregionen verringert werden. Dadurch können sich positive Effekte für den Gewässerschutz durch die Reduzierung diffuser Nährstoffeinträge (v. a. Nitrat) in Grund- und Oberflächengewässer ergeben, sodass zum Erreichen 
der Wasserschutzziele beigetragen werden kann. Allerdings ist darauf zu achten, dass durch die Ausbringung von in Ackerbauregionen transportierten Wirtschaftsdüngers die Erreichung von Wasserschutzzielen dieser Regionen nicht beeinträchtigen werden, was den Umfang der potenziell infrage kommenden Ackerbauregionen stark einschränkt. Des Weiteren können Stickstoffüberschüsse als eutrophierende und versauernde Luftschadstoffe in empfindliche Ökosysteme eingetragen werden und die Bodenversauerung beschleunigen (Flessa et al. 2014), sodass sich eine Reduzierung positiv auf die Biodiversität auswirken kann.

\subsubsection{Substitution fossiler Energie durch Bioenergie}

Hoher Energieverbrauch, Rückgang fossiler Brennstoffe und mit fossilen Brennstoffen in Verbindung stehende Umweltbeeinträchtigungen haben das Thema Bioenergie in den letzten Jahrzehnten stark vorangetrieben. Energiepflanzen können für die Erzeugung von Biogas, Strom, Wärme sowie Biokraftstoffen genutzt werden. Das ErneuerbareEnergien-Gesetz (EEG) hat zu einem starken Anstieg der Nutzung erneuerbarer Energien geführt, zu denen die Bioenergie zählt. So ist z. B. die Zahl der Biogasanlagen innerhalb von 13 Jahren um das 7,5-fache angestiegen: Während im Jahr 20001050 Biogasanlagen betrieben wurden, waren es 2013 bereits 7850 Anlagen (Fachverband Biogas e. V. 2014). Nachwachsende Rohstoffe machen fast die Hälfte der in Biogasanlagen eingesetzten Substratanteile aus (48\%); weitere Substrate sind Exkremente (Gülle, Mist: $44 \%$ ), industrielle und landwirtschaftliche Reststoffe (6\%) und Bioabfall (2\%; FNR 2014a).

Im Jahr 2014 wurden in Deutschland auf ca. 2,1 Mio. ha Energiepflanzen angebaut (FNR 2014a $\mathrm{a}^{13}$ ), also auf etwa 12,6\% der landwirtschaftlichen Fläche. Dieser Flächenanteil steht je nach Verfahren mehr oder weniger stark ausgeprägt in Konkurrenz zur Nahrungs- und Futtermittelproduktion um knappe Produktionsmittel (v. a. Fläche; Gömann und Kreins 2012). Durch die Ausdehnung der Bioenergie-Verfahren wird in der Regel das Nahrungsmittelangebot eingeschränkt, was bei sonst gleichbleibenden Bedingungen zu einem Anstieg der Agrarpreise führt. Für eine Bewertung der Gesamtbilanz der Bioenergie müssen Landnutzungsänderungen aufgrund von Produktionsverlagerungen mit einbezogen werden. Hierbei wird zwischen direkten und indirekten Landnutzungsänderungen unterschieden. Bei der direkten Landnutzungsänderung (dLUC) ändert sich die Nutzung einer bereits genutzten Fläche zur Nutzung für den Anbau von Energiepflanzen. Von indirekten Landnutzungsänderungen (iLUC) ist die Rede, wenn bisher nicht zur landwirtschaftlichen Produktion genutztes Land in

\footnotetext{
${ }^{13}$ Schätzwerte Anbau nachwachsender Rohstoffe in Deutschland für 2014: 2.074 .000 ha Energiepflanzen, davon 1.268.000 ha für Biogas, 629.000 ha Biodiesel/Pflanzenöl, 168.000 ha Bioethanol, 9000 ha Festbrennstoffe.
} 
Nutzung genommen wird, weil der Verwendungszweck oder die Produktionsmenge eines Rohstoffes sich ändert. Dies tritt ein, wenn der Anbau von Energiepflanzen den Anbau von Lebens- und Futtermitteln von Flächen verdrängt, die dann anderenorts angebaut werden, um die Nachfrage bedienen zu können sowie wenn durch die anderweitige Nutzung der Ernte die Lebensmittelpreise aufgrund einer Verknappung steigen und dies dazu führt, dass neue Flächen landwirtschaftlich erschlossen werden (Wicke et al. 2012). Diese mit der Bioenergiegewinnung in Verbindung stehenden indirekten Landnutzungsänderungen sind weder aus ökologischer noch politischer Sicht eine sinnvolle Strategie, da eingesparte THG-Emissionen aus fossilen Energieträgern überkompensiert werden können, wenn für neue Ackerflächen intakte Naturräume in anderen Ländern zerstört werden. Die Rodung von Regenwald für Ölpalmenplantagen ist hierfür ein gutes Beispiel (u. a. Schuler et al. 2014). Ravindranath et al. (2009) entwickelten globale Szenarien zur Biokraftstoffproduktion und kamen zu dem Ergebnis, dass die Einbeziehung von Lebenszyklusanalysen/Lifecycle-Assessment sowie THGEmissionen aus der Landnutzungsänderung wesentlich für die Bewertung des THGMitigationspotenzials von Biokraftstoffen sind. Werden ursprüngliche Ökosysteme für die Biokraftstoffproduktion umgewandelt, so ist die THG-Netto-Bilanz im Allgemeinen negativ (Ravindranath et al. 2009). Wenngleich Modellierungen von Landnutzungsänderungen ständig weiterentwickelt und verbessert werden, bestehen große Unsicherheiten bezüglich der Datengrundlagen und Annahmen, die die Erfassung der Komplexität von iLUC und deren Zuordnung schwierig gestalten (Wicke et al. 2012).

Wie bei iLUC spielt die vorherige Nutzung bei dLUC eine entscheidende Rolle, wie Fritsche und Wiegmann (2008), bezogen auf einen 20-Jahres-Zeitraum, zeigen: Beim Biomasseanbau auf vorherigem Grünland ergeben sich $\mathrm{CO}_{2}$-Emissionen, die für den Anbau von Pappel-KUP mit 1,255 t $\mathrm{CO}_{2}$ ha/a, für Rutenhirse mit 1,897 t CO ha/a und für Mais, Raps oder Weizen mit 2,630 t $\mathrm{CO}_{2}$ ha/a angegeben werden, während es beim Anbau auf Ackerstandorten aufgrund der Wurzelbildung bei Pappel-KUP zur Sequestrierung von 1,375 t $\mathrm{CO}_{2}$ ha/a und bei Rutenhirse von 0,733 t $\mathrm{CO}_{2}$ ha/a kommt. Die Kohlenstoffbilanz ist hingegen neutral, wenn ein Wechsel von einer Ackerkultur zu einer anderen erfolgt (Fritsche und Wiegmann 2008). Deller et al. (2011) zeigen, dass die Umstellung von Ackernutzung mit einjährigen Marktfrüchten zu mehrjährigen nachwachsenden Rohstoffen (Miscanthus, Weide, Pappeln) zu beachtlicher $\mathrm{C}_{\mathrm{org}^{-}}{ }^{-}$ Anreicherung im Boden führt.

Neben der untersuchten flächenbasierten Bioenergie-Produktion soll an dieser Stelle kurz auf die güllebasierte Biogaserzeugung eingegangen werden.

Flessa et al. (2012) verglichen Minderungspotenziale verschiedener bioenergetischer Nutzungspfade mit und ohne Einbeziehung von iLUC und zeigten, dass die höchsten THG-Einsparungen von $1237 \mathrm{~g} \mathrm{CO}_{2}$ - $\mathrm{Äqu} . \mathrm{kWh}^{-1}$ durch die güllebasierte Biogaserzeugung erzielt werden können. Unter Einbeziehung von iLUC kommt es beim Einsatz von Bioethanol aus Getreide sowie Biodiesel aus Raps sogar zu einer zusätzlichen Klimabelastung. Für die Verwendung von Holzhackschnitzeln aus Kurzumtriebsplantagen zur Strom- und Wärmeerzeugung sowie für die Biogaserzeugung 
aus Mais können trotz iLUC THG-Einsparungen entstehen, wobei die potenzielle Klimaschutzleistung der Bioenergieträger maßgeblich von der Art der Verwertungslinie beeinflusst wird (Flessa et al. 2012).

Die regionale Allokation des Anbaus von Bioenergie-Kulturen hängt u. a. von den Standortgegebenheiten und unternehmerischen Entscheidungen ab. Aufgrund der bei vielen Verfahren hohen Transportkosten richtet sich der Anbau nach der regionalen bzw. lokalen Nachfrage nach Biomasse, d. h. nach vorhandenen Anlagen (z. B. Biogas- oder Holzhackschnitzelanlagen), die die produzierte Biomasse zur Erzeugung von Biogas, Strom und/oder Wärme benötigen.

Durch die Substitution fossiler Energieträger ist ein Beitrag zum Klimaschutz möglich, wenn die Emissionen aus Düngeraufwendung sowie direkter und indirekter Landnutzungsänderung niedriger als die $\mathrm{CO}_{2}$-Einsparung aus fossilen Energien sind. Die Klimabilanz ist dabei stark abhängig von der Umsetzung des Verfahrens und fällt bei mehrjährigen Anbauarten im Allgemeinen positiver aus als bei einjährigen (WBGU 2009). Durch den Anbau von Bioenergiepflanzen können aber auch zahlreiche Umweltprobleme auftreten, die durch Intensivierung (gesteigerte Düngung, Pestizideinsatz), ausgedehnte Monokulturen oder Umwandlung von Grünland zu Acker (z. B. für Maisanbau) entstehen. Als gesellschaftliche Vorteile sind die Verringerung der nationalen Abhängigkeit von Energieimporten und die Schaffung neuer Wertschöpfungsketten in ländlichen Räumen zu nennen.

Die Zielsetzung der in diesem Abschnitt aufgeführten Maßnahmen ist die Verringerung von THG-Emissionen, indem fossile Energieträger durch nachwachsende Rohstoffe substituiert werden. Es werden ein- und mehrjährige Anbaukulturen sowie landwirtschaftliche Nebenprodukte betrachtet.

\subsubsection{Anbau einjähriger Biomassekulturen}

Einjährige Energiepflanzen zur Erzeugung erneuerbarer Energien sind Kulturen, die sonst für die Nahrungs- und Futtermittelproduktion genutzt werden. Diese Kulturen bieten den Vorteil, dass die herkömmlichen Anbaumethoden angewandt werden können, Erfahrungen mit der Anbaukultur bestehen und Märkte bereits vorhanden sind. Die höchsten Flächenanteile in Deutschland haben Silomais (Energiemais für Biogasproduktion: 0,9 Mio. ha in 2014; entspricht $35 \%$ der Maisanbaufläche; FNR 2014b) und Raps (Raps für Biodiesel/Pflanzenöle: 0,629 Mio. ha in 2014, FNR 2014a). Weitere, verbreitete Bioenergiekulturen sind Getreide und Zuckerrüben. Energiepflanzen können für die Erzeugung von Biogas, Strom, Wärme sowie Biokraftstoffen genutzt werden.

Das THG-Vermeidungspotenzial beim Anbau annueller Kulturen für Biogasanlagen ist mit 6 bis 10 t $\mathrm{CO}_{2}$-Äqu. ha/a (ohne dLUC/iLUC) wesentlich höher als bei Raps für Biodiesel (2,5 t $\mathrm{CO}_{2}$ - ̈̈qu. ha/a) und kohlehydratreichen Kulturen zur Produktion von Bioethanol (z. B. Zuckerrüben oder Weizen, ca. 2 t CO 2 -Äqu. ha/a; Schuler et al. 2014). Ebenso weisen die THG-Vermeidungskosten große Unterschiede auf und liegen bei Raps für Biodiesel mit ca. $175 € \mathrm{t}^{-1} \mathrm{CO}_{2}$ - ̈̈qu. unter den Kosten für annuelle Kulturen für Biogasanlagen (250 bis $400 € \mathrm{t}^{-1} \mathrm{CO}_{2}$ - ̈̈qu.; $500 \mathrm{~kW}$-Anlage, Referenzpreis kon- 
ventioneller Strom-Mix) und kohlehydratreiche Kulturen (ca. $459 €^{-1} \quad \mathrm{CO}_{2}$ - ̈̈qu.; Schuler et al. 2014).

Ein Vorteil gegenüber mehrjährigen Anbaukulturen ist der jährliche Ertrag und die Flexibilität, die Nutzung im Folgejahr ändern zu können. Da die einjährigen Bioenergiekulturen auch als Lebensmittel genutzt werden könnten, steht ihr Anbau in gesellschaftlicher Kritik. Vor allem der großflächige Anbau von Silomais für Biogasanlagen stößt in der Öffentlichkeit zunehmend auf Ablehnung. Alternative Bioenergie-Kulturen sind zwar vorhanden, schneiden allerdings in Bezug auf die Wirtschaftlichkeit in der Regel schlechter ab als Mais, auch wenn für ihren Anbau erprobte Verfahren zur technischen Umsetzung überwiegend vorhanden sind. Die Anreize zur Förderung ihres Anbaus sind derzeit unzureichend. Der massebezogene Substrateinsatz nachwachsender Rohstoffe in Biogasanlagen setzt sich derzeit zu $73 \%$ aus Maissilage, $12 \%$ Grassilage, $7 \%$ GetreideGanzpflanzensilage, $2 \%$ Getreidekorn, $2 \%$ Landschaftspflegematerial, $1 \%$ Zwischenfrüchte, $2 \%$ Zuckerrüben, $1 \%$ Sonstiges zusammen (Angaben für 2013; FNR 2014a).

Durch den Einsatz annueller Kulturen zur Bioenergiegewinnung können fossile Rohstoffe und damit in Verbindung stehende THG-Emissionen eingespart werden. Wichtig ist hierbei, dass keine negativen Effekte durch dLUC und iLUC entstehen, wodurch Emissionen lediglich verlagert und oftmals erhöht werden (Abschn. 3.2.4). Für den Natur- und Umweltschutz können sich Nachteile ergeben, wenn es zu Landnutzungsänderungen kommt oder die Anbauintensität auf bisher genutzten Flächen gesteigert wird. Eine Intensivierung tritt auf, da der energetische Biomasseanbau in Konkurrenz zur Nahrungs- und Futtermittelproduktion steht und so die Nachfrage steigt. Ein möglicher Vorteil ist eine Erhöhung der Anbaudiversität durch den Anbau alternativer Energiepflanzen.

\subsubsection{Anbau mehrjähriger Biomassekulturen}

Der Anbau mehrjähriger Kulturen steht in Deutschland noch am Anfang; Züchtung und Anbautechnik werden noch optimiert (FNR 2015). So beträgt der derzeitige Anbauumfang von Kurzumtriebsplantagen (KUP) ca. 5000 ha, wobei überwiegend Pappeln angebaut werden (FNR 2011). Für Miscanthus wird die Anbaufläche in Deutschland auf etwa 3000 ha geschätzt (Jahr 2011; Pude 2012), während es für die Durchwachsene Silphie 2011 ca. 150 ha waren (FNR 2012).

Das THG-Vermeidungspotenzial mehrjähriger Kulturen wie mehrjährigen Gräsern und Leguminosen für Biogasanlagen liegt zwischen 0,6 bis über $10\left[\mathrm{t}_{\mathrm{CO}_{2}-\text { Äqu. }} /(\right.$ ha*a) $]$; für KUP werden 5 bis 20 [ $\mathrm{t}_{\mathrm{CO}_{2}-\ddot{\mathrm{A} q u}} /$ (ha*a)] (Grundlage Hackschnitzel-BHKW; Schuler

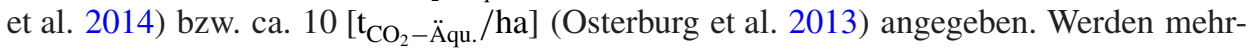
jährige Arten auf ehemaligem Ackerland angebaut, können sie zusätzlich Kohlenstoff im Boden sequestrieren: Pappeln und Weiden ca. $44 \mathrm{MgC}$ ha/a, Miscanthus 0,66 MgC ha/a. Beim Anbau der mehrjährigen Kulturen auf Grünland ergeben sich keine positiven oder sogar negative C-Bilanzen (Don et al. 2012). Für die THG-Vermeidungskosten für KUP geben Schuler et al. (2014), bezogen auf eine kombinierte Strom- und Wärmeerzeugung, 
$50 €\left[\mathrm{t}_{\mathrm{CO}_{2}-\ddot{\mathrm{Aqu}}}\right]$ an. Osterburg et al. (2013) decken diesen Wert mit ihrer Angabe von einer Spanne von -25 bis $75 €\left[\mathrm{t}_{\mathrm{CO}_{2}-\ddot{\mathrm{Aqu}}}\right]$. ab.

Ein Nachteil gegenüber einjährigen Anbaukulturen ist, dass nicht jedes Jahr eine Ernte stattfindet und somit kein jährlicher Ertrag erzielt werden kann. Auch entfällt die Flexibilität, die Nutzung im Folgejahr ändern zu können. Dies ist vor allem bei Pachtverträgen, die meist eine kürzere Laufzeit haben als die Länge der Flächenfestlegung beim Anbau mehrjähriger Kulturen, hinderlich. Weiter sind die Etablierungskosten z. B. bei KUP recht hoch und aufgrund unzureichender Förderanreize oftmals nicht attraktiv. Für viele mehrjährige Biomassekulturen fehlen bisher noch ausreichende Praxiserfahrungen (z. B. Durchwachsene Silphie) und geeignete Infrastrukturen. Darüber hinaus sind z. T. spezielle Maschinen notwendig, was Investitionen mit sich bringt. Ein Vorteil ist je nach Anbaukultur die bessere Verteilung von Arbeitsspitzen, da beispielsweise Miscanthus und KUP im Winter geerntet werden.

Durch den Einsatz mehrjähriger Kulturen zur Bioenergiegewinnung können fossile Rohstoffe und damit in Verbindung stehende THG-Emissionen eingespart werden. Wichtig ist hierbei, dass keine negativen Effekte durch dLUC und iLUC entstehen, wodurch Emissionen lediglich verlagert und oftmals erhöht werden (Abschn. 3.2.4). Für den Natur- und Umweltschutz können sich Nachteile ergeben, wenn es zu Landnutzungsänderungen kommt oder die Anbauintensität auf bisher genutzten Flächen gesteigert wird, da der Biomasseanbau in Konkurrenz zur Nahrungs- und Futtermittelproduktion steht. Positive Auswirkungen ergeben sich in Abhängigkeit von der Anbaukultur durch die längere Bodenruhe mehrjähriger Anbauverfahren, Erosionsschutz durch Wurzelbildung und dauernde Bodenbedeckung, den geringeren Energie-, Düngemittelund Pestizideinsatz sowie die geringe Bodenbearbeitungsintensität. Die Erhöhung der Anbaudiversität kann für bestimmte Arten Vorteile mit sich bringen, wobei die Standortwahl entscheidend ist. So ist die von Juli bis September blühende Durchwachsene Silphie eine ergiebige Nektar- und Pollenquelle für Honigbienen, hat allerdings für Wildbienen und andere Insektenarten keinen Vorteil sondern birgt sogar die Gefahr, dass sie auf Restarealen etabliert wird, die wichtige Rückzugsräume darstellen (Schmid-Egger und Witt 2014).

\subsubsection{Stärkerer Fokus auf landwirtschaftlichen Nebenprodukten in der Biomassennutzung}

Biogene Reststoffe fallen bei einer anderen Biomassenutzung an und werden im Gegensatz zu Energiepflanzen nicht für die Bioenergieerzeugung angebaut. Sie können zur Strom-, Wärme- und Biokraftstoffproduktion genutzt werden. $\mathrm{Zu}$ unterscheiden sind primäre Reststoffe, die bei der Ernte als erstem Schritt der Produktionskette anfallen (Erntereste), sekundäre Reststoffe aus weiteren Verarbeitungsschritten (Nahrungsmittel-, Tierproduktion) sowie nach einem (teilweisen) Endkonsum (Nahrung, Energie) anfallende tertiäre Reststoffe (Hoogwijk et al. 2013; Zeller et al. 2013). Beispiele sind Stroh, Rübenblätter, Wirtschaftsdünger, Bio- und Grünabfälle, Rapspresskuchen und 
Trester. Ihr Vorteil liegt darin, dass sie als Nebenprodukt ohnehin anfallen und nicht angebaut werden, sodass keine zusätzlichen Flächen in Anspruch genommen werden und keine Konkurrenzsituation zu anderen landwirtschaftlichen Nutzungen besteht.

Durch die thermische Nutzung landwirtschaftlicher Reststoffe können ca. 3 bis $13\left[\mathrm{t}_{\mathrm{CO}_{2}-\text { Äqu. }} /(\right.$ ha*a) $]$ vermieden werden, durch die Vergärung in Biogasanlagen ca. $3\left[\mathrm{t}_{\mathrm{CO}_{2}-\mathrm{A} q u} /(\mathrm{ha} * \mathrm{a})\right]$ und durch die Erzeugung von Biokraftstoffen aus Reststoffen bis zu $1,8\left[\mathrm{t}_{\mathrm{CO}_{2}-\ddot{A} q u .} /(\right.$ ha*a)] (Schuler et al. 2014). Die THG-Vermeidungskosten belaufen sich bei thermischer Nutzung auf etwa $45 €\left[\mathrm{t}_{\mathrm{CO}_{2}-\ddot{A} q u}\right]$. (Co-Verbrennung Stroh in Kohlekraftwerken) bis $130 €\left[\mathrm{t}_{\mathrm{CO}_{2}-\ddot{\mathrm{A} q u}}\right]$ (Getreideheizung: Ausschuss), bei Vergärung auf 60 bis $120 €\left[\mathrm{t}_{\mathrm{CO}_{2}-\ddot{\mathrm{A} q u}}\right.$ (95\% Masseanteile) und sind für den einfach mobilisierbaren Anteil mit „gering“ angegeben (Schuler et al. 2014).

Eine Studie des DBFZ (Zeller et al. 2013) zur nachhaltigen Strohnutzung aus dem Getreide- und Rapsanbau gibt für die Strohnutzung THG-Emissionen von ca. 8 bis $40\left[\mathrm{~g}_{\mathrm{CO}_{2}-\ddot{\mathrm{A} q u} \text {. }} / \mathrm{MJ}\right]$ an, wobei THG-Einsparungen gegenüber durchschnittlicher fossiler Referenz von 52 bis $126\left[\mathrm{~g}_{\mathrm{CO}_{2}-\text { Äqu. }} / \mathrm{MJ}\right]$ mit dem größten Potenzial für KWK-Konzepte möglich sind; jährlich könnten in Deutschland mit einer nachhaltigen Strohnutzung bis zu 13,5 Mio. [ $\mathrm{t}_{\left.\mathrm{CO}_{2}-\ddot{\mathrm{Aqu}}\right]}$ ] vermieden werden (Zeller et al. 2013).

Die FNR (2014a) schätzt das Potenzial für landwirtschaftliche Koppelprodukte und Reststoffe am Gesamtenergiebedarf Deutschlands (6950 PJ) für das Jahr 2050 auf $4 \%$ (entspr. $300 \mathrm{PJ}$ ), weitere $3 \%$ entfallen auf sonstige biogene Reststoffe (240 PJ). Insgesamt wird das Bioenergiepotenzial mit $23 \%$ am Gesamtenergiebedarf angenommen (FNR 2014a). Für die nachhaltige Strohnutzung aus dem Getreide- und Rapsanbau liegt das Potenzial, in Abhängigkeit der verwendeten Methode zur Humusbilanzierung, bei 8 bis 13 Mio. [ $\mathrm{t}_{\mathrm{FM}} / \mathrm{a}$ ], was 27 bis $43 \%$ der Getreidestrohmenge entspricht (Zeller et al. 2013). Stroh ist zur Strom-, Wärme- und Biokraftstoffproduktion verwendbar (Mühlenhoff 2013).

Das Aufkommen primärer, landwirtschaftlicher Reststoffe aus Stroh und Ernterückständen von Hackfrüchten beträgt etwa 60,5 Mio. [ $\mathrm{t}_{\mathrm{FM}} / \mathrm{a}$ ], wovon aktuell lediglich ein sehr geringer Teil des Getreidestrohs energetisch genutzt wird (Tab. 3.2; Zeller et al. 2013). Die sekundären und tertiären Reststoffe belaufen sich auf $155 \mathrm{Mio}$. [ $\left.\mathrm{t}_{\mathrm{FM}} / \mathrm{a}\right]$, wobei von der Rinder- und Schweinegülle 11,6\% als Biogassubstrat und vom Festmist $2,6 \%$ als Biogassubstrat verwendet werden. Bezogen auf die Trockenmasse machen Stroh und Ernterückstände $63 \%$ der Reststoffe aus, was einem sehr hohen theoretischen Potenzial entspricht (Zeller et al. 2013). Der Heizwert des Strohs ist vergleichsweise hoch. Übernimmt man die für eine nachhaltige Nutzung von Zeller et al. (2013) angegebenen 27 bis $43 \%$ der Getreidestrohmenge, liegt der Heizwert bei 114.400 bis 185.900 Mio. [MJ/a], und somit immer noch über dem für Mist und Gülle angegebenen Wert. Aus transporttechnischer Sicht hat Stroh den Vorteil eines mit $14 \%$ geringen Wassergehalts, der beim Rübenblatt bei $82 \%$ liegt (Zeller et al. 2013).

$\mathrm{Zu}$ den ökonomischen Hemmnissen zählen Investitions- und Transportkosten, die für Stroh höhere Gestehungskosten als bei konventioneller Bioenergie-Bereitstellung 
Tab.3.2 Aufkommen landwirtschaftlicher Reststoffe (Mittelwerte 1999-2007). (Quelle: Erweitert nach Zeller et al. (2013) und Heizwerte (z. T. FNR 2014a ${ }^{\mathrm{a}}$; FNR 2014c $\mathrm{c}^{\mathrm{b}}$ ))

\begin{tabular}{|c|c|c|c|c|}
\hline $\begin{array}{l}\text { Landwirtschaft- } \\
\text { licher Reststoff }\end{array}$ & $\begin{array}{l}\text { Menge } \\
\left(\text { Mio. }\left[\mathbf{t}_{\mathrm{FM}} / \mathrm{a}\right]\right)\end{array}$ & $\begin{array}{l}\text { Menge } \\
\left(\text { Mio. }\left[\mathbf{t}_{\mathrm{FM}} / \mathbf{a}\right]\right)\end{array}$ & $\begin{array}{l}\text { Heizwert ([MJ/ } \\
\left.\left.\mathbf{t}_{\mathrm{FM}}\right]\right)\end{array}$ & $\begin{array}{l}\text { Heizwert-Potenzial } \\
\text { (Mio. [MJ/a]) }\end{array}$ \\
\hline $\begin{array}{l}\text { Getreidestroh } \\
\text { (Winter-, Sommer- } \\
\text { weizen, Roggen, } \\
\text { Winter-, Sommer- } \\
\text { gerste, Triticale, } \\
\text { Hafer) }\end{array}$ & 30 & 25,8 & 14.300 & 429.000 \\
\hline Rapsstroh & 7,5 & 6,4 & $14.200^{\mathrm{a}}$ & 106.500 \\
\hline Körnermaisstroh & 4 & 3,1 & & \\
\hline $\begin{array}{l}\text { Ernterückstände } \\
\text { Hackfrüchte } \\
\text { (Kartoffel, Zucker- } \\
\text { rübe) }\end{array}$ & 19 & 3,1 & 1.357 (Rübenblatt) & 25.783 \\
\hline Rapspresskuchen & 3 & 2,7 & $30.600(\mathrm{w}<5 \%)^{\mathrm{b}}$ & 91.800 \\
\hline $\begin{array}{l}\text { Rinder- und } \\
\text { Schweinegülle }\end{array}$ & 122 & 12,2 & $538 / 653$ & $65.636 / 79.666$ \\
\hline $\begin{array}{l}\text { Festmist (Rinder-, } \\
\text { Schweine-, } \\
\text { Pferde-, Schafs-, } \\
\text { Geflügelkot inkl. } \\
\text { Hühnertrockenkot) }\end{array}$ & 30 & 7,5 & $\begin{array}{l}\text { 646/1.292/1.723 } \\
\text { (Rind, Schwein, } \\
\text { Huhn) }\end{array}$ & $19.380 / 38.760 / 51.690$ \\
\hline GESAMT & 215,5 & 60,8 & & \\
\hline
\end{tabular}

bewirken (Zeller et al. 2013). Darüber hinaus muss eine entsprechende Infrastruktur mit Abnehmern vorhanden sein.

Durch die bioenergetische Nutzung von landwirtschaftlichen Nebenprodukten können fossile Brennstoffe substituiert und THG-Emissionen eingespart werden. Bei vollständiger Ernte würden die Böden Humus und Nährstoffe verlieren, sodass zum Ertragserhalt gedüngt werden müsste. Dem kann mit einer Beschränkung der Entnahme von Stroh und Ernteresten entgegengewirkt werden, sodass trotz Nutzung ein Beitrag zum Bodenkohlenstoffhaushalt erfolgt. Des Weiteren kann der Düngemitteleinsatz durch eine andere Sortenwahl, von z. B. Sorten mit höherem Strohertrag, steigen. Durch den Einsatz von Gärresten aus Biogasanlagen kann Mineraldünger substituiert werden. Für die Bioenergieerzeugung ist die Maßnahme gut geeignet. Für den Natur- und Umweltschutz ist positiv zu beurteilen, dass kein zusätzlicher Flächenverbrauch anfällt. Allerdings darf keine vollständige Ernte erfolgen (s. o.). 


\subsubsection{Erhalt und Schaffung von Treibhausgassenken}

Böden speichern unterschiedliche Mengen an Kohlenstoff. Auch die Bodennutzung ist für die Speicherung ausschlaggebend. So wird unter Grünland wesentlich mehr Kohlenstoff sequestriert als unter Ackerland. Weiter ist die Speicherung z. B. auf alten, humosen sowie moorigen Grünland-Standorten höher als unter jungem Grünland auf Mineralböden (Schuler et al. 2014). Kommt es zum Grünlandumbruch, werden THGEmissionen freigesetzt. Diese Emissionen sind bei organischen Standorten wesentlich höher als bei Mineralböden. Der Erhalt von Grünland sowie die Ackerumwandlung in Grünland tragen zur THG-Einsparung bei (Abschn. 3.2.4.5).

Bei der Nutzung organischer Böden ist der Wasserstand entscheidend für die Höhe der THG-Emissionen. Die Vermeidung der Entwässerung organischer Böden sowie Wiedervernässung können zum Erhalt noch vorhandener THG-Senken wesentlich beitragen (Abschn. 3.2.2).

Hinsichtlich möglicher Humusanreicherungen durch pfluglose und konservierende Bodenbearbeitung gehen die Meinungen auseinander. Studien berichten sowohl von negativen (z. B. Six et al. (2002): $-0,2\left[\mathrm{t}_{\mathrm{CO}_{2}-\mathrm{Äqu}} /(\mathrm{ha} * \mathrm{a})\right]$; Oorts et al. (2007): $-0,17 \pm 0,07\left[\mathrm{t}_{\mathrm{CO}_{2}-\ddot{\mathrm{Aqu}}}\right.$ ( (ha*a)]) als auch von positiven THG-Bilanzen (z. B. Smith et al. (2008): 0,53 (-0,04-1,12) $\left[\mathrm{t}_{\mathrm{CO}_{2}-\ddot{\mathrm{Aqu}}} /(\right.$ ha*a)]; Naumann und Frelih-Larsen (2010): 0,25 bzw. 0,94 $\left[\mathrm{t}_{\mathrm{CO}_{2}-\ddot{\mathrm{A} q u}} /(\right.$ ha*a) $]$ für reduzierte bzw. keine Bodenbearbeitung), was auch an den unterschiedlichen Untersuchungsdesigns liegen dürfte. Einen umfassenden Überblick hierzu liefern Flessa et al. (2012). Die Analysen müssten größere Bodentiefen und neben Kohlenstoff auch Lachgas umfassen. Dies ist oft nicht gegeben. Studien, die den IPCC-Ansatz verwenden, bei dem lediglich die Kohlenstoffspeicherung im Oberboden bis in maximal $30 \mathrm{~cm}$ Bodentiefe untersucht wird, kommen zu positiven Bilanzen. Pfluglose und konservierende Bodenbearbeitung sowie Direktsaat führen nachweislich zur Humusanreicherung in den ersten $15 \mathrm{~cm}$ Bodentiefe. Wird die Bilanzierung jedoch bis in 40 bis $60 \mathrm{~cm}$ vorgenommen, treten zumeist keine Differenzen gegenüber konventioneller Bearbeitung auf, da in den Unterböden gepflügter Böden oft höhere Humusgehalte festgestellt werden; Grund hierfür ist die Einarbeitung des organischen Materials und die langsame Zersetzungsrate in tieferen Bodenschichten. Weiter können Lachgas-Emissionen die THG-Bilanz von Bodenbearbeitungssystemen in Abhängigkeit von Standortfaktoren (Klima, Bodenstruktur) entscheidend beeinflussen. Flessa et al. (2012) kommen zu dem Ergebnis, dass derzeit keine wissenschaftlich gesicherte Klimawirksamkeit bodenkonservierender Verfahren möglich ist und weisen auf mögliche Ertragsunsicherheiten hin. Gesichert ist lediglich die THG-Einsparung über den reduzierten Dieselverbrauch, der als relativ gering angegeben wird. Die Vorteile einer pfluglosen Bodenbearbeitung bestehen bzgl. der Bodeneigenschaften im Aufbau eines ungestörten Makroporensystems, Erosionsschutz, erhöhter Wasserinfiltration und Bodenfruchtbarkeit sowie geringeren Nährstoffausträgen. Durch die Humusanreicherung im Oberboden ist eine Steigerung der Biodiversität möglich (Tebrügge 2003). Allerdings ist eine dauerhafte und stark reduzierte Bodenbearbeitung durch Fruchtfolgeprobleme 
wie Pilz- und Insektenbefall begrenzt (Osterburg et al. 2009), was ggf. den Einsatz von Pflanzenschutzmitteln erhöht. Besonders aus Sicht des Ökolandbaus stellt die wendende Pflugbodenbearbeitung die effektivste mechanische Unkrautkontrolle dar; weiter erhöht die Bodenlockerung durch Pflugeinsatz die mikrobielle N-Mineralisation und damit den Ertrag (Bloch und Bachinger 2010).

Aufgrund unserer Literaturanalyse und dem vorrangigen Ziel, möglichst hohe THG-Einsparungen in der landwirtschaftlichen Bodennutzung $\mathrm{zu}$ erzielen, wurde die Maßnahme pfluglose bzw. konservierende Bodenbearbeitung ausgeschlossen. Im Folgenden wird Grünlandnutzung als sehr effiziente THG-Senke näher betrachtet.

\subsubsection{Grünlandnutzung}

In den letzten Jahren ist der Konkurrenzdruck auf Flächen aufgrund zunehmender Erzeugerpreise durch die steigende Nachfrage im Nahrungs- und Energiesektor sowie durch die Konkurrenz zwischen Energie- und Nahrungs- sowie Futtermittelproduktion gestiegen. Dies führte zu einer Intensivierung der Landwirtschaft, Reaktivierung von Stilllegungsflächen und der Umwandlung von Grünland in Ackerland (Gensior et al. 2012).

In Deutschland hat sich der Umfang der Grünlandfläche zwischen 1991 und 2012 um 0,7 Mio. ha (15\%) von 4,6 Mio. ha auf 3,9 Mio. ha reduziert, wohingegen die Ackerfläche um 0,3 Mio. ha auf 11,8 Mio. ha anstieg (Laggner et al. 2014). Bei der Umwandlung von Grünland zu Acker kommt es über die verstärkte Mineralisation organischer Bodensubstanz zur Freisetzung von überwiegend $\mathrm{CO}_{2}$ und in geringerem Ausmaß $\mathrm{N}_{2} \mathrm{O}$ (Osterburg et al. 2013). Hierbei erfolgt die $\mathrm{CO}_{2}$-Freisetzung zunächst sehr schnell; ein Gleichgewicht des Bodenkohlenstoffgehaltes stellt sich, in Abhängigkeit von Temperatur, Niederschlag, Bodentiefe und Lehmgehalt, nach ca. 17 Jahren ein. Der ursprüngliche Bodenkohlenstoffgehalt reduziert sich in diesem Zeitraum um etwa $36 \%$ (Poeplau et al. 2011). Anders herum wird bei einer Landnutzungsänderung von Acker zu Grünland Kohlenstoff im Boden sequestriert und somit eine THG-Senke geschaffen (NIR 2014). Durch die Anlage von Grünland wird eine dauerhafte Senke mit einer $\mathrm{CO}_{2}-$ Anreicherung um im Mittel etwa $128 \%$ etabliert, wobei auch nach 100 Jahren noch kein $\mathrm{CO}_{2}$-Gleichgewicht wiederhergestellt ist (Poeplau et al. 2011); die Neuanlage von Grünland kann also nicht zeitnah die durch einen Grünlandumbruch rasch verursachten $\mathrm{CO}_{2}{ }^{-}$ Emissionen kompensieren.

Die Kohlenstoffspeicherung im Boden ist unter Grünland wesentlich größer als unter Acker (s. o.). Bodenbürtige THG-Emissionen aus der Umwandlung von Grünland zu Acker beliefen sich nach der Nationalen THG-Berichterstattung im Jahr 2012

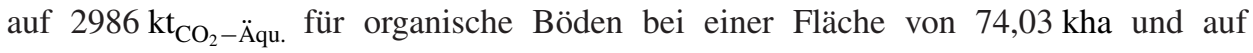

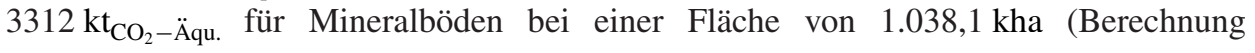
S. Baum nach NIR 2014); $47 \%$ der durch Umbruch von Grünland zu Acker verursachten THG-Emissionen entstammten also aus organischen Böden, die lediglich 
6,7 \% der umgebrochenen Flächen ausmachten. Dies zeigt, dass insbesondere auf organischen Standorten ein Grünlandumbruch vermieden werden sollte.

Bei einem zehnjährigen Betrachtungszeitraum lassen sich über die Ackerflächenumwandlung $\mathrm{zu}$ Grünland etwa $10\left[\mathrm{t}_{\mathrm{CO}_{2}-\ddot{\mathrm{A} q u}} /(\right.$ ha*a) $]$ einsparen. Unter Einbeziehung eines verminderten N-Austrags um $50[\mathrm{~kg} \mathrm{~N} /($ ha*a)]; belaufen sich die THG-Vermeidungskosten auf 35 bis $55 €\left[\mathrm{t}_{\mathrm{CO}_{2}-\ddot{A} q u}\right]$ (Osterburg et al. 2009). Entsprechend lassen sich durch den Erhalt von Grünland gut 10 [ $\mathrm{t}_{\mathrm{CO}_{2}-\text { Äqu. }} /($ ha*a) $]$ vermeiden. Direkte Kosten sind hiermit nicht verbunden, Opportunitätskosten sind jedoch möglich. Diese belaufen sich je nach Ausgangsbedingungen auf ca. 15 bis $60 €\left[\mathrm{t}_{\mathrm{CO}_{2}-\mathrm{A} q u}\right]$ (Osterburg et al. 2009).

Aus Sicht der Landwirte stehen der Ackerflächenumwandlung zu Grünland Opportunitätskosten entgegen, die sich aufgrund gestiegener Flächennutzungskonkurrenzen der letzten Jahre ebenfalls erhöht haben. Dies gilt ebenso für den Grünlanderhalt, wenn dieses auch für eine anderweitige Nutzung geeignet ist. Da allerdings in der Vergangenheit viel Grünland umgebrochen wurde, ist heute kaum noch umbruchsfähiges Grünland vorhanden. Die Umwandlung von Acker zu Grünland kann zu indirekten Verlagerungseffekten in Form von intensiverer Ackernutzung anderenorts führen, da die Produktivität auf dem Acker höher als auf dem Grünland ist.

Durch die Schaffung und den Erhalt von Grünland kann eine THG-Senke geschaffen bzw. erhalten werden, sodass diese Maßnahmen für die Strategie „Klimaschutz“ gut geeignet sind. Dies gilt insbesondere für organische Böden. Für die Strategie „Bioenergie" sind diese Maßnahmen ungeeignet, da durch eine Ackernutzung mehr Biomasse gewonnen werden könnte. Für den Natur- und Umweltschutz ist die Maßnahme „Grünlanderhalt" sehr gut geeignet, da so der Lebensraum für viele Tier- und Pflanzenarten erhalten bleibt, darunter zahlreiche gesetzlich geschützte. Weiter sind Erosionsschutz, positiver Einfluss auf Temperaturausgleich und Luftfeuchte sowie die Vermeidung von Nitratauswaschungen zu nennen (Schuler et al. 2014). Auch die ,Ackerflächenumwandlung zu Grünland“ ist gut geeignet, wenngleich eine Umwandlung nicht den Verlust der ökologischen Funktionen durch Grünlandumbruch kompensieren kann (Nitsch et al. 2010).

Im Folgenden wird unter der Maßnahme „Erhalt von Grünland“ der Trend der Anbaustrukturentwicklung vom Grünlandumbruch zur Schaffung von Ackerflächen unterbunden. Bei der Maßnahme „Ackerflächenumwandlung in Grünland“ werden Ackerflächen in Grünland umgewandelt, wobei Grünlandetablierung durch Selbstbegrünung oder Ansaat erfolgt.

\subsubsection{Notwendige Anpassungen an den Klimawandel}

Die Strategie „Klimaanpassung“ wurde im Sektor Landwirtschaft nicht untersucht, weil sich für die Landwirtschaft angesichts der kurz- bis mittelfristig erwarteten geringen 
Klimaänderungen und der hohen Anpassungsfähigkeit der Landwirtschaft in den nächsten 15 Jahren kein akuter Handlungsbedarf ergibt. Anpassungen an das Klima sind ein kontinuierlicher Prozess mit einer Vielzahl betriebsspezifischer Anpassungsmöglichkeiten wie der Nutzung neuer/anderer Kulturen oder Züchtungs-Weiterentwicklungen.

\subsection{Forstliche Handlungsoptionen für den Klimaschutz}

Peter Elsasser

\section{Zusammenfassung}

Mangels nennenswerter Emissionen zielen forstliche Klimaschutzoptionen auf die Steigerung von Sequestrierungs- und Substitutionspotenzialen in einem Gesamtsystem aus Wäldern, Holzprodukten und deren Alternativen. Zusätzlich verkomplizieren Kuppelproduktion, Wechselwirkungen zwischen Klimaschutz und -anpassung sowie die Langfristigkeit der forstlichen Produktion die Betrachtung. Geeignete Klimaschutzmaßnahmen müssen daher aufeinander abgestimmt sein. Dafür stehen Bausteine aus vier Bereichen zur Verfügung: (i) Erhöhung der Kohlenstoffvorräte im Wald (durch Baumartenwahl; Erhöhung der Bestandesdichte und/oder des Baumalters; Nutzungsverzichte; Speicheraufbau in Totholz, Streu und mineralischen und organischen Böden; Düngung, Züchtung, Gentechnik); (ii) Vergrößerung der Waldfläche; (iii) Ausweitung des Holzproduktespeichers und der Substitutionspotenziale; (iv) Vermeidung von Kohlenstoffverlusten (durch Kalamitäten, forstliche Bewirtschaftung oder Aktivitäten außerhalb des Forstsektors).

\subsection{1 Überblick über mögliche forstliche Maßnahmen}

Die Forstwirtschaft weist in Bezug auf mögliche Klimaschutzmaßnahmen einige Besonderheiten im Vergleich zu anderen Wirtschaftstätigkeiten einschließlich der Landwirtschaft auf:

1. Die forstliche Produktion verursacht in ihrem biologischen Kernbereich - nämlich dem Baumwachstum - keine Netto-Emissionen. Vielmehr entziehen die Bäume der Atmosphäre Kohlenstoff im Zuge ihres Wachstums. Sie fungieren damit als Kohlenstoffsenken. Emissionen im Rahmen der technischen Produktion (z. B. durch Forstmaschinen) fallen demgegenüber quantitativ nicht ins Gewicht. Unter den Bedingungen nachhaltiger Waldbewirtschaftung sind forstliche 
Klimaschutzmaßnahmen entsprechend auf Erhalt und Erweiterung dieser Kohlenstoffspeicher gerichtet, nicht auf Emissionsminderungen. ${ }^{14}$

2. Will man die Klimaschutzwirkung forstlicher Maßnahmen verstehen, so darf die Betrachtung nicht allein auf den Wald beschränkt bleiben. Der durch Bäume (und sonstige Waldpflanzen) gebundene Kohlenstoff wird nicht nur in deren ober- und unterirdischer Biomasse gespeichert, sondern auch in Streu, Boden und Totholz sowie in Holzprodukten einschließlich Papier. Darüber hinaus kann die Verwendung dieser Holzprodukte anstelle emissionsintensiverer Materialien einen positiven Klimaeffekt haben (stoffliche und energetische Substitution). Für die Klimawirksamkeit forstlicher Maßnahmen ist dieses Gesamtsystem relevant, nicht allein die Speicherung in der lebenden Biomasse. Die einzelnen Speicher beeinflussen sich dabei gegenseitig: Eine Vergrößerung des Holzproduktespeichers erfordert Holzentnahmen aus dem Wald. Umgekehrt schränkt eine Vergrößerung des Waldspeichers die Potenziale zur Speicherung in Holzprodukten und zur Substitution ein.

3. Die Rohholzerzeugung ergibt kein homogenes Produkt, sondern Sortimente aus unterschiedlichen Kuppelprodukten. So fallen beispielsweise unter dem verbreiteten Produktionsziel „Starkholz“ neben (starkem) sägefähigem Stammholz zwangsläufig auch schwächere Sortimente während der Durchforstungsphase sowie als Nebenprodukte der Endnutzung an. Holzverwendungs- und Substitutionspotenziale und die auf ihnen fußende Klimawirkung sind maßgeblich von der Sortenstruktur abhängig.

4. Aufgrund des langsamen Baumwachstums und der entsprechenden Langfristigkeit der forstlichen Produktion können Klimaschutz- und Anpassungsmaßnahmen im Wald kaum voneinander getrennt werden. Das Anpassungserfordernis hat dabei zwei Facetten. Die eine ist, die Wälder selbst so an veränderliche Klimabedingungen anzupassen, dass sie auch in Zukunft ihre Produktivität aufrechterhalten und dabei gleichzeitig möglichst hohe Leistungen für den Klimaschutz (und für andere Ansprüche an die Wälder) erbringen können. Die andere besteht darin, Schutzleistungen der Wälder möglichst sinnvoll für eine Anpassung der Gesellschaft an zukünftige Klimaunbillen zu nutzen (z. B. für den Hochwasserschutz).

5. Wegen der langen Produktionsdauern, und weil Bäume gleichzeitig Produktionsmittel der Forstwirtschaft wie auch deren Produkte sind, sind forstliche Klimaschutzmaßnahmen pfadabhängig und kaum unabhängig voneinander plan- und durchführbar - sie bedingen sich gegenseitig (und werden ihrerseits durch die jeweils gegebene Altersstruktur der Wälder bedingt). So ist etwa die Baumartenzusammensetzung eines Bestandes für viele Jahre nach der Bestandesbegründung kaum noch

\footnotetext{
${ }^{14}$ Neben Kohlenstoff kann Waldbewirtschaftung auch die Bilanz weiterer Treibhausgase beeinflussen (z. B. Lachgas-Emissionen nach Starkregen, Holznutzungen oder Waldkalkungen (vgl. Schulze et al. 2009). Da die primäre Ursache dieser Emissionen jedoch nicht in der Waldbewirtschaftung zu suchen ist, sondern vielmehr im Eintrag reaktiven Stickstoffs aus der Landwirtschaft und aus verschiedenartigen Verbrennungsprozessen, stehen sie hier nicht im Fokus.
} 
(bzw. nur unter erheblichen Kosten) veränderbar, und sie beeinflusst die späteren Maßnahmen (wie z. B. Durchforstungsregime und Endnutzungszeitpunkt).

Die Klimawirksamkeit einer einzelnen Maßnahme kann daher nicht isoliert bilanziert werden, und geeignete Klimaschutzmaßnahmen müssen aufeinander abgestimmt sein (siehe dazu auch Abschn. 7.3). Sie können entweder darauf abzielen, die in Wäldern und Holzprodukten zusammen gebundenen Kohlenstoffvorräte zu erhalten und zu vergrößern, oder sie müssen überproportionale Emissionseinsparungen in anderen Wirtschaftssektoren ermöglichen (oder beides). Grundsätzlich sind dafür ein dauerhafter Baumbestand, hohe Kohlenstoffvorräte im Wald bei geringen Verlustrisiken, eine möglichst effiziente und möglichst langfristige Verwendung des geernteten und verarbeiteten Holzes sowie die Generierung umfassender Substitutionseffekte dienlich (Hartje et al. 2015, S. 159). Diese Ansprüche konfligieren allerdings teilweise miteinander; sie lassen sich nicht unabhängig voneinander maximieren, sondern allenfalls in ihrer Gesamtheit optimieren. Diesbezügliche forstliche Handlungsmöglichkeiten bestehen in der Steuerung von Vorrats- und Zuwachshöhe, der Verringerung von Verlustrisiken sowie in der Bereitstellung von Holzsortimenten, welche sich für eine dauerhafte Verwendung bzw. hohe Substitutionseffekte eignen (ob die so bereitgestellten Sortimente anschließend tatsächlich in der beschriebenen Form genutzt werden, entzieht sich jedoch dem forstlichen Einfluss).

Im Folgenden werden unterschiedliche denkbare forstlichen Klimaschutzmaßnahmen im Einzelnen vorgestellt - darunter auch solche, die in diesem Buch später nicht mehr aufgegriffen werden. Das Zusammenspiel der Maßnahmen in abgestimmten Strategiekonzepten ist erst in Abschn. 4.6 Thema. Dort werden diejenigen Maßnahmen zu Strategien gebündelt, die sich für eine entsprechende großräumige Modellierung eignen.

\subsubsection{Erhöhung der Kohlenstoffvorräte im Wald}

\subsubsection{Baumartenwahl}

Da sich die in Deutschland anbaufähigen Baumarten je nach Standort hinsichtlich Wachstumshöhe und -verlauf, Kohlenstoffdichte sowie hinsichtlich ihrer Risikoanfälligkeit unterscheiden, beginnen forstliche Klimaschutzmaßnahmen bereits mit der Baumartenwahl. Tab. 3.3 zeigt beispielhaft für die meistverbreiteten Baumarten die zu unterschiedlichen Altern akkumulierten Vorräte an Kohlenstoff und die entsprechende durchschnittliche Erlebenswahrscheinlichkeit ${ }^{15}\left(\mathrm{P}_{\mathrm{E}}\right)$ auf Basis traditioneller Ertragstafeln (jeweils für die erste Ertragsklasse sowie mäßige Durchforstung).

Diese Beispiele illustrieren bereits im Alter 40 eklatante Unterschiede zwischen den Baumarten. Wüchsige Bedingungen vorausgesetzt, speichern die in Deutschland gängigen

\footnotetext{
${ }^{15}$ Definiert als Wahrscheinlichkeit, dass ein Baumbestand einen bestimmten Zeitraum überlebt.
} 


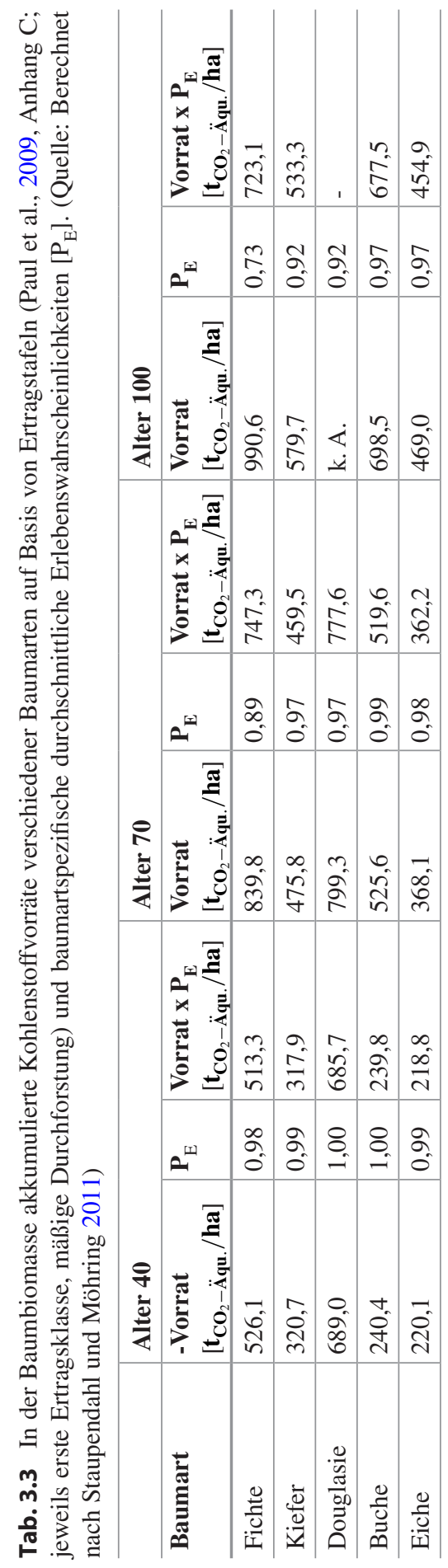


Nadelbaumbestände in ihrer Jugend deutlich höhere Kohlenstoffmassen in ihrer Biomasse als Laubbaumbestände. Dies zeigt sich insbesondere bei Fichten und Douglasien, deren Kohlenstoffbindung im Alter $40 \mathrm{mehr}$ als doppelt so hoch ist wie diejenige von Buchen oder Eichen. Die Berücksichtigung unterschiedlicher Erlebenswahrscheinlichkeiten verändert dieses Bild aufgrund der zunächst geringen Bestandsrisiken nur wenig. Im Alter 70 bzw. 100 machen sich im Wesentlichen zwei Veränderungen bemerkbar: Die Kohlenstoffakkumulation in Buchenbeständen wird (aufgrund der späten Zuwachskulmination der Buche) relativ zu den anderen Baumarten größer; umgekehrt macht sich bei Beständen aus Fichten (und möglicherweise auch aus Douglasien) ${ }^{16}$ deren stärkere Risikoanfälligkeit bemerkbar. Selbst unter Berücksichtigung dieses Risikos übertreffen die absoluten Kohlenstoffvorräte in bewirtschafteten Fichten- und Douglasienbeständen aber stets die Kohlenstoffvorräte gleichaltriger bewirtschafteter Buchenbestände; bereits im Alter 70 sind sie höher als selbst bei 100 -jährigen Buchen.

Bei ertragstafelähnlicher Bestandesentwicklung ist es daher zur Erhöhung des Kohlenstoffvorrats im Baumbestand zweckmäßig, für Bestandesbegründung oder Waldumbau schnellwüchsige und ertragsstarke Baumarten zu wählen. Dies sind in erster Linie Nadelbäume, namentlich Douglasien. Die Begründung von Laubbaumbeständen aus Eiche und/oder Buche ist im Vergleich dazu weniger geeignet, in absehbarer Zeit die C-Vorräte im Baumbestand zu erhöhen (dies schließt nicht aus, dass eine Beimischung von Laubbäumen in Nadelbaumkulturen zur Stabilisierung der Bestände und damit zu Zielen des Klimaschutzes und der Klimaanpassung beitragen kann, oder auch aus ganz anderen Gründen gewünscht wird, wie z. B. zugunsten von Naturschutzzielen).

Das Flächenpotenzial für die Maßnahme „Baumartenwahl“ ist auf die jeweilige Bestandesbegründungs- bzw. Waldumbaufläche begrenzt, und daher von der gegebenen Altersverteilung abhängig. Pro Jahr sind in den letzten 20 Jahren laut Bundeswaldinventur weniger als $1 \%$ der Waldfläche neu begründet worden (Thünen-Institut 2012). Da rasch- und starkwüchsige Baumarten frühere und höhere Holzerträge ermöglichen, erhöhen sie gleichzeitig das Potenzial zur Vergrößerung des Holzproduktespeichers und von Substitutionseffekten. Zudem sind die Opportunitätskosten für die Betriebe in diesem Fall grundsätzlich gering (bzw. nicht vorhanden) - mit Ausnahme der Fälle, wo ein Baumartenwechsel künstliche Bestandesbegründung anstelle von Naturverjüngung erfordern würde. Dies würfe zusätzliche Investitionskosten mit erheblichen Zinsbelastungen auf.

\subsubsection{Erhöhung der Bestandesdichte}

Über Bestandespflege, Durchforstungs- und schließlich das Endnutzungsregime lässt sich der während des Bestandeslebens akkumulierte Kohlenstoffvorrat (innerhalb der

\footnotetext{
${ }^{16} \mathrm{Da}$ Douglasien seit verhältnismäßig kurzer Zeit in Deutschland angebaut werden, gibt es zu dieser Baumart nur wenige empirische Risikoanalysen. Aktuelle Untersuchungen legen nahe, dass das Ausmaß von Sturmschäden an Douglasie das der Fichte erreichen kann (Albrecht et al. 2015).
} 
durch die natürliche Wachstumsdynamik gezogenen Grenzen) steuern. Es liegt nahe, dass insbesondere verlichtete Waldbestände Potenziale zur zusätzlichen Kohlenstoffakkumulation aufweisen. Ungeplante Verlichtungen können durch Kulturausfälle, Wildverbiss, Sturm- und Insektenkalamitäten etc. bedingt sein. Kann ihnen nicht hinreichend vorgebeugt werden, bestehen entsprechende Gegenmaßnahmen in Vorverjüngung, Ergänzungs- bzw. Ersatzpflanzungen sowie ggf. Zäunung, Reduktion der Wilddichte und/oder Schädlingsbekämpfung.

Auch bei regulärer Bewirtschaftung lässt sich die Bestandesdichte je nach örtlichen Gegebenheiten begrenzt steigern, etwa durch geringere Durchforstungshäufigkeit und -stärke oder geringere Endnutzungsmengen in Verbindung mit längeren Endnutzungszeiträumen, durch Einzelbaum-Ernte und durch Erhöhung der Zielstärke (ZS), gegebenenfalls durch den Aufbau mehrschichtiger Bestände. Allerdings sind die diesbezüglichen Wechselwirkungen komplex. Mit zunehmender Bestockungsdichte nimmt die Konkurrenz um Licht, Wasser und Nährstoffe zu, sodass jenseits eines standort- und baumartenspezifischen Optimums Zuwachseinbußen eintreten und die Bestandesstabilität sinkt. Diese Wechselwirkungen lassen sich kaum pauschal quantifizieren; hierzu ist der Einsatz von (Einzelbaum-)Wachstumssimulatoren notwendig.

Das Flächenpotenzial dieser Maßnahme ist zwar grundsätzlich nicht auf bestimmte Altersstufen beschränkt; messbar dürften die Einflüsse auf den Kohlenstoffvorrat aber primär in verlichteten Beständen sein, deren Wachstumspotenzial nicht vollständig ausgeschöpft ist, sowie in mittelalten Beständen (da in der Jugendphase die Ausgangsbasis für die Erhöhung der Bestandesdichte niedrig ist, in der Alters- und Erntephase dagegen die dann eingeleitete Verjüngung zwangsläufig zu einer Vorratsabsenkung führt).

\subsubsection{Erhöhung der Umtriebszeiten bzw. Zielstärken}

Es scheint offensichtlich, dass eine spätere Ernte der Bäume die Kohlenstoffvorräte im Wald vergrößert, solange die Bäume noch einen Netto-Massenzuwachs aufweisen. Allerdings schränkt dies den Zufluss zum Holzproduktespeicher ein; zudem verändert sich durch das höhere Alter und die damit verbundenen größeren Durchmesser der schließlich geernteten Bäume die Sortimentsstruktur, und die Untergangsrisiken steigen.

Umtriebszeiten (Uz) und Zielstärken (ZS) sind aber zunächst rein planerische Größen. Ihre Erhöhung wirkt sich nur dort unmittelbar auf Kohlenstoffvorräte aus, wo tatsächlich anstehende Endnutzungen hinausgezögert werden. Das diesbezügliche Flächenpotenzial ist daher auf Altbestände beschränkt, in denen solche Erntemaßnahmen innerhalb überschaubarer Zeiträume geplant sind. Auch in zeitlicher Hinsicht können Produktionszeiten nur so lange ausgedehnt werden, wie alters- oder vorschadensbedingte Abbauprozesse noch nicht den laufenden Zuwachs überwiegen, da sonst die Kohlenstoffvorräte insgesamt abnehmen. Wie lang dies dauert, ist stark von der jeweiligen Baumart abhängig. Typische Klimaxbaumarten wie Rotbuche und Weißtanne sind im hohen Alter noch zu plastischen Zuwachsreaktionen in der Lage, wenn auch über deren Ausmaß keine völlige Einigkeit besteht (vgl. z. B. NWFVA 2008). Opportunitätskosten entstehen bei aufgeschobener Ernte dann, wenn die dadurch entstehenden Zinsbelastungen sowie 
mögliche Schäden durch die genannten Abbauprozesse nicht durch den zusätzlichen Wertzuwachs der Bestände kompensiert werden.

Verlängerte Produktionszeiten haben in Bezug auf Klimaschutz- und -anpassungsziele zwei ungünstige Nebenwirkungen: Einerseits steigt dadurch generell das Untergangsrisiko, weil die Bäume sämtlichen Bestandsrisiken länger ausgesetzt sind. Zum anderen nimmt der durchschnittliche Gesamtzuwachs von Waldbeständen nach einer Kulminationsphase kontinuierlich ab. Eine Verlängerung über diesen Zeitpunkt hinaus beeinträchtigt also den insgesamt möglichen Zuwachs, und damit die erzielbare Senkenwirkung des Waldes (unter der Voraussetzung, dass die entsprechenden Flächen wiederbestockt werden). Da die in Deutschland üblichen Umtriebszeiten tendenziell hoch sind und oft oberhalb der baumartenspezifischen Wachstumskulmination liegen, führen längere Umtriebszeiten grundsätzlich zwar zu höheren Vorräten, aber auch zu geringerem Gesamtzuwachs (Dieter und Elsasser 2004). Empirisch deutet sich an, dass dieser Effekt für Europa insgesamt bereits die Senkenfunktion der Wälder beeinträchtigen könnte (Nabuurs et al. 2013). Ferner können verlängerte Umtriebszeiten gegebenenfalls einen geplanten Baumartenwechsel verzögern.

\subsubsection{Dauerhafter Verzicht auf die Nutzung von Einzelbäumen oder Waldbeständen}

Die vorstehend erwähnten Ernteaufschübe stellen einen temporären Nutzungsverzicht dar. Für den dauerhaften Verzicht auf die Nutzung von Einzelbäumen oder ganzen Waldbeständen gelten viele der oben angesprochenen Aspekte daher verstärkt. Ob die Maßnahme sich überhaupt in absehbarer Zeit oder erst in ferner Zukunft spürbar auf die Kohlenstoffspeicherung auswirkt, ist entscheidend von Alter und Zustand der Ausgangsbestände abhängig: In jungen und mittelalten Beständen entfallen durch eine Stilllegung im Wesentlichen Pflege- und Durchforstungs- (sowie möglicherweise Forstschutz-) Maßnahmen. Dies führt zur Erhöhung der Bestandesdichte, soweit dieser Effekt nicht durch konkurrenzbedingte Mortalität oder Kalamitäten konterkariert wird. Erst bei erntereifen Altbeständen wirkt sich eine Stilllegung deutlich auf die Kohlenstoffvorräte im Wald aus, da dann auf die Endnutzung verzichtet wird. Dieser Speichereffekt hält an, bis natürliche Abbauprozesse die Zuwachsprozesse übersteigen oder der Bestand aufgrund von Überalterung oder Kalamitäten zusammenbricht (und dabei den bislang gespeicherten Kohlenstoff sukzessiv wieder freisetzt).

Im Unterschied zu temporären Nutzungsverzichten werden der Zufluss zum Holzproduktespeicher sowie Substitutionspotenziale durch dauerhafte Nutzungsverzichte nicht nur aufgeschoben, sondern aufgehoben. Auch in Hinblick auf betriebliche Opportunitätskosten bestehen erhebliche Zielkonflikte, da die Betriebe auf den Ertrag ihrer zuvor getätigten Investitionen komplett verzichten müssen.

\subsubsection{Speicheraufbau in Totholz, Streuschicht und Boden}

Auch die abgestorbene Biomasse im Wald stellt einen wichtigen Kohlenstoffspeicher dar. Laut Klimaberichterstattung geht die jährliche Sequestrierungsleistung des 
deutschen Waldes zu sieben Achteln auf den Zuwachs an lebender Phytomasse zurück, das restliche Achtel auf die Akkumulation in Totholz, Streuschicht und Böden (NIR 2014, S. 526). Totholz entsteht entweder durch das Belassen von Ernterückständen im Wald (einschließlich der im Boden verbleibenden Stubben), durch das Absterben oder Abbrechen von Baumteilen und -ästen oder durch das Absterben ganzer Bäume, die nicht verwertet werden - also letztlich durch dauerhaften Nutzungsverzicht (s. o.). Das abgestorbene Holz wie auch die Streu werden langsam biologisch abgebaut. Der darin gebundene Kohlenstoff entweicht dabei z. T. in die Atmosphäre, ein anderer Teil wird längerfristig im Boden gebunden.

Die Klimaschutzwirkungen dieses Speicheraufbaus stehen zu denjenigen einer anderweitigen Holzverwendung in ähnlicher Wechselwirkung wie unter „Nutzungsverzichte“ beschrieben: Im Wald verbleibende Biomasse ist zwar eine Nährstoffquelle für spätere Waldgenerationen, steht aber nicht mehr für die stoffliche oder energetische Verwendung zur Verfügung. Betriebliche Opportunitätskosten sind von der Qualität der im Wald belassenen Sortimente und den zugehörigen Preis- und Kostenrelationen abhängig. Eine gezielte „Produktion“ stehenden Totholzes (die aus Naturschutzsicht ggf. wünschenswert sein könnte) wäre mit sehr hohen Opportunitätskosten verbunden, wenn das Holz anderweitig hohe Marktpreise erzielen könnte. Geringere Opportunitätskosten entstehen, wenn es sich um bereits vorgeschädigte Bäume (z. B. durch Blitzschlag oder Rückeschäden) handelt. Auch ein Verzicht auf die Nutzung von Ernterückständen wirft bei hohen Energieholzpreisen Opportunitätskosten auf, denen andererseits insbesondere bei der Nutzung von Stubben auch hohe Bringungskosten gegenüberstehen können.

\subsubsection{Wiedervernässung von Moorwäldern}

Etwa 2,3 \% der Waldfläche in Deutschland (knapp 250.000 ha) stockt auf Moorböden (nach Röder und Osterburg 2012). Ein erheblicher Anteil davon wurde in der Vergangenheit entwässert, um Holzzuwachs oder -qualität zu verbessern, um zusätzliche Optionen für die Baumartenwahl zu gewinnen oder um das Wachstum von Bäumen überhaupt erst zu ermöglichen. Viele der Entwässerungseinrichtungen sind noch vorhanden und funktionstüchtig. Dadurch degradieren die betroffenen Moorstandorte weiterhin. Entwässerte Moorböden stellen Emissionsquellen dar, sobald Luft an die Torfschichten gelangt und diese mineralisieren können. Dabei wird sowohl der bislang gebundene Kohlenstoff als auch Lachgas $\left(\mathrm{N}_{2} \mathrm{O}\right)$ frei. Ein Rückbau der Entwässerungsanlagen kann diese Emissionen langfristig zum Stillstand bringen und eine weitere Akkumulation organischer Substanz ermöglichen - letzteres sogar im Prinzip unbegrenzt. Allerdings sterben die vorhandenen Waldbestände durch die Anhebung des Wasserspiegels unter Umständen ab; zudem werden aus den Böden zumindest in einer Übergangsphase erhebliche Mengen an Methan $\left(\mathrm{CH}_{4}\right)$ emittiert, in Abhängigkeit insbesondere vom Wasserstand unter Flur sowie dessen Schwankungen. Die THG-Emissionen insgesamt gehen daher erst nach einigen Jahren des Moorwachstums zurück (Wolters et al. 2013). Dann erst kann die Kohlenstoffspeicherung die Emissionen überwiegen. 
Erhalt und Wiederherstellung solcher Sonderstandorte ist ein wichtiges Naturschutzziel, das auch mit Klimaargumenten begründet wird (BMU 2007) und generell als preisgünstige Klimaschutzmaßnahme gilt (Schäfer 2009). Aus forstbetrieblicher Sicht stellen nicht allein die möglichen Beeinträchtigungen von Holzqualität und -quantität Konfliktpotenziale dar; auch die Holzernte kann auf wiedervernässten Moorböden stark behindert bzw. sogar ausgeschlossen sein. Für die Betriebe dürften die Wechselwirkungen zu anderen forstlichen Klimaschutzmaßnahmen sowie langfristige Opportunitätskosten nur dort verhältnismäßig gering sein, wo auf solchen Moorstandorten nur niedrige Bonitäten und Holzqualitäten erzielbar sind.

\subsubsection{Düngung, Züchtung und Gentechnik}

Grundsätzlich ließe sich der Zuwachs (und nachfolgend der Vorrat) von Waldbeständen, ähnlich wie in der Landwirtschaft, durch künstlich erhöhtes Nährstoffangebot sowie durch den Einsatz verbesserten Pflanzenmaterials steigern. Der Erfolg von Düngemaßnahmen hängt stark von der standörtlichen Bodenstruktur und den jeweiligen Bedürfnissen der Pflanzen ab. In Deutschland sind Düngemaßnahmen im Wald (mit Ausnahme von Startdüngungen in Kulturen sowie Kompensationskalkungen) unüblich; ihnen stehen hohe Kosten sowie die lange Laufzeit entsprechender Investitionen entgegen.

Ähnliches gilt für Züchtung und Gentechnik. Der Einsatz verbesserten Pflanzenmaterials im Wald erfordert grundsätzlich, Bestände per Pflanzung statt kostengünstiger durch Naturverjüngung zu begründen, und er kann sich erst mit geraumer Zeitverzögerung rentieren. Züchterisch verbesserte Pflanzen sind daher auf Sonderfälle beschränkt (z. B. Pappel) und finden sich primär außerhalb der konventionellen Forstwirtschaft (z. B. in Kurzumtriebsplantagen). Dem Einsatz gentechnisch veränderten Materials im Wald stehen zudem nicht nur erhebliche Bedenken des Naturschutzes wie auch der Forstwirtschaft, sondern auch rechtliche Hindernisse entgegen.

\subsubsection{Vergrößerung der Waldfläche}

Die Begründung neuer Wälder auf bislang nicht forstlich genutzten Flächen durch Aufforstung oder Zulassen der natürlichen Sukzession impliziert eine dauerhafte Änderung der bisherigen Landnutzung - dauerhaft nicht nur wegen des langsamen Waldwachstums, sondern auch wegen des Rodungsverbots nach $\S 9$ des Bundeswaldgesetzes, das eine Waldneubegründung nahezu irreversibel macht. Mit der Begründung neuer Wälder ist eine sehr langanhaltende Akkumulation von Kohlenstoff in Baumbestand und Böden verbunden, die zudem auf lange Sicht einen verstärkten Zufluss zum Holzproduktespeicher sowie Substitutionspotenziale ermöglicht. Für Aufforstungen von Mischbeständen aus einheimischen Baumarten auf ehemaligen Acker- oder Weideflächen werden die GesamtMinderungspotenziale während der ersten beiden Jahrzehnte auf durchschnittlich 5 bis $20\left[\mathrm{t}_{\mathrm{CO}_{2}}\right.$ ! (ha*a)]; veranschlagt (Paul et al. 2009), in den darauf folgenden Jahrzehnten auf mehr als das Doppelte (a. a. O, Anhang D; vgl. auch Dunger et al. 2009). 
Flächenpotenziale bestehen i. W. auf ehemals landwirtschaftlich genutzten sowie sonstigen Flächen, deren bisherige Nutzung aufgegeben wurde (namentlich städtische Brachflächen, ehemalige Truppenübungsplätze und Braunkohle-Tagebauflächen). Der jährliche Umfang landwirtschaftlicher Erstaufforstungen wird für die letzten Jahrzehnte mit 2000 bis 4000 ha/a angegeben, der von Braunkohle-Rekultivierungen mit etwa 1000 ha/a; das Gesamtpotenzial beträgt grob etwa 60.000 ha an BraunkohleRekultivierungsflächen, 100.000 ha an städtischen Brachflächen und weitere 100.000 ha an ehemaligen Militärflächen, zusammen also etwa eine Viertel Million Hektar (Elsasser 2008).

Bezüglich der Baumartenwahl gilt weitgehend das oben Gesagte: Wenn es allein um die Kohlenstoffspeicherung geht, sind rasch- und starkwüchsige Baumarten auf kurze und mittlere Frist überlegen; zur Stabilisierung empfehlen sich geeignete Beimischungen. Bei Erstaufforstungen ist ferner zu bedenken, dass (große) Aufforstungsflächen Pionierstandorte sind. Klimaxbaumarten wie z. B. Buche und Weißtannen sind ökologisch weniger an die dortigen Licht- und Klimaverhältnisse angepasst.

\subsubsection{Ausweitung des Holzproduktespeichers und von Substitutionen}

Verwendetes Holz ist über drei Wege klimawirksam: Zum einen stellen die Holzprodukte selbst, einschließlich Papier, einen (vergrößerbaren) Kohlenstoffspeicher dar. Zum zweiten vermeidet die stoffliche Verwendung von Holz anstelle alternativer Materialien Emissionen, die mit der Gewinnung und Verarbeitung dieser alternativen Materialien einhergehen (stoffliche Substitution). Ein Beispiel hierfür ist die Verwendung von Holz- anstelle von Aluminiumfenstern. Zum dritten ersetzt die Verbrennung von Holz zur Energiegewinnung fossile Energieträger (energetische Substitution). Beide Arten von Substitution sind in dem Maße wirksam, zu dem der jeweils aktuelle Energiemix aus fossilen Energieträgern besteht; sie vermeiden Emissionen von Kohlenstoff, der in fossilen Lagerstätten gespeichert ist. Auf sehr lange Sicht gesehen, beruht die Klimawirkung von Wald und Holz zudem ausschließlich auf Substitutionseffekten (Werner et al. 2010), da Wald- wie auch Holzproduktspeicher nicht unendlich erweiterbar sind. Das energetische Substitutionspotenzial von Holz im Vergleich zu leichtem Heizöl beträgt + 0,67 t C/t C (Rüter 2011); eine zur Energiegewinnung genutzte Tonne Kohlenstoff aus Holz ersetzt also 0,67 t Kohlenstoff aus fossilen Quellen, die aufgrund der Substitution dauerhaft gespeichert bleiben können. Für die stoffliche Substitution liegen keine Zahlen vor, welche sämtliche Verwendungsmöglichkeiten des Holzes abdecken würden. Eine internationale Metaanalyse ergibt eine Spannbreite stofflicher

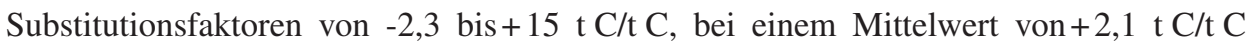
(Sathre und O'Connor 2010).

Verwendung und Weiterverarbeitung des geernteten Holzes sind keine Aktivitäten der forstlichen Landnutzung und können waldbaulich nicht unmittelbar gesteuert werden. 
Waldbaulich steuerbar sind dagegen die Höhe des Zuwachses und das Ausmaß seiner Abschöpfung. Zudem geben die Sortenaushaltung bei der Ernte und langfristig auch die allgemeinen forstlichen Produktionsziele indirekt den Rahmen dafür vor, in welcher Form das Holz anschließend verwendet und weiterverarbeitet werden kann. Um Kohlenstoffspeicherung und Substitutionseffekte in der Holzverwendung zu vergrößern, gibt es auch aus waldbaulicher Sicht mehrere Ansatzpunkte. Sie bestehen grundsätzlich darin, die bereitgestellte Holzmenge aus dem Wald zu maximieren, indem der Gesamtzuwachs vergrößert und (im Rahmen der Nachhaltigkeit) möglichst weitgehend ausgeschöpft wird. Die entsprechenden Maßnahmen sind z. T. gegenläufig zu Maßnahmen, welche v. a. auf eine Vorratsakkumulation im Wald setzen (s. o.):

- Alle o. g. Arten von Nutzungsverzichten sind offensichtlich für die Holzverwendung kontraproduktiv und wären folglich zu unterlassen;

- Umtriebszeiten wären zwecks Zuwachsmaximierung an der Kulmination des durchschnittlichen Gesamtzuwachses der jeweiligen Baumart zu orientieren (Burschel und Huss 1987, S. 44), was in der Regel kürzere Umtriebszeiten und frühere Ernte bedeutet - insbesondere auf wüchsigen Standorten, da das Wachstum dort früher kulminiert;

- Bestandesdichten und Gesamtvorräte wären deutlich unter der maximalen Tragfähigkeit der Wälder anzusiedeln, um Nutzungspotenziale auszuschöpfen und Zuwachsdepressionen zu vermeiden;

- Im Zuge der Bestandesbegründung stünde noch stärker als oben im Vordergrund, auf raschwüchsige Baumarten (wie z. B. Fichte oder Douglasie) zu setzen, auf Baumarten mit später Zuwachskulmination (wie z. B. Buche oder Eiche) dagegen weitgehend $\mathrm{zu}$ verzichten. Maßnahmen der Bestandesbegründung (wie auch Erstaufforstungen) schlagen allerdings erst mit erheblicher Zeitverzögerung auf die Holzverwendung durch.

Auch wenn man neben der reinen Volumenproduktion zusätzlich die Nachfragestruktur auf den Holzmärkten berücksichtigt, verändert das die genannten Kriterien nur wenig. So sprechen technische wie ökonomische Gründe oft gegen die Produktion hoher Zielstärken (s. z. B. Tzschupke 2005), und auch in Bezug auf die Baumartenwahl ist zumindest derzeit die Nachfrage nach Nadelholz stärker ausgeprägt als die nach Laubholz (Jochem et al. 2015), was sich auch in der Preisentwicklung der letzten Jahre zeigt (Ermisch et al. 2014).

Die Weiterverarbeitung des Rohholzes aus dem Wald im Bereich der Holzwirtschaft wird letztendlich nicht von den Produzenten, sondern von den Konsumenten der jeweiligen Endprodukte bestimmt; entsprechende Maßnahmen müssen daher an der Endnachfrage ansetzen. Ihre Diskussion führt allerdings im Rahmen dieses auf die Landnutzung konzentrierten Projektes zu weit; hierzu sei auf die diesbezügliche Literatur verwiesen (u. a. Petersen und Solberg 2005; Gustavsson et al. 2006; Pingoud et al. 2010; Werner et al. 2010; Rüter 2011; Wördehoff et al. 2012; Weimar und Jochem 2013; Mund et al. 2015). 


\subsubsection{Vermeidung von Kohlenstoffverlusten}

Mögliche Ursachen für Kohlenstoffverluste lassen sich in drei Gruppen einteilen:

1. Forstliche Kalamitäten wie Sturmwürfe, Insektengradationen und Waldbrände können Vorräte (wie auch Zuwächse) der Biomasse sowie ggf. anderer Speicherkompartimente empfindlich beeinträchtigen.

2. Die forstliche Bewirtschaftung wirkt sich nicht nur auf Derbholzvorräte und Holzverwendung aus, sondern kann auch die Kohlenstoffvorräte in Streu, Totholz und Böden spürbar beeinflussen.

3. Aktivitäten außerhalb des Forstsektors wie der Bau einer Eisenbahnlinie durch Wald oder der Abriss von Holzbauten tragen ebenfalls zu Kohlenstoffverlusten in den Waldund Holzproduktespeichern bei.

\subsubsection{Verluste durch forstliche Kalamitäten}

Bekannte und einschätzbare Kalamitätsrisiken lassen sich ggf. durch geeignete technische Maßnahmen verringern. Hierzu zählen etwa die Kontrolle und ggf. Bekämpfung von Borkenkäfern mittels Pheromonfallen und (im Wald derzeit noch unübliche) chemische Insektenbekämpfung, oder die Einrichtung von Brandmeldesystemen bei erhöhter Waldbrandgefahr.

Die waldbaulichen Ansatzpunkte für den Umgang mit forstlichen Kalamitätsrisiken sind während des Bestandeslebens die gleichen wie schon oben genannt wurden: Beginnend mit der Baumartenwahl über Bestandespflege und Durchforstung bis hin zu Endnutzungszeitpunkt und -regime sowie Totholzmanagement haben waldbauliche Maßnahmen auch Einfluss auf das jeweilige Risiko von Kohlenstoffverlusten. Wie zuvor sind die Auswirkungen des entsprechenden Risikomanagements in Bezug auf ihre Klimawirkungen teilweise gegenläufig zueinander:

- Maßnahmen zur Stabilisierung der Bestände gegen biotische und abiotische Risiken sind häufig gut mit Naturschutzzielen kompatibel, weil sie Vielfalt fördern, und werden entsprechend von Naturschutzseite oft in den Vordergrund gestellt (z. B. BMU 2007). Sie zielen insbesondere darauf ab, stabile Mischbestände aus standortgerechten bzw. standortheimischen Baumarten zu begründen und diese regelmäßig zu pflegen und zu durchforsten sowie vor selektivem Wildverbiss zu schützen, damit die angestrebte Baumartenmischung erhalten bleibt und sich sturmstabile Schaftformen herausbilden können. Bei der Endnutzung verhelfen lange Endnutzungszeiträume und geringe Eingriffsstärken dazu, die Bestandesstabilität in der Erntephase möglichst wenig zu beeinträchtigen. Insbesondere in der Pflege- und Durchforstungsphase setzen Stabilisierungsaspekte einer Erhöhung der Bestandesdichte zur Maximierung von Kohlenstoffvorräten enge Grenzen. 
- Maßnahmen zur Risikostreuung (Pretzsch 2003; Knoke 2012) gehen weitgehend in die gleiche Richtung. Auch hierzu sind Mischungen aus unterschiedlichen Baumarten, Bestandesstrukturen und -altern in Verbindung mit entsprechender Pflege und Durchforstung dienlich. Allerdings ist es für die reine Risikostreuung unerheblich, ob derartige Mischungen auf Einzelbestands- oder auf höherer regionaler Ebene erfolgen.

- Maßnahmen zur Risikovermeidung setzen dagegen daran an, Bäume (und deren Kohlenstoffvorräte) möglichst kurz den jeweiligen Risiken auszusetzen und die entsprechende Vorratshöhe gering zu halten (vgl. z. B. Pauli et al. 2016). Konkret bedeutet dies, Bestände im Weitstand zu begründen, durchgehend stark zu durchforsten und früh zu ernten. Kohlenstoffakkumulationen im Totholzspeicher sind in dieser Hinsicht insbesondere bei Feuergefahr ebenso kontraproduktiv wie jede Art von Nutzungsverzicht.

Der prognostizierte Klimawandel verlangt überdies eine Adaptation an zukünftige Umweltänderungen. Da deren standörtliche Auswirkungen auf zukünftige Wachstumsbedingungen und Risikostrukturen nicht bekannt sind, kommt damit ein zusätzliches Unsicherheitselement ins Spiel. Die Auswahl von Adaptationsmaßnahmen ist daher zwangsläufig durch spekulative Momente beeinflusst.

Aufgrund der Langfristigkeit des Klimawandels wie auch der Langlebigkeit von Bäumen müssen Adaptationsmaßnahmen weit im Vorhinein ergriffen werden und daher insbesondere an der Bestandesbegründung ansetzen. Unter Adaptationsaspekten ist hier weniger die derzeitige Standortangepasstheit der Bäume entscheidend als vielmehr deren Resistenz gegenüber veränderten Temperatur-, Sturm-, Insekten-, Überschwemmungsund Trocknisereignissen, welche für die Zukunft prognostiziert sind. Für spätere Bestandesstadien bieten sich die gleichen Elemente des Risikomanagements an, die schon oben beschrieben wurden (Stabilisierung, Risikostreuung und/oder -vermeidung). Ob bei deren Dosierung allerdings eher antizipativ oder reaktiv vorgegangen wird, ist von der Risikofreude der jeweiligen Entscheider abhängig. In Hinblick auf die Klimaschutzleistung der Wälder nähmen antizipative Strategien tendenziell in Kauf, zur Vermeidung zukünftig möglicher Kohlenstoffverluste auf heutige Speicher- und Senkenoptionen zu verzichten. Umgekehrt setzten reaktive Strategien stärker auf die Optimierung der heutigen Klimawirksamkeit, mit dem Risiko erheblicherer zukünftiger Verluste (vgl. auch Jandl et al. 2015).

\subsubsection{Verluste durch forstliche Bewirtschaftung}

Die forstliche Bewirtschaftung selbst kann - beabsichtigt wie auch als unbeabsichtigte Nebenwirkung von Bewirtschaftungsmaßnahmen - Kohlenstoffverluste aus verschiedenen Speicherkompartimenten bedingen. Mit einigen der bisher diskutierten Maßnahmen (Endnutzung, Durchforstung, Vorratsabbau im Zuge des Risikomanagements) gehen zwangsläufig Kohlenstoffverluste aus der Baumbiomasse einher. Sie bewirken per Saldo allerdings nur insoweit Emissionen, als sie nicht durch 
den Holzproduktespeicher aufgefangen oder durch entsprechende Substitutionen kompensiert werden.

Problematischer sind unbeabsichtigte Nebenwirkungen der Bewirtschaftung auf die Kohlenstoffvorräte in anderen Speicherkompartimenten, insbesondere in Böden. Grob die Hälfte der gesamten Wald-Kohlenstoffvorräte in Deutschland ist in den Böden gespeichert (NIR 2014, Abschn. 7.2; Wellbrock et al. 2014). Grundsätzlich steigt deren Kohlenstoff-Speicherkapazität mit steigender Produktivität der Bestände, weil dies einen erhöhten Kohlenstoff-Input in die Böden ermöglicht. Störungen der Bestandes- und Bodenstrukturen erhöhen dagegen das Risiko unbeabsichtigter Kohlenstoffverluste. Aufgrund von Durchforstungen und stärker noch von Endnutzungen aufgelichtete Bestände zeichnen sich durch gesteigerte Wärmezufuhr am Boden aus, zudem bewirkt das Befahren der Böden durch Forstmaschinen Störungen der Bodenstruktur; beides begünstigt den Abbau von Bodenkohlenstoff. Auch Sondermaßnahmen wie Kompensationskalkungen und Bodenvorbereitung zur Kulturbegründung können zu Kohlenstoffverlusten im Boden führen, erstere aufgrund der dadurch begünstigten mikrobiellen Aktivität, letztere wegen der damit verbundenen Störung der Bodenstruktur. Geeignete Gegenmaßnahmen sind daher darauf gerichtet, Störungen von Bestandes- und Bodenstrukturen zu minimieren. Dies impliziert, Maschinen möglichst selten und bodenschonend einzusetzen (indem beispielsweise Befahrungen auf ein festes Rückegassensystem begrenzt bleiben, Durchforstungsintervalle verlängert und Erntemaßnahmen hinausgezögert werden) sowie für eine möglichst durchgehende Bodenbedeckung zu sorgen und starke Auflichtungen (etwa durch Kleinkahlschläge) zu vermeiden (Jandl et al. 2007, mit weiteren Nachweisen).

\subsubsection{Verluste durch Aktivitäten außerhalb des Forstsektors}

Abschließend sei auf Kohlenstoffverluste in den Wald- und Holzproduktespeichern hingewiesen, deren Ursachen außerhalb des Forstsektors angesiedelt sind. Waldspeicher sind vor allem durch Waldumwandlungen im Zuge von Infrastrukturmaßnahmen (Verkehrs- und Siedlungsentwicklung) betroffen. Für das Jahr 2012 wurden die dadurch bedingten Kohlenstoffverluste in Deutschland auf fast eine halbe Million t $\mathrm{CO}_{2}$ beziffert (NIR 2014, S. 850). Selbst wenn diese Waldumwandlungen flächenmäßig durch Ersatzaufforstungen kompensiert werden (müssen), bewirken sie doch einen Ersatz älterer und kohlenstoffreicherer Wälder durch kohlenstoffarme Jungbestände. Der Holzproduktespeicher ist in Bezug auf seine Dauerhaftigkeit wie auch sein Gesamtvolumen durch kontinuierliche Änderungen in der Struktur des Materialeinsatzes in der Volkswirtschaft bedroht - etwa durch verkürzte Abschreibungszeiträume für Gebäude und die Substitution von Holz- durch Stahlkonstruktionen. In beiden Fällen können Gegenmaßnahmen nicht seitens der Forstwirtschaft erfolgen. Sie bedürfen übergreifender politischer und planerischer Reaktionen. 


\subsubsection{Zusammenfassung zu Maßnahmenbündeln (Strategien)}

Im Rahmen dieser Studie ist es angesichts der sehr langen forstlichen Produktionszeiträume und der Pfadabhängigkeit der Produktion nicht sinnvoll, die Auswirkungen isolierter Einzelmaßnahmen auf Klimaziele zu beschreiben. Stattdessen werden diejenigen Maßnahmen, die sich für eine großräumige Modellierung eignen, entsprechend ihrer zeitlichen Abfolge im Bestandesleben zu Maßnahmenbündeln zusammengefasst; anschließend werden untereinander abgestimmte Bündel von Maßnahmenvarianten einer Referenz- sowie vier Bewirtschaftungsstrategien zugeordnet (vgl. Abschn. 4.6.1 und 4.6.2). Deren Auswirkungen auf naturale und finanzielle Erträge sowie die Kohlenstoffspeicherung werden jeweils mit Hilfe des in Abschn. 4.2.2.4 beschriebenen forstbetrieblichen Simulationsmodells FoBeSiMo abgeschätzt. Die Referenzprojektion (Abschn. 4.6.1) orientiert sich dabei an den derzeitigen Bewirtschaftungsplanungen, insbesondere der Landesforstbetriebe. Die Strategien (vgl. Abschn. 4.6.2) unterscheiden sich v. a. in Bezug darauf, ob sie Klimaschutz- und -anpassungsziele primär über eine Erhöhung der Kohlenstoffvorräte im Wald oder über eine Ausweitung des Holzproduktespeichers und von Substitutionen $\mathrm{zu}$ erreichen trachten, und welchen Ansatz sie zum Umgang mit Risiken von Kohlenstoffverlusten wählen.

In diesen Strategien werden die oben beschriebenen waldbaulichen Klimaschutzmaßnahmen den Phasen Bestandesbegründung bzw. -verjüngung, Bestandespflege und Durchforstung sowie der Endnutzungsphase zugeordnet, an die sich die Holzverwendung anschließt. Für die Bestandesbegründungsphase wird die Maßnahme „Baumartenwahl“ (Abschn. 3.3.2.1) in vier verschiedenen Variationen abgebildet. In der Pflege- und Durchforstungsphase werden „Häufigkeit“ und „Stärke der Durchforstung“ variiert, mit der u. a. die Bestandesdichte (Abschn. 3.3.2.2) gesteuert wird. Für die Endnutzungsphase werden „Zielstärke“, „Endnutzungsmenge“ (pro Erntemaßnahme) sowie die „Dauer des Endnutzungszeitraums“ in unterschiedlichen Varianten kombiniert; dies beeinflusst ebenfalls die Bestandesdichte in dieser Phase (Abschn. 3.3.2.2) sowie die jeweiligen Umtriebszeiten (Abschn. 3.3.2.3). Zeitpunkt sowie Intensität von Vor- und Endnutzungen beeinflussen weiterhin die Sortenaushaltung der Maßnahme „Holzbereitstellung“, und damit die Potenziale für eine Ausweitung des Holzproduktespeichers und für Substitutionen (Abschn. 3.3.4). Die Realisierung solcher Potenziale kann nicht durch eine forstbetriebliche Simulation abgebildet werden, da sie außerhalb von Wäldern bzw. Forstbetrieben stattfindet; diese Potenziale werden vielmehr berücksichtigt, indem den aus den jeweiligen Waldbewirtschaftungsstrategien entstehenden Sortimenten jeweils unterschiedliche konstante Verwendungspfade zugerechnet werden (s. Abschn. 4.2.2.4). Vergleichbar wird zur Berücksichtigung unterschiedlicher Totholzmengen (Abschn. 3.3.2.5) vorgegangen, die bei den verschiedenen Behandlungsvarianten anfallen; sie werden diesen Varianten jeweils pauschaliert 
zugerechnet. ${ }^{17}$ Forstliche Kalamitätsrisiken (Abschn. 3.3.5.1) werden in Form von baumart- und altersspezifischen Überlebenswahrscheinlichkeiten in die Simulation integriert (s. Abschn. 4.2.2.4).

Zwei weitere Maßnahmen sind dagegen nicht zwingend an bestimmte Nutzungspfade gebunden, nämlich Nutzungsverzichte (Abschn. 3.3.2.4) sowie die Vergrößerung der Waldfläche (Abschn. 3.3.3). Ihre Auswirkungen werden daher in jeweils separaten Modulen simuliert, die anschließend unterschiedlichen Strategien zugeordnet werden können. Abschn. 4.6.2 bietet eine Übersicht über die in der Simulation variierten Maßnahmen und ihre Zuordnung zu Strategien.

\section{Literatur}

Akiyama H, Yan X, Yagi K (2010) Evaluation of effectiveness of enhanced-efficiency fertilizers as mitigation options for $\mathrm{N} 2 \mathrm{O}$ and $\mathrm{NO}$ emissions from agricultural soils: meta-analysis. Glob Change Biol 16:1837-1846

Albrecht A, Hanewinkel M, Bauhus J, Kohnle U (2015) Wie sturmstabil ist die Douglasie? AFZDerWald 9:30-34

Arnold CL, Gibbons CJ (1996) Impervious surface coverage: the emergence of a key environmental indicator. J Am Plann Assoc 62(2):243-258

Augustin J, Joosten H (2007) Peatland rewetting and the greenhouse effect. IMCG Newsletter 2007-3:29-30

Birkmann J, Vollmer M, Schanze J (2013) Raumentwicklung im Klimawandel. Herausforderungen für die räumliche Planung. Forschungsberichte der ARL 2, Hannover

Bloch R, Bachinger J (2010) Anpassung an den Klimawandel im Praxistest. Innovationen im Ökologischen Landbau. Forschungsreport 2/2010, S 18-21

Bonn A, Bues A, Couwenberg J, Drösler M, Jensen R, Kantelhardt J, Luthardt V, Permien T, Röder N, Schaller L, Schweppe-Kraft B, Tanneberger F, Trepel M, Wichmann S (2015) Klimaschutz durch Wiedervernässung von kohlenstoffreichen Böden. In: Hartje V, Wüstemann H, Bonn A (Hrsg) Naturkapital Deutschland - TEEB DE: Naturkapital und Klimapolitik - Synergien und Konflikte. Technische Universität Berlin, Helmholtz-Zentrum für Umweltforschung-UFZ, Berlin, S 124-147

Brake K (1998) Dezentrale Konzentration in Großstadtregionen. Die begrenzten Umsetzungspfade stadtregionaler Raumordnung. RaumforschRaumordm 5(6):343-351

Bronsema H, Theuvsen L, Warnecke S, Broll G, Biberbacher M (2012) Effizienssteigerung bei der Verwertung von Wirtschaftsdüngern in Norddeutschland - eine modellbasierte Transportoptimierung. Efficient Use of Farm Manures in Northwest Germany - Model-based Transport Optimization. In: Hambrusch J, Hambrusch C, Kantelhardt J, Oedl-Wieser T (Hrsg) Jahrbuch der Österreichischen Gesellschaft für Agrarökonomie. Facultas Verlags- und Buchhandel AG, Wien

Bund/Länderarbeitsgemeinschaft Wasser (LAWA) (2014) Nationales Hochwasserschutzprogramm, beschlossen auf der Umweltministerkonferenz am 24. Oktober 2014 in Heidelberg, Kiel, S 9

\footnotetext{
${ }^{17}$ Veränderungen der Kohlenstoffspeicher in Streuschicht und Böden werden in diesem Untersuchungsteil nicht berücksichtigt.
} 
Bundesamt für Naturschutz (BfN) (o. J.) Bundesnaturschutzgebiete. https://geodienste.bfn.de/ schutzgebiete?lang=de. Zugegriffen: 1. Okt. 2018

Bundesamt für Naturschutz (BfN) und Bundesinstitut für Bau-, Stadt- und Raumforschung (BBSR) (2014) Den Landschaftswandel gestalten! Potentiale der Landschafts- und Raumplanung zur modellhaften Entwicklung und Gestaltung von Kulturlandschaften vor dem Hintergrund aktueller Transformationsprozesse. Bundesweite Übersichten, Bd 1. Bundesamt für Naturschutz (BfN), Bonn, S 66

Bundesinstitut für Bau-, Stadt- und Raumforschung (BBSR) (2010) Vielfalt des Demographischen Wandels. Eine Herausforderung für Stadt und Land. BBSR-Online-Publikation 6/2010

Bundesinstitut für Bau-, Stadt- und Raumforschung (BBSR) (2013) Innenentwicklungspotenziale in Deutschland. Ergebnisse einer bundesweiten Umfrage und Möglichkeiten einer automatisierten Abschätzung. Unter Mitarbeit von: Schiller G, Blum A, Hecht R, Meinel G, Oertel H, Ferber U, Petermann E, Bonn, S 163

Bundesinstitut für Bau-, Stadt- und Raumforschung (BBSR) (2014a) Aktuelle und zukünftige Entwicklung von Wohnungsleerständen in den Teilräumen Deutschlands. Datengrundlagen, Erfassungsmethoden und Abschätzungen, Bonn

Bundesinstitut für Bau-, Stadt- und Raumforschung (BBSR) (2014b) Städtebauliche Nachverdichtung im Klimawandel. Ein ExWoSt-Fachgutachten. ExWoSt-Informationen 46(1)

Bundesministerium für Umwelt, Naturschutz und nukleare Sicherheit (BMU) (2007) Nationale Strategie zur biologischen Vielfalt (National Strategy on Biological Diversity). Bundesministerium für Umwelt, Naturschutz und Reaktorsicherheit, Bonn

Bundesministerium für Umwelt, Naturschutz und nukleare Sicherheit (BMU) und Bundesministerium für Ernährung, Landwirtschaft und Verbraucherschutz (BMELV) (2012) Nitratbericht 2012. Gemeinsamer Bericht der Bundesministerien für Umwelt, Naturschutz und Reaktorsicherheit sowie für Ernährung, Landwirtschaft und Verbraucherschutz

Bundesministerium für Verkehr, Bau und Stadtentwicklung (BMVBS) (2010) Klimawandel als Handlungsfeld der Raumordnung. Ergebnisse der Vorstudie zu den Modelvorhaben „Raumentwicklungsstrategien zum Klimawandel“. Forschungen, Bd 144. Bundesministerium für Verkehr, Bau und Stadtentwicklung (BMVBS), Bonn, S 121

Bundesministerium für Verkehr, Bau und Stadtentwicklung (BMVBS) (2011) Klimawandelgerechte Stadtentwicklung. Ursachen und Folgen des Klimawandels durch urbane Konzepte begegnen. Forschungen, Bd 149. Bundesministerium für Verkehr, Bau und Stadtentwicklung (BMVBS), Bonn, S 100

Bundesministerium für Verkehr, Bau und Stadtentwicklung (BMVBS) (2012) Stadtumbau vor neuen Herausforderungen. 4. Statusbericht der Bundestransferstelle Stadtumbau Ost. Bundesministerium für Verkehr, Bau und Stadtentwicklung (BMVBS), Berlin, S 118

Bundesministerium für Verkehr, Bau und Stadtentwicklung (BMVBS) (2013) Rechtliche Anforderungen an raumplanerische Festlegungen zur Hochwasservorsorge, insbesondere im Baubestand. BMVBS-Online-Publikation, Bonn

Bundesministerium für Verkehr und digitale Infrastruktur (BMVI) (2014) Grundkonzeption für den Bundesverkehrswegeplan 2015. https://www.bmvi.de/SharedDocs/DE/Anlage/G/BVWP/ bvwp-2015-grundkonzeption-langfassung.pdf?_blob=publicationFile. Zugegriffen: 13. Febr. 2020

Bundesregierung (2013) Koalitionsvertrag der 18. Legislaturperiode zwischen CDU, CSU und SPD „Deutschlands Zukunft gestalten“. Bundesregierung, Rheinbach

Burschel P, Huss J (1987) Grundriß des Waldbaus. Parey, Hamburg

Couwenberg J (2007) Biomass energy crops on peatland: on emissions and perversions. IMCG Newsletter 3:12-14 
Deller B, Mastel K, Augustenberg LTZ (2011) Humusanreicherung unter Kulturen nachwachsender Rohstoffe. Landinfo 3:38-41

Deutscher Wetterdienst (DWD) (2014) Großwetterlage ,Tief Mitteleuropa' (TM) brachte Ende Juli 2014 monsunartige Niederschläge in Teilen Deutschlands. Wird diese sommerliche Wetterlage mit dem Klimawandel künftig in Deutschland häufiger auftreten? Stellungnahme des Deutschen Wetterdienstes (DWD), Offenbach. https://www.dwd.de/DE/leistungen/besondereereignisse/niederschlag/20140730_dwd_stellungnahmeextremeniederschlaegejuli2014.html. Zugegriffen: 13. Febr. 2020

Dieter M, Elsasser P (2004) Wirtschaftlichkeit und Wettbewerbschancen von WaldSenkenprojekten in Deutschland, vol 2004/11. Arbeitsbericht des Instituts für Ökonomie. BFH, Hamburg

Don A, Osborne B, Hastings A, Skiba U, Carter MS, Drewer J, Flessa H, Freibauer A, Hyvönen N, Jones MB, Lanigan GJ, Mander Ü, Monti A, Djomo SN, Valentine J, Walter K, ZegadaLizarazu W, Zenone T (2012) Land-use change to bioenergy production in Europe: implications for the greenhouse gas balance and soil carbon. GCB Bioenergy 4:372-391

Drösler M, Freibauer A, Adelmann W, Augustin J, Bergman L, Beyer C, Chojnicki B, Förster C, Giebels M, Görlitz S, Höper H, Kantelhardt J, Liebersbach L, Hahn-Schöfl M, Minke M, Petschow U, Pfadenhauer J, Schaller L, Schägner P, Sommer M, Thuille A, Wehrhan M (2011) Klimaschutz durch Moorschutz in der Praxis - Ergebnisse aus dem BMBF-Verbundprojekt „Klimaschutz - Moornutzungsstrategien“ 2006-2010. Arbeitsberichte aus dem vTI-Institut für Agrarrelevante Klimaforschung 2011/04, Braunschweig, S 21

Dunger K, Stümer W, Oehmichen K, Riedel T, Bolte A (2009) Der Kohlenstoffspeicher Wald und seine Entwicklung. Ergebnisse einer Kohlenstoffinventur auf Bundeswaldinventur-Basis. AFZ Der Wald 64(20):1072-1073

Elsasser P (2008) Neuwaldbildung durch Sukzession: Flächenpotentiale, Hindernisse, Realisierungschancen (Using succession for new forests: potential area, obstacles, opportunities for implementation), vol OEF 2008/5. Arbeitsbericht. von-Thünen-Institut, Hamburg

Ermisch N, Seintsch B, Dög M (2014) Ergebnisse des Testbetriebsnetzes Forst des BMEL. AFZ 23:18-20

Fachagentur Nachwachsende Rohstoffe (FNR) (2011) Pappeln mit neuen Methoden züchten. Gesunde Pflanzen 63:205-209

Fachagentur Nachwachsende Rohstoffe (FNR) (2012) Energiepflanzen für Biogasanlagen Sachsen. Fachagentur für Nachwachsende Rohstoffe e. V., Gülzow-Prüzen

Fachagentur Nachwachsende Rohstoffe (FNR) (2014a) Basisdaten Bioenergie Deutschland 2014. Fachagentur Nachwachsende Rohstoffe (FNR), Gülzow-Prüzen

Fachagentur Nachwachsende Rohstoffe (FNR) (2014b) Maisanbau in Deutschland. Fachagentur für Nachwachsende Rohstoffe e. V. https://mediathek.fnr.de/grafiken/daten-und-fakten/bioenergie/biogas/maisanbau-in-deutschland.html. Zugegriffen: 12. März 2018

Fachagentur Nachwachsende Rohstoffe (FNR) (2014c) Energiegehalt fester Bioenergieträger. Fachagentur für Nachwachsende Rohstoffe e. V. http://www.google.de/url?sa=t\&rc $\mathrm{t}=\mathrm{j} \& \mathrm{q}=\& \mathrm{esrc}=\mathrm{s} \&$ source $=$ web $\& \mathrm{~cd}=2 \& \mathrm{ved}=0 \mathrm{CCcQFjAB} \& \mathrm{url}=\mathrm{http} \% 3 \mathrm{~A} \% 2 \mathrm{~F} \% 2 \mathrm{Fmed}$ iathek.fnr.de $\% 2$ Fleitfaden-bioenergie $\% 2$ Fdaten $\% 2$ Ftab-2-6-20\%2FEnergiegehalt_fester_ Bioenergietraeger.xlsx\&ei=JluRVaL8FISpsgHrt4CABg\&usg=AFQjCNFwlfKA9Cvhdhmsxjw 5515orxuuTw\&bvm=bv.96783405,d.bGg. Zugegriffen: 12. März 2018

Fachagentur Nachwachsende Rohstoffe (FNR) (2015) Energiepflanzen. Homepage. http://www. fnr.de/nachwachsende-rohstoffe/bioenergie/energiepflanzen/. Zugegriffen: 12. März 2018

Fachverband Bioenergie e. V. (2014) Branchenzahlenprognose für die Jahre 2014 und 2015. Freising. http://www.biogas.org/edcom/webfvb.nsf/id/DE_Branchenzahlen. Zugegriffen: 12. März 2018 
Flessa H, Greef JM, Hofmeier M, Dittert K, Ruser R, Osterburg B, Poddey E, Wulf S, Pacholski A (2014) Minderung von Stickstoffemissionen aus der Landwirtschaft - Empfehlungen für die Praxis und aktuelle Fragen an die Wissenschaft. Forschung Themenheft 1/2014

Flessa H, Müller D, Plassmann K, Osterburg B, Techen AK, Nitsch H, Nieberg H, Sanders J, Meyer Zu Hartlage O, Beckmann E, Anspach V (2012) Studie zur Vorbereitung einer effizienten und gut abgestimmten Klimaschutzpolitik für den Agrarsektor. Landbauforschung Sonderheft 361:472

Freibauer A, Drösler M, Gensior A, Schulze E (2009) Das Potenzial von Wäldern und Mooren für den Klimaschutz in Deutschland und auf globaler Ebene. Natur und Landschaft 1:20-25

Fritsche U, Wiegmann K (2008) Treibhausgasbilanzen und kumulierter Primärenergieverbrauch von Bioenergie-Konversionspfaden unter Berücksichtigung möglicher Landnutzungsänderungen. Externe Expertise für das WBGU-Hauptgutachten „Welt im Wandel: Zukunftsfähige Bioenergie und nachhaltige Landnutzung“. Öko-Institut, Darmstadt

Fuhrich M, Dosch F, Pahl-Weber E, Zillmann K (2004) Kompass für den Weg zur Stadt der Zukunft. Indikatorengestützte Erfolgskontrolle nachhaltiger Stadtentwicklung. Eine Orientierungshilfe für die kommunale Praxis. Ein ExWoSt-Forschungsfeld. BBR, Bonn

Gensior A, Roth G, Well R (2012) Landwirtschaftliche Bodennutzung: eine Bestandsaufnahme aus Sicht der Klimaberichterstattung. Bodenschutz 17:81-89

Geupel M, Frommer J (2014) Reaktiver Stickstoff in Deutschland. Ursachen, Wirkungen, Maßnahmen. Umweltbundesamt (UBA), Dessau-Roßlau

Gömann H, Kreins P (2012) Landnutzungsänderungen in Deutschlands Landwirtschaft - Rückläufige Anbaudiversität hat viele Ursachen. Mais 39:118-122

Greiving S, Fleischhauer M (2008) Raumplanung: in Zeiten des Klimawandels wichtiger denn je! Größere Planungsflexibilität durch informelle Ansätze einer Klimarisiko-Governance. RaumPlanung 137:61-66

Gustavsson L, Pingoud K, Sathre R (2006) Carbon dioxide balance of wood substitution: comparing concrete- and wood-framed buildings. Mitig Adapt Strat Glob Change 11(3):667691

Hartje V, Wüstemann H, Bonn A (Hrsg) (2015) Naturkapital und Klimapolitik: Synergien und Konflikte. Naturkapital Deutschland - TEEB DE. TUB/UFZ, Berlin, Leipzig

Heiland S, Reinke M, Siedentop S, Träger T, Knigge M, Meyer-Ohlendorf N, Blobel D (2006) Beitrag naturschutzpolitischer Instrumente zur Steuerung der Flächeninanspruchnahme. BfN Skripten, Bd 176, Bonn, S 154

Hoogwijk M, Faaij A, Van Den Broek R, Berndes G, Gielen D, Turkenburg W (2013) Exploration of the ranges of the global potential of biomass for energy. Biomass Bioenerg 25:119-133

Huth V, Günther A, Jurasinski G, Glatzel S (2013) The effect of an exceptionally wet summer on methane effluxes from a 15-year re-wetted fen in north-east Germany. Mires and Peat 13:1-7

Institut für angewandte Sozialwissenschaften GmbH (infas) und Deutsches Zentrum für Luft- und Raumfahrt e. V., Institut für Verkehrsforschung (DLR) (2010) Mobilität in Deutschland 2008. Ergebnisbericht Struktur - Aufkommen - Emissionen - Trends, Bonn, S 208

Jandl R, Bauhus J, Bolte A, Schindlbacher A, Schüler S (2015) Effect of climate-adapted forest management on carbon pools and greenhouse gas emissions. Curr Forestry Rep 1(1):1-7

Jandl R, Lindner M, Vesterdal L, Bauwens B, Baritz R, Hagedorn F, Johnson DW, Minkkinen K, Byrne KA (2007) How strongly can forest management influence soil carbon sequestration? Geoderma 137(3-4):253-268

Jenssen T (2009) Klimaschutz durch städtebauliche Dichte! Möglichkeiten und Grenzen der räumlichen Steuerung von THG-Emissionen. RaumPlanung 147:281-284 
Jochem D, Weimar H, Bösch M, Mantau U, Dieter M (2015) Estimation of wood removals and fellings in Germany: a calculation approach based on the amount of used roundwood. Eur J Forest Res 134(5):869-888

Joosten H, Gahlert F, Gaudig G, Prager A, Quesada AS, Wichmann S (2010) InnoNetVerbundprojekt: Torfmooskultivierung auf schwimmfähigen Vegetationsträgern für ein nachhaltiges und umweltfreundliche Torfsubstitut im Erwerbsgartenbau - MOOSFARM, Schlussbericht. Universität Greifswald, Mat.-Nat., Institut für Botanik und Landschaftsökologie, Greifswald

Knieling J, Kretschmann N, Zimmermann T (2013) Regionalplanerische Festlegungen zur Anpassung an den Klimawandel. Urban and regional studies working paper 14, Hamburg

Knoke T (Hrsg) (2012) Forstbetriebsplanung als Entscheidungshilfe. Ulmer, Stuttgart

Köbbing JF, Groth M, von Oheimb G (2012) Klimaschutz durch Moorrenaturierung. Ansätze zur ökonomischen Bewertung. ibidem-Verlag, Stuttgart

Kreins P, Gömann H, Herrmann S, Kunkel R, Wendland F (2007) Integrated agricultural and hydrological modeling within an intensive livestock region. Adv Econ Environ Res 7:113-142

Kröger R, Theuvsen L, Robert J, Konerding JR (2014) Güllefeststoffe als Gärsubstrat für Biogasanlagen - Ergebnisse einer empirischen Erhebung unter Biogasanlagenbetreibern. Berichte über die Landwirtschaft: Zeitschrift für Agrarpolitik und Landwirtschaft 92(3)

Laggner B, Orthen N, Osterburg B, Röder N (2014) Ist die zunehmende Biogasproduktion die alleinige Ursache für den Grünlandschwund in Deutschland? - eine Analyse von georeferenzierten Daten zur Landnutzung. Raumforsch Raumordn 72:195-209

Landtag Rheinland-Pfalz (2004) Zukunft in Rheinland-Pfalz mit erneuerbaren Energien. Studie zur Weiterentwicklung der energetischen Verwertung von Biomasse in Rheinland-Pfalz (Zusammenfassung). Unterrichtung durch die Landesregierung, Drucksache 14/3397, Mainz. http://www.landtag.rlp.de/landtag/drucksachen/3397-14.pdf. Zugegriffen: 12. März 2018

Landwirtschaftskammer Niedersachsen (2015) Nährstoffbericht in Bezug auf Wirtschaftsdünger für Niedersachsen 2013/2014, Oldenburg

Landwirtschaftskammer Nordrhein-Westfalen (2014) Nährstoffbericht 2014 über Wirtschaftsdünger und andere organische Düngemittel für Nordrhein-Westfalen. Der Direktor der Landwirtschaftskammer Nordrhein-Westfalen, Münster

Ministerium für Bauen, Wohnen, Stadtentwicklung und Verkehr NRW (MBWSV) (2014) Urbanes Grün - Konzepte und Instrumente. Leitfaden für Planerinnen und Planer, Düsseldorf

Ministerkonferenz für Raumordnung (MKRO) (2013) Raumordnung und Klimawandel. Umlaufbeschluss, Berlin

Mühlenhoff J (2013) Reststoffe für Bioenergie nutzen. Potenziale, Mobilisierung und Umweltbilanz. Agentur für Erneuerbare Energien e. V., Berlin, Renews Spezial, Ausgabe 64/April 2013

Mund M, Frischbier N, Profft I, Raacke J, Richter F, Ammer C (2015) Klimaschutzwirkung des Wald- und Holzsektors: Schutz- und Nutzungsszenarien für drei Modellregionen in Thüringen. BfN-Skripten 396:1-168

Nabuurs G-J, Lindner M, Verkerk PJ, Gunia K, Deda P, Michalak R, Grassi G (2013) First signs of carbon sink saturation in European forest biomass. Nat Clim Change 3(9):792-796

National Inventory Report (NIR) (2014) Berichterstattung unter der Klimarahmenkonvention der Vereinten Nationen und dem Kyoto Protokoll 2014. Nationaler Inventarbericht zum Deutschen Treibhausgasinventar 1990-2012. Umweltbundesamt, Dessau-Roßlau

Naumann S, Frelih-Larson A (2010) Klimaschutz in der Landwirtschaft. Ziele und Anforderungen zur Senkung von Treibhausgasemissionen. NABU (Hrsg), Berlin

Nitsch H, Osterburg B, Laggner B, Roggendorf W (2010) Wer schützt das Grünland? Analysen zur Dynamik des Dauergrünlandes und entsprechender Schutzmechanismen. Vortrag anlässlich der 50. Jahrestagung der GEWISOLA „Möglichkeiten und Grenzen der wissenschaftlichen Politikanalyse“. Braunschweig, 29.09.-01.10.2010 
Nordwestdeutsche Forstliche Versuchsanstalt (NW-FVA) (Hrsg) (2008) Ergebnisse angewandter Forschung zu Buche. Beiträge aus der Nordwestdeutschen Forstlichen Versuchsanstalt, Bd 3. Universitätsverlag, Göttingen

Oke T (1997) Urban climates and global environmental change. In: Thompson R, Perry A (Hrsg) Applied climatology: principles and practice. Taylor and Francis, London, S 273-287

Oorts K, Merckx R, Gréhan E, Labreuche J, Nicolardot B (2007) Determinants of annual fluxes of $\mathrm{CO} 2$ and $\mathrm{N} 2 \mathrm{O}$ in long-term no-tillage and conventional tillage systems in northern France. Soil Tillage Res 95:133-148

Osterburg B, Nieberg H, Rüter S, Isermeyer F, Haenel HD, Hahne J, Krentler JG, Paulsen HM, Schuchardt F, Schweinle J, Weiland P (2009) Erfassung, Bewertung und Minderung von Treibhausgasemissionen des deutschen Agrar- und Ernährungssektors. Studie im Auftrag des Bundesministeriums für Ernährung, Landwirtschaft und Verbraucherschutz. Arbeitsberichte aus der vTI-Agrarökonomie 2009/03. Braunschweig, Hamburg

Osterburg B, Rüter S, Freibauer A, de Witte T, Elsasser P, Kätsch S, Leischner B, Paulsen HM, Rock J, Röder N, Sanders J, Schweinle J, Steuk J, Stichnothe H, Stümer W, Wolff A (2013) Handlungsoptionen für den Klimaschutz in der deutschen Agrar- und Forstwirtschaft. Johann Heinrich von Thünen-Institut, Thünen Report 11, Braunschweig

Paul C, Weber M, Mosandl R (2009) Kohlenstoffbindung junger Aufforstungsflächen (Carbon sequestration in young afforestations). Karl Gayer Institut, Freising

Pauli B, Stöckli B, Rosset C (2016) Wirtschaftliche Konsequenzen waldbaulicher Strategien zur Bewältigung des Klimawandels. Schweiz Z Forstwesen 167(1):39-48

Petersen AK, Solberg B (2005) Environmental and economic impacts of substitution between wood products and alternative materials: a review of micro-level analyses from Norway and Sweden. Forest Policy Econ 7(3):249-259

Pingoud K, Pohjola J, Valsta L (2010) Assessing the integrated climatic impacts of forestry and wood products. Silva Fennica 44(1):155-175

Poeplau C, Don A, Vesterdal L, Leifeld J, Van Wesemael B, Schumacher J, Gensior A (2011) Temporal dynamics of soil organic carbon after land-use change in the temperate zone - carbon response functions as a model approach. Glob Change Biol 17:2415-2427

Pretzsch H (2003) Diversität und Produktivität von Wäldern. AFJZ 174(5-6):88-98

Preuß T (2006) Wege zur Flächenkreislaufwirtschaft. ExWoSt-Forschungsfeld „Fläche im Kreis“ präsentiert Ergebnisse. Difu-Berichte 4:12-14

Preuß T (2010) Flächenmanagement. In: Henckel D, Kuczkowski K, Lau P, Pahl-Weber E, Stellmacher F (Hrsg) Planen - Bauen - Umwelt. Ein Handbuch. VS Verlag, Wiesbaden, S 177-181

Preuß T, Beißwenger K-D (2007) Kreislaufwirtschaft in der städtischen/stadtregionalen Flächennutzung. Das ExWoSt-Forschungsfeld „Fläche im Kreis“. Werkstatt 51. Bundesamt für Bauwesen und Raumordnung (BBR), Bonn, S 90

Pude R (2012) Geschätzte Miscanthus-Anbauflächen Deutschland und Europa. http://www. miscanthus.de/anbauflaeche.html. Zugegriffen: 12. März 2018

Ravindranath NH, Manuvie R, Fragione J, Canadell JG, Berndes G, Woods J, Watson H, Sathaye J (2009) Greenhouse Gas Implications of Land Use and Land Conversion to Biofuel Crops. In: Howarth RW, Bringezu S (Hrsg) Biofuels: environmental consequences and interactions with changing land use. Proceedings of the Scientific Committee on Problems of the Environment (SCOPE) International Biofueld Project Rapid Assessment. Cornell University, Ithaca NY, USA, 22-25 September 2008, Gummersbach, Germany, S 111-125

Reichardt M, Jürgens C (2009) Adoption and future perspective of precision farming in Germany: results of several surveys among different agricultural target groups. Precision Agric 10:73-94 
Rittel K, Bredow L, Wanka ER, Hokema D, Schuppe G, Wilke T, Nowak D, Heiland S (2014) Grün, natürlich, gesund: Die Potenziale multifunktionaler städtischer Räume. Ergebnisse des gleichnamigen F+E-Vorhabens (FKZ 351182 0800). BfN-Skripten, Bonn, S 61, 371

Röder N, Grützmacher F (2012) Emissionen aus landwirtschaftlich genutzten Mooren - Vermeidungskosten und Anpassungsbedarf. Natur und Landschaft 87:56-61

Röder N, Osterburg B (2012) The impact of map and data resolution on the determination of the agricultural utilisation of organic soils in Germany. Environ Manage 49(6):1150-1162

Rösch C, Dusseldorp M, Mayer R (2005) Precision agriculture. 2. Bericht zum TA-Projekt „Moderne Agrartechniken und Produktionsmethoden - ökonomische und ökologische Potenziale“. TAB-Arbeitsbericht, Berlin, S 106

Rüter S (2011) Welchen Beitrag leisten Holzprodukte zur CO2-Bilanz? AFZ 66(15):15-18

Sathre R, O'Connor J (2010) Meta-analysis of greenhouse gas displacement factors of wood product substitution. Environ Sci Policy 13(2):104-114

Schäfer A (2009) Moore und Euros - die vergessenen Millionen. Archiv für Forstwesen und Landschaftsökologie 43(4):156-160

Schmid-Egger C, Witt R (2014) Ackerblühstreifen für Wildbienen - Was bringen sie wirklich? AMPULEX 6(2014):13-22

Schuler J, Bues A, Henseler M, Krämer C, Krampe L, Kreins P, Liebersbach H, Osterburg B, Röder N, Uckert G (2014) Instrumente zur Stärkung von Synergien zwischen Natur- und Klimaschutz im Bereich Landbewirtschaftung. BfN-Skripten. Bonn, Bad Godesberg, S 187

Schulze ED, Luyssaert S, Ciais P, Freibauer A, Janssens IA (2009) Importance of methane and nitrous oxide for Europe's terrestrial greenhouse-gas balance. Nat Geosci 2:842-850

Six J, Feller C, Denef K, Ogle SM, De Moraes SAJC, Albrecht A (2002) Soil organic matter, biota and aggregation in temperate and tropical soils - effects of no-tillage. Agronomie 22:755-775

Smith P, Martino D, Cai Z, Gwary D, Janzen H (2008) Greenhouse gas mitigation in agriculture. Phil Trans R Soc B 363:789-813

Sommer K (2005) CULTAN-Düngung. Physiologisch, ökologisch, ökonomisch optimiertes Düngeverfahren für Ackerkulturen, Grünland, Gemüse, Zierpflanzen und Obstgehölze. Verlag Th. Mann, Gelsenkirchen

Staupendahl K, Möhring B (2011) Integrating natural risks into silvicultural decision models: a survival function approach. Forest Policy Econ 13(6):496-502

Tebrügge J (2003) Konservierende Bodenbearbeitung gestern, heute, morgen - von wendender über nicht wendende Bodenbearbeitung zur Direktsaat. Landbauforschung Völkenrode 256(Sonderheft): 49-59

Thünen-Institut (2012) Dritte Bundeswaldinventur - Ergebnisdatenbank. https://bwi.info. Zugegriffen: 19. März 2019

Tzschupke W (2005) Wie sinnvoll ist die Nadelstarkholzproduktion? Wald und Holz 6:31-35

Umweltbundesamt (UBA) (2013) Berichterstattung unter der Klimarahmenkonvention der Vereinten Nationen und dem Kyoto-Protokoll 2013. Nationaler Inventarbericht zum Deutschen Treibhausgasinventar 1990-2011. Climate Change 11/2011. Umweltbundesamt, DessauRoßlau, S 885

Waltersbacher M (2015) Wohnungsbau: Großstädte verzeichnen starken Zuwachs. BBSR (Bundesinstitut für Bau-, Stadt- und Raumforschung). https://www.bbsr.bund.de/BBSR/DE/ WohnenImmobilien/Immobilienmarktbeobachtung/ProjekteFachbeitraege/Wohnungsbau/ wohnungsbau.html. Zugegriffen: 13. Febr. 2020

Weimar H, Jochem D (Hrsg) (2013) Holzverwendung im Bauwesen - Eine Marktstudie im Rahmen der „Charta für Holz“, Bd 9. Thünen Report. Johann Heinrich von Thünen-Institut, Hamburg 
Wellbrock N, Grüneberg E, Stümer W, Rüter S, Ziche D, Dunger K, Bolte A (2014) Wälder in Deutschland speichern Kohlenstoff. AFZ 69(18):38-39

Werner F, Taverna R, Hofer P, Thürig E, Kaufmann E (2010) National and global greenhouse gas dynamics of different forest management and wood use scenarios: a model-based assessment. Environ Sci Policy 13(1):72-85

Wichmann S, Wichtmann W (2009) Bericht zum Forschungs- und Entwicklungsprojekt Energiebiomasse aus Niedermooren (ENIM). Universität Greifswald, Institut für Botanik und Landschaftsökologie

Wichtmann W, Wichmann S (2011a) Paludikultur: Standortgerechte Bewirtschaftung wiedervernässter Moore. Paludiculture - site adapted management of re-wetted peatlands. TELMA 4:215-234

Wichtmann W, Wichmann S (2011b) Environmental, social and economic aspects of a sustainable biomass production. J Sustain Energ Environ, Spec Issue, 77:81

Wichtmann W, Wichmann S, Tanneberger F (2010) Paludikultur - Nutzung nasser Moore: Perspektiven der energetischen Verwertung von Niedermoorbiomasse. Naturschutz und Landschaft in Brandenburg 19:211-218

Wicke B, Verweij P, Van Meijil H, Van Vuuren DP, Faaij APC (2012) Indirect land use change: review of existing models and strategies for mitigation. Biofuels 3:87-100

Wissenschaftlicher Beirat der Bundesregierung Globale Umweltveränderungen (WBGU) (2009) Welt im Wandel: Zukunftsfähige Bioenergie und nachhaltige Landnutzung. Wissenschaftlicher Beirat der Bundesregierung Globale Umweltveränderungen (WBGU), Berlin

Wolters S, Tänzler D, Theiler L, Drösler M (2013) Entwicklung von Konzepten für einen nationalen Klimaschutzfonds zur Renaturierung von Mooren, Bd 05/2013. Climate Change. Umweltbundesamt, Dessau

Wördehoff R, Spellmann H, Evers J, Aydin CT, Nagel J (2012) Kohlenstoffstudie Forst und Holz Schleswig-Holstein. Nordwestdeutsche Forstliche Versuchsanstalt, Göttingen

Zeller V, Thrän D, Zeymer M, Bürzle B, Adler P, Ponitka J, Postel J, Müller-Langer F, Rönsch S, Gröngröft A, Kirsten C, Weller N, Schenker M, Wedwitschka H, Wagner B, Deumelandt P, Reinicke F, Vetter A, Weiser C, Henneberg K, Wiegmann K (2013) Basisinformationen für eine nachhaltige Nutzung von landwirtschaftlichen Reststoffen zur Bioenergiebereitstellung. DBFZ Report Nr. 13, Leipzig

Open Access Dieses Kapitel wird unter der Creative Commons Namensnennung 4.0 International Lizenz (http://creativecommons.org/licenses/by/4.0/deed.de) veröffentlicht, welche die Nutzung, Vervielfältigung, Bearbeitung, Verbreitung und Wiedergabe in jeglichem Medium und Format erlaubt, sofern Sie den/die ursprünglichen Autor(en) und die Quelle ordnungsgemäß nennen, einen Link zur Creative Commons Lizenz beifügen und angeben, ob Änderungen vorgenommen wurden.

Die in diesem Kapitel enthaltenen Bilder und sonstiges Drittmaterial unterliegen ebenfalls der genannten Creative Commons Lizenz, sofern sich aus der Abbildungslegende nichts anderes ergibt. Sofern das betreffende Material nicht unter der genannten Creative Commons Lizenz steht und die betreffende Handlung nicht nach gesetzlichen Vorschriften erlaubt ist, ist für die oben aufgeführten Weiterverwendungen des Materials die Einwilligung des jeweiligen Rechteinhabers einzuholen.



